\title{
Polymeric Dopant-Free Hole Transporting Materials for Perovskite Solar Cells: Structures and Concepts towards Better Performances
}

\author{
Mohamed M. H. Desoky ${ }^{1}(\mathbb{D})$, Matteo Bonomo ${ }^{1}\left(\mathbb{D}\right.$, Nadia Barbero $^{1}(\mathbb{D})$, Guido Viscardi ${ }^{1}$ (D), Claudia Barolo ${ }^{1,2}(\mathbb{D})$ \\ and Pierluigi Quagliotto ${ }^{1, *(\mathbb{D})}$
}

1 Department of Chemistry and NIS Interdepartmental Center and INSTM Reference Centre, University of Torino, Via Pietro Giuria 7, 10125 Torino, Italy; mohamedmagdyhassan.desoky@unito.it (M.M.H.D.); matteo.bonomo@unito.it (M.B.); nadia.barbero@unito.it (N.B.); guido.viscardi@unito.it (G.V.); claudia.barolo@unito.it (C.B.)

2 ICxT Interdepartmental Centre, Università degli Studi di Torino, Via Lungo Dora Siena 100, 10153 Torino, Italy

* Correspondence: pierluigi.quagliotto@unito.it; Tel.: +39-011-6707593

check for updates

Citation: Desoky, M.M.H.; Bonomo, M.; Barbero, N.; Viscardi, G.; Barolo, C.; Quagliotto, P. Polymeric Dopant-Free Hole Transporting Materials for Perovskite Solar Cells: Structures and Concepts towards Better Performances. Polymers 2021 13, 1652. https://doi.org/10.3390/ polym13101652

Academic Editor: Hyeonseok Yoon

Received: 1 April 2021

Accepted: 12 May 2021

Published: 19 May 2021

Publisher's Note: MDPI stays neutral with regard to jurisdictional claims in published maps and institutional affiliations.

Copyright: (C) 2021 by the authors Licensee MDPI, Basel, Switzerland. This article is an open access article distributed under the terms and conditions of the Creative Commons Attribution (CC BY) license (https:// creativecommons.org/licenses/by/ $4.0 /)$
Abstract: Perovskite solar cells are a hot topic of photovoltaic research, reaching, in few years, an impressive efficiency ( $25.5 \%$ ), but their long-term stability still needs to be addressed for industrial production. One of the most sizeable reasons for instability is the doping of the Hole Transporting Material (HTM), being the salt commonly employed as a vector bringing moisture in contact with perovskite film and destroying it. With this respect, the research focused on new and stable "dopantfree" HTMs, which are inherently conductive, being able to effectively work without any addition of dopants. Notwithstanding, they show impressive efficiency and stability results. The dopant-free polymers, often made of alternated donor and acceptor cores, have properties, namely the filming ability, the molecular weight tunability, the stacking and packing peculiarities, and high hole mobility in absence of any dopant, that make them very attractive and a real innovation in the field. In this review, we tried our best to collect all the dopant-free polymeric HTMs known so far in the perovskite solar cells field, providing a brief historical introduction, followed by the classification and analysis of the polymeric structures, based on their building blocks, trying to find structure-activity relationships whenever possible. The research is still increasing and a very simple polymer (PFDT-2F-COOH) approaches PCE $=22 \%$ while some more complex ones overcome $22 \%$, up to $22.41 \%$ (PPY2).

Keywords: hole transporting materials; dopant-free polymers; organic materials; perovskite solar cells

\section{Introduction}

The photovoltaic research field has grown enormously in the last few decades and, after the silicon technology, several other new technologies appeared such as Organic PhotoVoltaic (OPV), [1] Dye-sensitized Solar Cells (DSC) [2] and last but surely not least, the Perovskite Solar Cells (PSC) [3]. This latter showed its efficiency to boost in only the last decade from the initial $9.1 \%$ of 2012 [4] to the actual $25.5 \%$ of early 2021, [5,6] also thanks to the development of materials for the charge transport, [7] becoming a reliable hot topic. While we will discuss the structure of those cells later, here we can stress that the perovskite layer can efficiently achieve charge separation when hit by sunlight rays, and the migration of charges is very fast in this material $[7,8]$. Due to this, it is of the utmost importance to extract efficiently the charges from perovskite, to avoid charge recombination $[9,10]$ and to gain high photovoltaic efficiencies. In this context, the Hole Transporting Materials (HTMs) are of crucial importance [7,11]. Although inorganic HTMs have been effectively implemented in PSCs (especially when inverted geometry is considered), [12] most of the HTMs have organic nature and can be roughly separated into two main classes: (i) Small Molecule [12,13] and (ii) Polymeric HTMs [12,14]. Conductive 
polymers [15] were the first organic materials that showed the ability to conduct electricity and they were essentially prepared as highly/fully conjugated organic polymers. Since then, the conductive polymers field developed enormously, and they were used in several organic electronic applications such as OLED, OPV, OFET, but not only those $[1,16,17]$. In the past, organic molecules were known to behave as insulants being their native conductivity of organic materials (molecules and polymers) often minimal, so that they can be induced to enhance their conductivity by the doping process $[9,18-20]$. This roughly means that the organic structures need to be oxidized to become cationic and thus be able to receive electrons on one side leaving the holes to flow in opposite directions. The doping process can be easily accessed with good results, but has also several drawbacks, e.g., the lowered chemical stability of the HTM in presence of tert-butylpyridine (tBP) [21], chemical and photochemical instability [22] and to behave as a vector for moisture and oxygen that could lead to degradation of the perovskite film and, consequently, of the whole devices. Due to this, in the last years, a great effort was made to prepare new conductive molecules and polymers in which the high polarization of the different moieties composing them can enhance the intrinsic conductivity. As a result, it was found that some polymers and molecules can show a decent to high native conductivity that can make them useful for the PSCs application without any doping. These novel materials are now known as dopant-free HTMs. Throughout the present review, the focus will be directed to dopant-free HTM polymers being small molecules already analyzed in a dedicated paper [23]. While conductive polymers were introduced and studied a long time ago, the conductive behavior of these polymers is still a challenge since it is strictly related to the solid-state film organization. The chemical structure is important but also the formation of amorphous or crystalline domains is important, such as in the case of the well-known poly(3-hexylthiophene) (P3HT) [24,25]. The way in which the long polymeric molecules pack is of the utmost importance, since the conductivity is normally related to the charge flow along the main conjugated chain and to the hopping among contiguous polymeric chains, which should have tight contact distances among them $[9,25-28]$. This means that not only the difference in acceptor/donor character of the moieties is important, but also the contact distance among chains, to help the charge to flow at high rate [29].

The HTM research field covers an enormous number and a variety of structures and different applications and so it is practically unaffordable to cover all aspects. Even reducing the search to the application in PSCs makes this search highly challenging since this field sees a few papers published per day, making it a rapidly growing hot topic. Luckily, the limitation to the dopant-free polymeric HTMs $[12,30,31]$ made this work feasible even if we cannot exclude losing some papers due to the fast increase of the literature about this topic and we apologize for any unintentional omission.

We also tried to discuss the polymers by looking at the donor and acceptor moieties and tried to find, if any, some structure-activity relationships or at least some indication about the effect that every moiety can give to the final HTM. This is essential to evidence the most promising donor and acceptor moieties and to guide chemists to prepare novel generations of polymeric HTMs aiming at high photovoltaic efficiency.

\section{Perovskite Solar Cells: The Essential}

The use of perovskites in the solar cells field appeared for the first time in 2009 on Dye Sensitized Solar Cells (DSSC or DSC), just to substitute the dye as a light harvester, obtaining a modest efficiency (3.9\%) [32]. This was mainly due to intrinsic instability of the perovskite towards liquid systems commonly employed as electrolytes in DSC (see below). The first perovskite solar cell was prepared in 2012 as a solid-state cell, with no liquid inside and where the perovskite could show that its light-harvesting properties were consistently better than that shown in DSSC (efficiency 9.1\%) [4], and confirmed that a novel structure of the solar cells would have been developed to exploit properly the high potential of perovskites. Up to now, an excellent and potentially competitive certified efficiency as high as $25.5 \%$ was obtained [6]. In order to introduce properly the PSC into the 
context of this review, we will start with a brief introduction on perovskites and their main characteristics, and we will continue with a discussion of the main different structures of PSC. At the end we will introduce the organic HTMs, mainly focusing on the polymeric ones and on the mechanism of doping.

\subsection{Perovskite Structure and Properties}

Perovskites have a chemical structure represented by the formula $\mathrm{ABX}_{3}$. In the perovskite mostly used in the photovoltaic field, $\mathrm{A}$ is normally a large volume organic cation (methylammonium (MA), ethylammonium (EA), formamidinium (FA)), B is a small volume inorganic cation, usually consisting of $\mathrm{Pb}$ even if also $\mathrm{Sn}$ was tried [33]. The $\mathrm{Pb}$ is however better protected from oxidation than Sn [34]. giving better stability to the perovskite [35]. The A cation is situated at the corners of the unit cell, $X$ is the halide anion in the six-face center and B is the metal cation placed at the body center (Figure 1) [35].
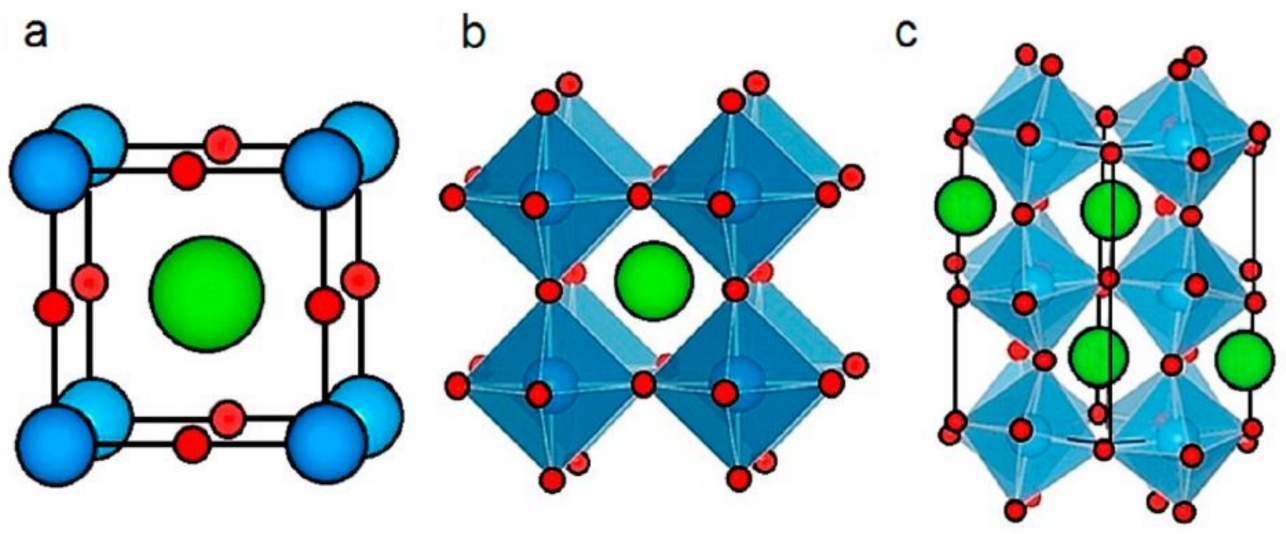

Figure 1. Different visualization of the perovskite structure: (a) Crystal structure of organometal trihalide with chemical structure of $\mathrm{ABX}_{3}$, where $\mathrm{A}$ is the organic cation (green), $\mathrm{B}$ the metal cation (blue), and $\mathrm{X}$ the halide anion (red); (b) perovskite structure showing the $\mathrm{B}$ cation assembled around $\mathrm{X}$ anions to form $\mathrm{BX} 6$ octahedra. (c) Tilting of $\mathrm{BX} 6$ octahedra occurring from nonideal size effects and other factors. Reprinted with permission from (J. Phys. Chem. Lett. 2016, 7, 851-866, ref. [35]) Copyright (2016) American Chemical Society.

As a typical example, the most used perovskite is the $\mathrm{MAPbI}_{3}$, formed by methylammonium iodide and lead iodide. The typical band-gap (BG) of perovskite used in solar cells is around 1.2-1.6 eV, since it needs to cover almost all the visible range, thus harvesting light at all the possible visible wavelengths. Perovskites of more than $2.0 \mathrm{eV}$ BG can exploit only a minimal fraction of the visible light, while being interesting for applications in which transparency is a mandatory requirement, such as indoor and Building Integrated Photovoltaics (BIPV) [36,37]. The band-gap of these materials is decreasing with (i) an increase of the in-plane $\mathrm{M}-\mathrm{I}-\mathrm{M}$ ( $\mathrm{M}=$ metal) bond angle (through octahedral distortion), (ii) the increase in the dimensionality of the $\mathrm{M}(\mathrm{X})_{6}$ network and (iii) the decrease in the electronegativity of the anions [38]. The band-gap can be tuned by changing the A cation and it increases in the order $\mathrm{FAPbI}_{3}<\mathrm{MAPbI}_{3},<\mathrm{CsPbI}_{3}$. By preparing a proper mixture of FA and MA cations, a "double cation" $\mathrm{MA}_{x} \mathrm{FA}_{1-\mathrm{x}} \mathrm{PbI}_{3}$ perovskite (FAMA) can be obtained whose absorption is red shifted, enhancing the light-harvesting properties. This mixture showed better carrier-collection efficiency, due to their increased diffusion length and reduced charge recombination [39]. The crucial property of the perovskite, in fact, is its carrier diffusion length. In a study comparing the $\mathrm{MAPbI}_{3}$ vs. $\mathrm{MAPbI}_{3-\mathrm{x}} \mathrm{Cl}_{\mathrm{x}}$ it was found that the second one can afford a longer diffusion length for both electrons and holes, reaching even more than $1 \mathrm{~mm}$, one order of magnitude higher than that of $\mathrm{MAPbI}_{3}[40]$. Besides, the $\mathrm{FAPbI}_{3}$ shows a larger hole-diffusion length than electron diffusion length with respect to the $\mathrm{MAPbI}_{3}[41,42]$. This also holds in the double cation mixed perovskites, such as $\mathrm{MA}_{\mathrm{x}} \mathrm{FA}_{1-\mathrm{x}} \mathrm{PbI}_{\mathrm{x}}$ and, in general, holes can travel more than electrons, while the 
electron and hole diffusion lengths are however longer than the mm scale. These show why it was essential to modify the perovskite structure to improve it by limiting the charge recombination [40]. The determination of bandgap (and energy levels) of perovskite is of utmost importance in the design and choice of a proper HTM; indeed, if the HTM has correctly aligned energy levels to be able to block electron flow from perovskite, even relatively low hole mobility as shown by the organic HTMs is sufficient to ensure a good hole extraction performance [43].

Double cation perovskites such as $\mathrm{MA}_{x} \mathrm{FA}_{1-x} \mathrm{PbI}_{3}$, however, showed problems in the control of different crystalline phases and, as such, the results obtained can be dependent on the different phase composition. In view of solving this, Saliba et al. incorporated Cs cation into the previous formulations and obtained a stabilization of the black (active) phase for this "triple cation" perovskite (CsFAMA) [44]. Different processes were set up and while the spin coating method is the most used one, this can give problems such as small crystals and many grain boundaries and defects. These facts have important effects on the final device stability, and were efficiently addressed in many ways which are excellently described in a dedicated review [45]. The superior behavior of this kind of perovskite is also witnessed by its use in the cell that achieved the actual PCE record of $25.5 \%[6]$.

\subsection{Deposition Method of Perovskite for PSCs}

The deposition methods of perovskite to build the PSC (Figure 2) are divided into two classes: (i) solution deposition and (ii) vapor deposition [46]. The solution deposition, on its own, can be divided into two categories: (i) one-step method, and (ii) two-step method. The one-step method is based on the preparation of a solution of all the reactants which is deposited onto the conductive glass and spin-coated. The two-step method requires the deposition of one component, normally the lead halide, followed by further deposition of the second component which will react on the surface, producing the perovskite. While the two-step method was initially preferred to better control the process, in most cases both methods afford excellent results [47]. Starting from this, a lot of modifications can be made by using additives and promoters to control the nucleation and other aspects of the perovskite crystal growth, which is still far from being fully comprehended. These aspects can be found in an excellent dedicated review [46] along with other ways to improve the perovskite film formation, such as the optimization of precursor solvents [48] and antisolvents [49], and additive engineering [50].

Vacuum deposition is an interesting process, which however requires a high vacuum apparatus and the related cost. This method can be performed in two ways: (i) co-deposition, and (ii) sequential deposition. In every case, the instrumentation is complicated by the need to check the thickness rate of the deposition for the co-deposition and of annealing and processes for the sequential deposition. A modified method is the vapor-assisted solution process (VASP) which starts from solutions. The metal halide is deposited first onto the electrode with a solution process and the organic halide is simply evaporated and deposited onto it [51]. Another method used is chemical vapor deposition (CVD), in which the evaporation is thermally assisted [52].

\subsection{Perouskite Solar Cells_PSCS}

Classical PSCs can be conceived as a series of layers of different materials, sandwiched between a TCO (Transparent Conductive Oxide) glass (anode) and a metal electrode (cathode), that can be combined in different ways but that need to be finely tuned in their properties to work properly. Basically, the perovskite combines in itself both the light-harvesting and the charge transport properties, showing excellent diffusion length for both holes and electrons. Yet, these charges are prone to recombine among them. Thus, to avoid charge recombination the perovskite needs to be packed in between two different layers, the ETL (Electron Transporting Layer) which extracts preferentially the electrons and blocks the hole transfer and the HTL (Hole Transporting Layer) which performs in the 
opposite way, extracting holes efficiently and blocking electrons. This happens in an ideal way, but in practice, it depends on the charge diffusion length of these materials and on their correct alignment of energy levels with the perovskite [53,54].

a)

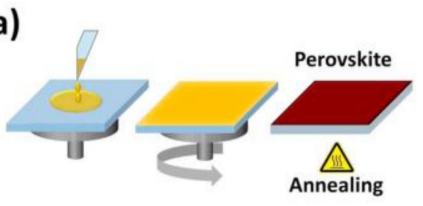

b)

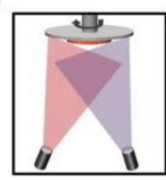

c)

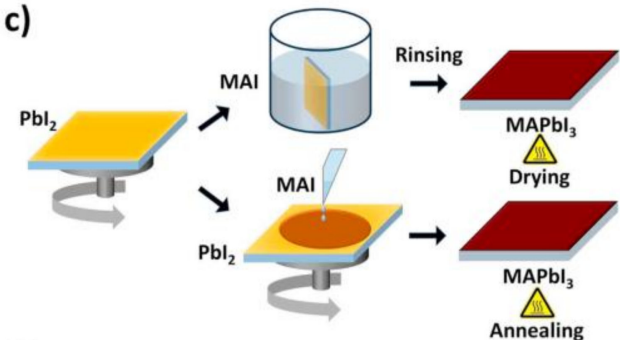

d)

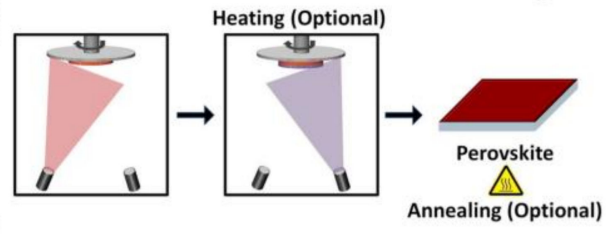

e)

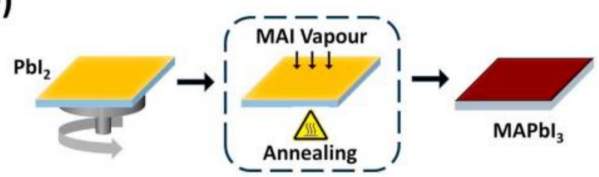

Figure 2. Different perovskite deposition methods (a) solution-based one-step method (b) coevaporation; (c) solution-based two-step method; (d) sequential evaporation; (e) vapor-assisted solution process (VASP). Reprinted from Progr. Quantum Electron. 2017, 53, 1-37, Djurišić, A. et al., Perovskite solar cells-An overview of critical issues. [46] Copyright (2017), with permission from Elsevier.

The disposition of the different layers among the electrodes can give different configurations [55]. The so-called conventional cells show, starting from the bottom, first the conductive glass (or polymeric in flexible PSCs [56]) substrate, then the ETL (an n-type semiconductor, ETM), followed by the perovskite (an intrinsic ambipolar semiconductor) and finally by the HTL (a p-type semiconductor, HTM): these cells are known as belonging to the n-i-p type. In the so-called "inverted" configuration, HTL and ETL are swapped and are referred to as belonging to the $p$-i-n type $[57,58]$.

In theory, since the perovskite is an ambivalent semiconductor with both fast electrons and holes diffusion, one can think to conceive configuration avoiding the ETL, HTL or even both but this simplification showed limited efficiency results up to now [57].

From the practical point of view, some main configurations were developed. The first one is derived from the DSCs and is known as the mesoporous configuration (Figure 3a). This requires a conductive glass electrode on which the ETL layer is made of the first compact titania $\left(\mathrm{TiO}_{2}\right)$ layer followed by a second mesoporous titania layer. A further perovskite layer was deposited, which was finally covered by an HTL, which can be made of an organic or inorganic HTM $[59,60]$. A metal $(\mathrm{Ag}, \mathrm{Au})$ electrode is deposited onto the upper HTL.

A second configuration is known as the planar configuration (Figure 3b) and can be conceived as a simpler configuration with respect to the mesoporous one. In practice, the mesoporous titania layer is not present in this configuration while the other elements are still part of the cell and are placed in the same order as for the mesoporous cells. This configuration required a relatively low temperature $\left(<150^{\circ} \mathrm{C}\right)$ for the whole process, 
opening the doors to the employment of polymeric substrates and leading to flexible PSCs [56].
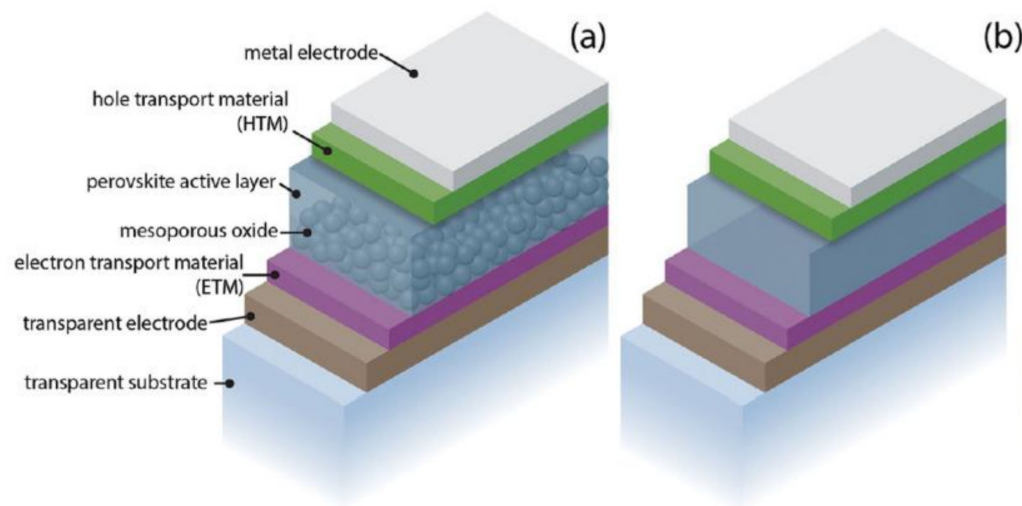

(b)

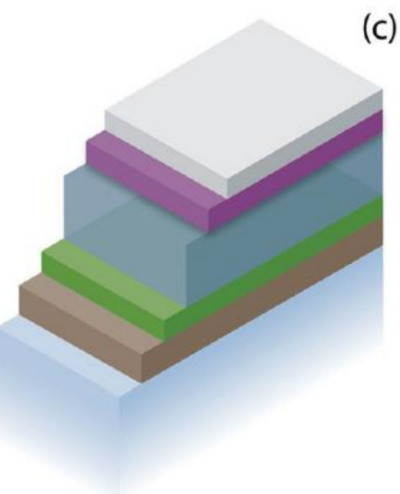

Figure 3. Schematic representation of different PSC device architectures with the (a) mesoporous n-i-p configuration, (b) planar $\mathrm{n}-\mathrm{i}-\mathrm{p}$ configuration, and (c) planar-inverted $(\mathrm{p}-\mathrm{i}-\mathrm{n})$ device stacks. Reprinted with permission from ref. [55] Copyright 2015 John Wiley and Sons.

A third configuration is the inverted one in which, starting from the bottom, the conductive glass is covered by the HTM on which the perovskite is deposited. An ETL is thus layered onto the perovskite, followed by a metal electrode (often Al). The solar cells are referred to as inverted-planar p-i-n (Figure 3c).

\section{Organic HTMs}

\subsection{Organic HTMs, Doping and Dopant-Free HTMs}

As shown before, the topic of this review is focusing on dopant-free organic HTM polymers, since their scientific interest and their application in the last generation of photovoltaic devices $[12,30,31]$. It was just shown above that the HTMs are a crucial element to build efficient PSCs. The added value of organic HTMs is due to the tunability of organic molecules by synthesis, aiming at meeting the desired requirements for optimized performance. Organic HTMs, both small molecules and polymers, can be tailored towards better performances of photovoltaic devices. [12,30,31] Ideally speaking, they should extract holes and transport them to the metal electrode at the same rate at which they are produced into the perovskite, which is a condition hard to reach. Organic molecules/polymers usually show a limited conductivity and hole mobility which, since the first conductive polymer [15], were sustained by adding doping chemicals. An organic HTM can be considered as a relatively good p-type semiconductor, with hole mobility normally in the range $10^{-4}-10^{-6} \mathrm{~cm}^{2} \mathrm{~V}^{-1} \mathrm{~s}^{-1}$ [7]. Yet, a desirable value for application in PSCs should be higher than $10^{-3} \mathrm{~cm}^{2} \mathrm{~V}^{-1} \mathrm{~s}^{-1}$. The doping process often increases the hole mobility even of orders of magnitude [53]. The doping phenomenon consists in the introduction of one or more chemicals which can give or extract electrons from the conductive material, so that it becomes negatively or positively charged, i.e., it behaves as an n-doped or a p-doped material, respectively. Here we will give some general info about doping of conductive polymers, leaving the reader to deepen those topics if interested [9,53,61,62].

Usually, the organic HTMs are deposited on perovskite (or different materials for other organic electronic applications) starting from liquid solutions, mainly by spin coating, sometimes by drop-casting techniques mainly for inorganic HTMs [63]. The doping is normally achieved by adding an oxidant compound to the organic HTM (Scheme 1). The quantity of chemicals needed to achieve doping is normally at the level of impurities and by analogy with silicon technology this modification took the name "doping" [9,53]. Since the oxidation process requires that an anion should compensate the positive charge left into the polymer, this anion is usually called "dopant". The first doping agent for conductive polymers was iodine [15] but now the most known (and used) is the lithium 
bis(trifluomethylsulfonyl)imide (LiTFSI), which can extract electrons from the organic molecule/polymer. In the last years, also the FK 209 (tris(2-(1H-pyrazol-1-yl)-4-tertbutylpyridine)cobalt(III) tri[hexafluorophosphate]), an organic cobalt complex salt was used as an alternative doping agent. Very recently, the use of AgTFSI was also proposed, to directly oxidize the HTM. Since the silver can be eliminated by precipitation and centrifugation, the HTM salt with TFSI can be produced and used to control the doping into the HTMs mixtures. We will discuss this below in this section [64]. Recently, 4-isopropyl-4' methyldiphenyliodonium tetrakis(pentafluorophenylborate) (DPITPFB) was proposed as a further dopant agent, since it showed improved hole mobility of a cross-linked polymer of 3-4 orders of magnitude [65].
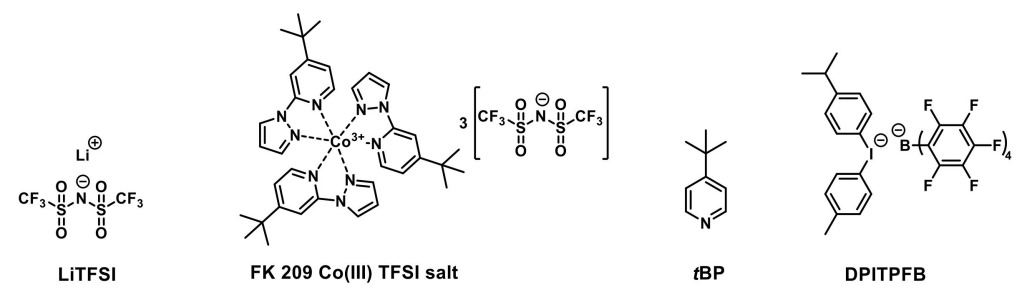

Scheme 1. Main dopants/additive used in the doping process of organic Hole Transporting Materials (HTMs).

When the HTM is working as a solid-state film in an electric circuit, it is in between two electrodes that give electrons to the HTM (cathode) and extract electrons from it (anode). In the film, the doped molecule (cation) receives an electron from a closer neutral molecule which takes the positive charge (hole), so while electrons flow in one direction, the holes flow in the opposite direction.

Other additives are often used to improve conductivity and other aspects related to the HTM performance. The tert-butylpyridine (tBP) was used in nearly all doped HTM formulations but its role is still unclear, at least in part. For sure, it can avoid phase segregation between the LiTFSI and the HTM, helping the solubilization of LiTFSI. The tBP improves the smoothness of the HTL film avoiding pinhole formation. It also seems to enhance the conductivity, by acting at the interface with the perovskite, by reducing the trap surface states and charge recombination [66].

However, the additives used in doping formulations are far to be innocent. They decrease substantially the cell performance and stability over a long time, compromising the cell stability. The LiTFSI is problematic since it is a highly hygroscopic salt that induces the absorption of water into the HTM film or can leave pinholes in the film. Humidity can reach the perovskite, leading to the formation of Lead Iodide destroying the perovskite structure [67]. On the other hand, lithium ions are also known to migrate to the ETL layer causing a further decrease in the efficiency and stability of the PSCs [68]. The tBP, on its own, can dissolve the perovskite-making complexes with $\mathrm{PbI}_{2}$ and, differently from the external humidity uptake, this phenomenon is intrinsic to the cell materials [69]. As a matter of fact, organic polymers, can make better films than small molecules, often pinholefree and since their high hydrophobic nature they often overcome the small molecules also in term of perovskite protection from both liquid water and humidity. Moreover, the extension of conjugation in the polymers and the probability of contacts among the different polymer chains, often can help to obtain high hole mobility and to improve whole PCE performances. As it will be shown later, the dopant-free behavior was observed first on small molecules, which are essentials in the attempt to derive some structure-property general relationships.

\subsection{Dopant-Free Organic HTM Polymers-Why?}

The above considerations pushed the researchers towards the concept of dopantfree HTMs and forced them to try to prepare and exploit them. The dopant-free organic 
HTMs are materials showing higher conductivity with respect to most classic HTMs, also in the undoped state. Sometimes, their conductivity is higher in the undoped than in the doped one, and this makes them very attractive to avoid the use of dopants in view of practical applications [12,16]. The main concept to build a dopant-free HTM is to assemble moieties with different (acceptor/donor) characters from each other so that the final structure is highly polarized and can, in principle, receive electrons on one side and release them on the other side. Several organic groups were built to play the role of donors and acceptors and their combinations are almost infinite. Moreover, also the assembly and packing of molecules in the solid-state are important factors to give enough fast hole transfer, since close contacts among the electroactive centers of molecules are crucial to transfer charges efficiently. In this respect, the state-of-the-art small molecules HTM, spiroOMeTAD $\left(N^{2}, N^{2}, N^{2^{\prime}}, N^{2^{\prime}}, N^{7}, N^{7}, N^{7^{\prime}}, N^{7^{\prime}}\right.$-octakis(4-methoxyphenyl)-9, $9^{\prime}$-spirobi[fluorene]$2,2^{\prime}, 7,7^{\prime}$-tetraamine, see Scheme 2) needs a thick layer (around $140 \mathrm{~nm}$ ) to work properly and thus the doping is essential to overcome its low inherent conductivity [70]. HTMs showing in their pristine state higher hole mobility and conductivity should afford very thin HTM layers that will properly work without any doping. All compounds whose data are reported in Tables and structures in Schemes, will be reported in bold throughout the review to help the reader.
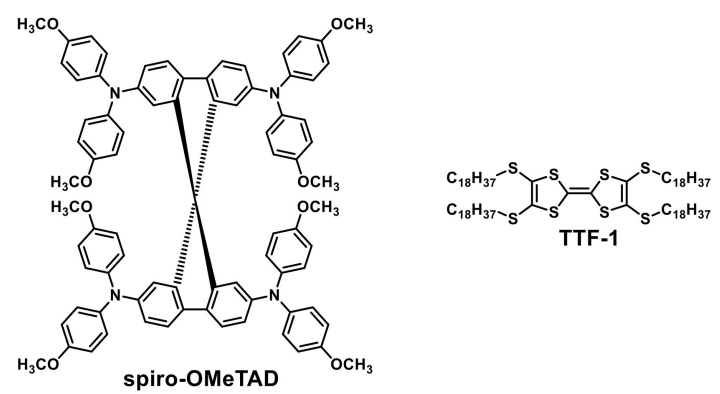

Scheme 2. The HTM reference small molecules, spiro-OMeTAD and first dopant-free HTM, TTF-1.

The first occurrence of an organic dopant-free HTM was found in 2014, with the simple small molecule TTF-1 (Scheme 2) [71], which gave a respectable efficiency of 11.1\%. In 2015 the PCE of dopant-free organic HTMs approached the 15\% limit with the DOR3T-TBDT HTM (14.9\%) [72] and after that, the efficiency of dopant-free PSCs increased abruptly, up to the actual $21.17 \%$ for MPA-BTTI [73], as a result of an enormous and thoughtful research effort. While the small molecules are easier to be prepared and controlled in their structure with respect to polymers, the latter play an essential role for PSCs, since their filming ability can help to achieve better protection of the perovskite layer and their long conjugated main skeleton can give longer charge-diffusion length. The dopant-free polymeric HTMs topic showed an impressive growth in these years since several findings showed that a reasonable control of the properties can be achieved by tuning the structure and polymer characteristics. With this in mind, we approached to review them as peculiar materials for PSCs.

\subsection{Organic HTM Polymer Classification}

Polymers were largely exploited in organic electronics, such as OPV [74], OFET [75], OLED [16,76], etc. Since the appearance of PSCs, they quickly appeared onto the scene [77]. Polymers used as HTMs can be classified as homopolymers, copolymers and D-A (donoracceptor) copolymers. Necessarily, this classification is a large approximation. The homopolymers were widely studied since their availability and relatively easy synthesis, mainly in the doped state since the polarization, as for small molecules, is important to increase the hole transport ability. Notwithstanding, the two main homopolymers used as HTMs were P3HT and PTAA, the last one being considered, undoubtedly, the main reference standard (PCE 22.6\% in its doped state) [5]. A PTAA (doped with tBP and LiTFSI), 
in fact, was used in normal planar cells, based on $\mathrm{FTO} / \mathrm{c}-\mathrm{TiO}_{2} / \mathrm{MAPbI}_{3} / \mathrm{PTAA} \mathrm{tBP}+\mathrm{Li}-$ TFSI/Au architecture, showing a behavior with little hysteresis between the forward and back scan [78]. The efficiency was quite good $(17.2 \%)$ and it showed to be quite stable. The same PTAA was used in PSCs where the perovskite was prepared by modulating an excess of iodide ions added to the formulation [5]. This gave very high-quality perovskites, for which the PCE reached outstanding values, such as $22.1 \%$ in small cells $(22.6 \%$ for the best cell) and $19.7 \%$ in large cells. Stability tests (ISO 170025) demonstrated that the devices maintained at least $93 \%$ of the original PCE after storing at ambient conditions and $40 \%$ relative humidity for 13 months. However, no dopant-free applications of PTAA were found to approach these excellent PCE results, while, on the other hand, P3HT showed great improvements.

In fact, very recently, P3HT reached an impressive efficiency (average: $22.7 \%$, best cell: $23 \%$ ) in its undoped state, thanks to a specifically engineered perovskite, which was passivated by the deposition of a very thin layer (a so-called 2D layer) of a wide bandgap perovskite over the main perovskite layer, separated by a double layer of a surfactant hexyltrimethylammonium bromide [79]. This is the best result ever obtained in the domain of dopant-free HTMs. This particularly engineered system can open a new way to improve the PSC efficiency and could revolutionize the use of polymers as HTMs.

\subsubsection{Homopolymers}

Apart from the already cited PTAA [5], and P3HT [79], the latter showing an impressive PCE in the undoped state, few homopolymers were produced and tested in PSC (Scheme 3 and Table 1).

The only synthesis, present in literature, of the common PTAA was recently published and involves the Suzuki coupling. Two different batches were produced using different catalytic systems, showing a $10.7 \mathrm{kDa}$ and $20.8 \mathrm{kDa}$ molecular weight respectively [80]. It was shown that the highest molecular weights are beneficial for the photovoltaic behavior, greatly enhancing the fill factor. Into a planar PSC, with the $\mathrm{MAPbI}_{3}$ perovskite, the best material gave a PCE of $17.7 \%$ thus overcoming the commercial reference sample $(16.7 \%)$.

A modified PTAA polymer was produced, $\mathrm{CH}_{3} \mathrm{O}$-PTAA, and the difference between the presence of a methyl (common PTAA) or methoxy group in para position of the pendant phenyl group $\left(\mathbf{C H}_{3} \mathbf{O}\right.$-PTAA) was explored [81]. In PSC made with the $\left(\mathrm{FAPbI}_{3}\right)_{0.85}\left(\mathrm{MAPbBr}_{3}\right)_{0.15}$ perovskite, the $\mathbf{C H}_{3} \mathrm{O}$-PTAA HTM showed an outstanding PCE value of $18.75 \%$, while PTAA gave only $14 \%$, essentially due to a higher fill factor. The whole behavior was attributed to the ability of the methoxy groups to stabilize the radical cation form on the HTM during the hole transport.

P3HT was also used in an undoped state into a PSC based on a more classical perovskite solar cell, with the FTO/ALD- $\mathrm{TiO}_{2} / \mathrm{CH}_{3} \mathrm{NH}_{3} \mathrm{PbI}_{3-\mathrm{x}} \mathrm{Cl}_{x} / \mathrm{P} 3 \mathrm{HT} / \mathrm{Ag}$ architecture. The crucial effect of the deposition method for $\mathrm{TiO}_{2}$ was shown: the atomic layer deposition method (ALD) was superior to a commonly spin-coating deposited $\mathrm{TiO}_{2}$ layer, giving a higher PCE (13.6\% vs. 8.7\%) [82].

The dopant-free P3HT was also used in all-inorganic $\mathrm{CsPbI}_{2} \mathrm{Br}$ perovskite, in inverted PSCs geometry [83]. The cells were built using a very thin interlayer of poly[ $(9,9-$ dioctylfluorenyl-2,7-diyl)-co-(4,4'-(N-(4-sec-butylphenyl)diphenylamine)] (TFB) that was deposited between $\mathrm{CsPbI}_{2} \mathrm{Br}$ and $\mathbf{P 3 H T}$ since its deeper HOMO helps to regulate the energy level alignment of the different layers. In those conditions, the PCE reached $15.50 \%$ while the stability at room temperature and under $25 \%$ of relative humidity was very high, by maintaining $98 \%$ of the pristine PCE over 1 month. 
Table 1. Dopant-free homo-polymeric HTM performances. (see legend for details).

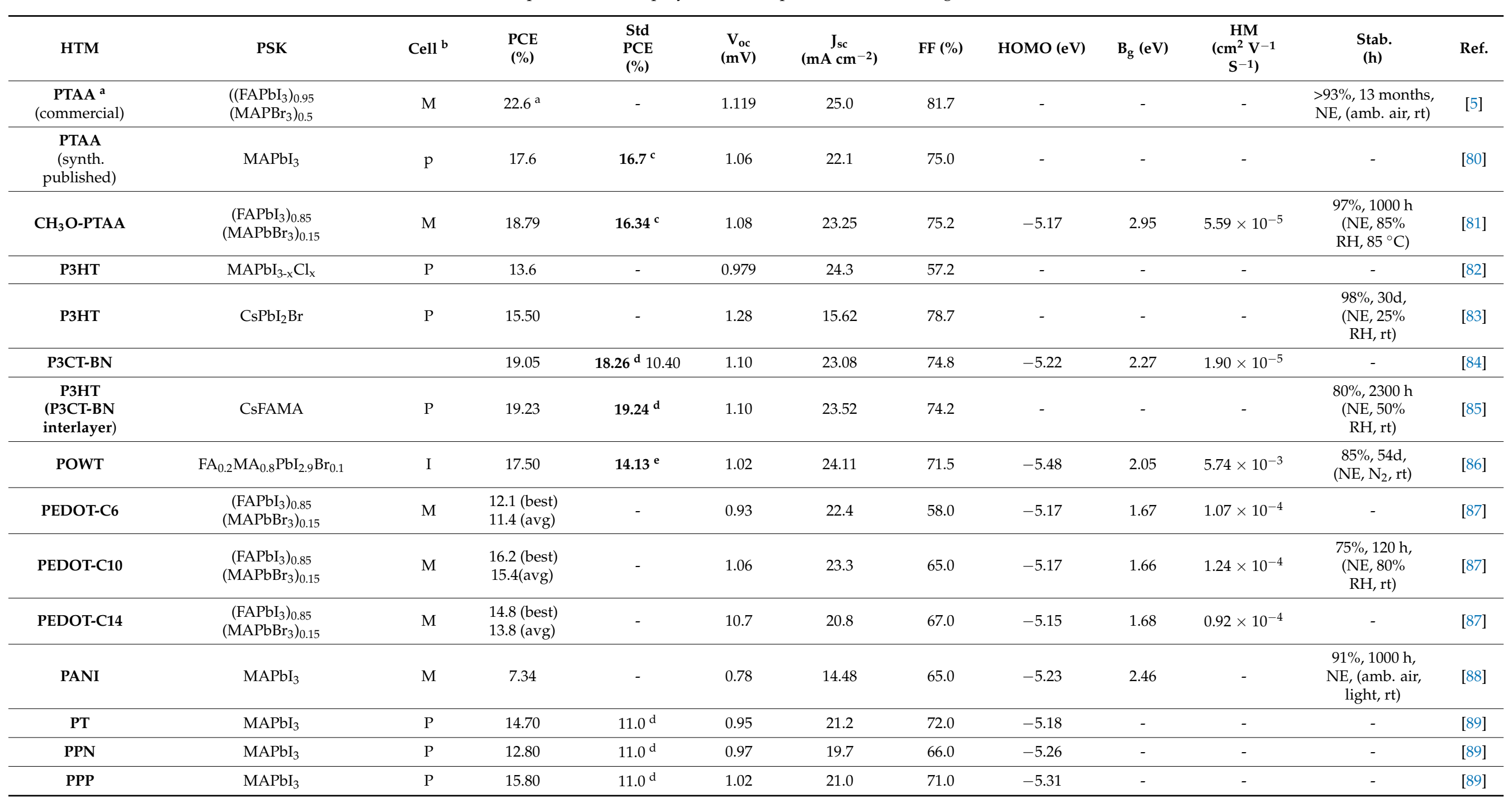


Table 1. Cont

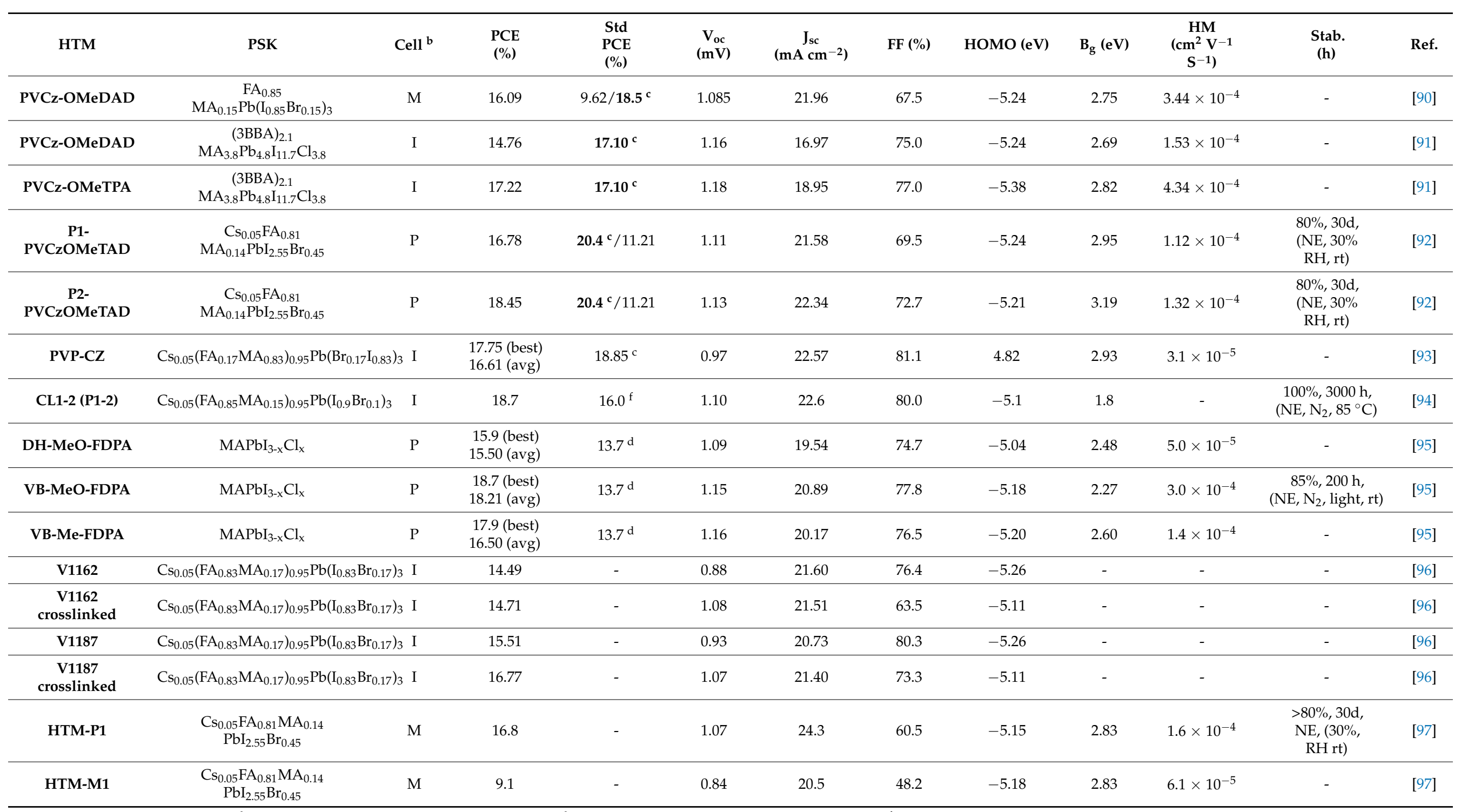

${ }^{a}$ doped; ${ }^{b}$ M: mesoporous, P: planar, I: inverted; ${ }^{c}$ PTAA; ${ }^{d}$ ref. std. spiro-OMeTAD; ${ }^{\mathrm{e}}$ ref. std. PEDOT:PSS; ${ }^{\mathrm{f}}$ polyTPD. PCEs for doped standards are reported in bold. 


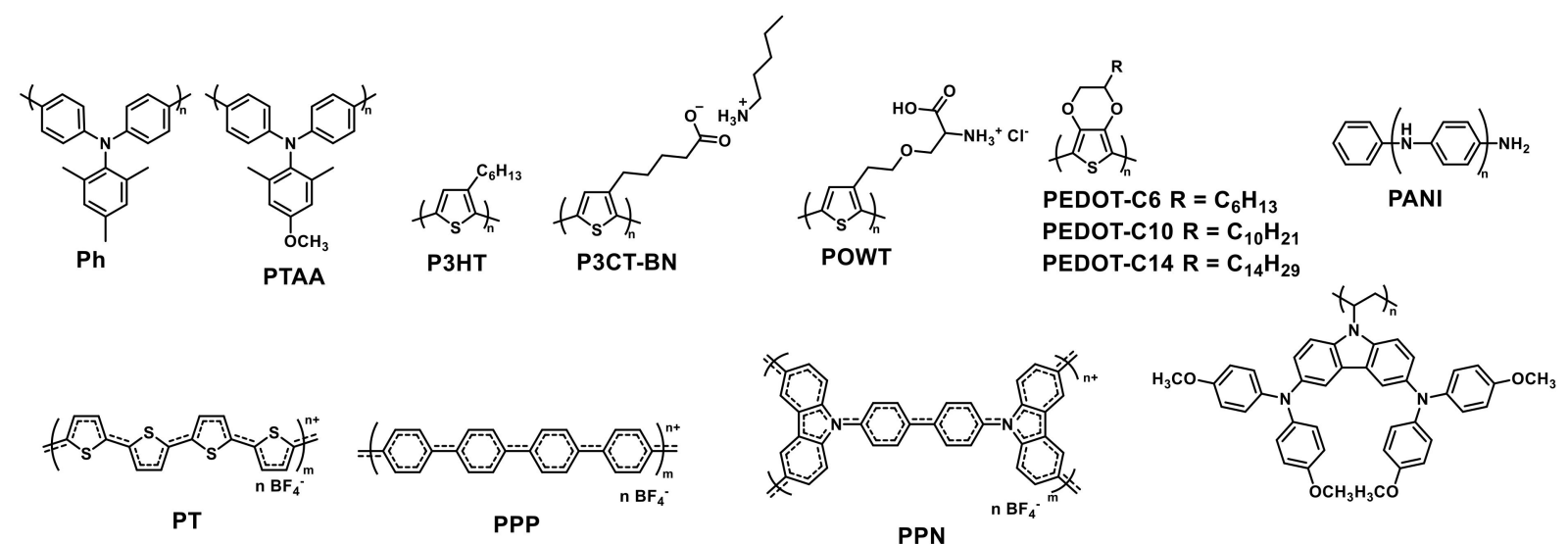

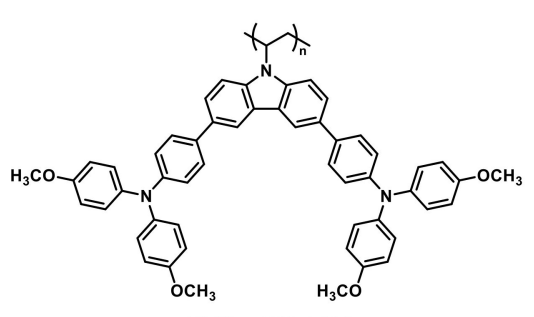

PVCz-OMeTPA

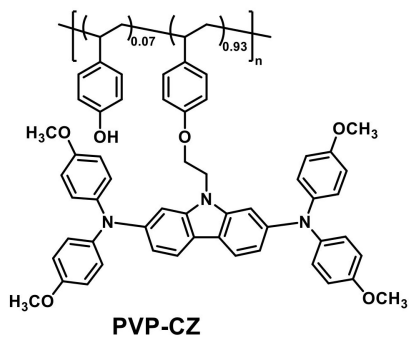

PVP-CZ
PPP

PPN

PVCz-OMeDAD

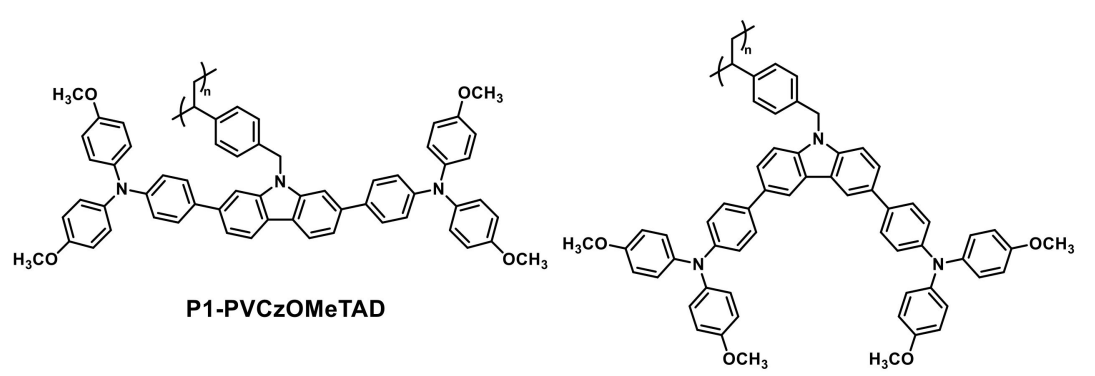

P2-PVCzOMeTAD

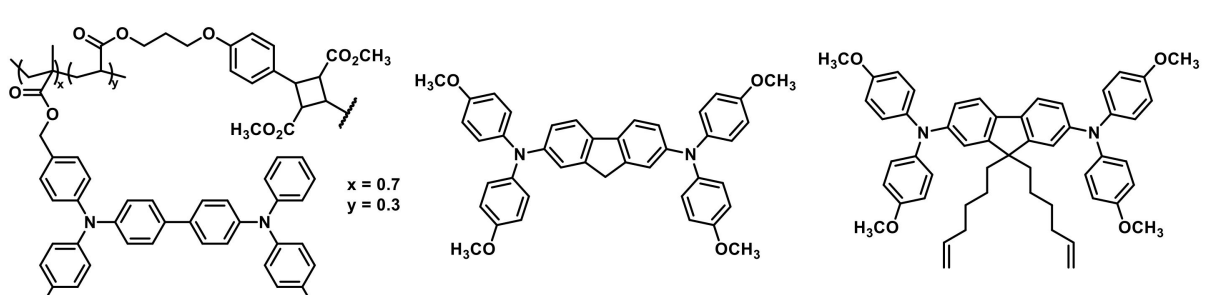

CL1-2

MeO-FDPA

DH-MeO-FDPA
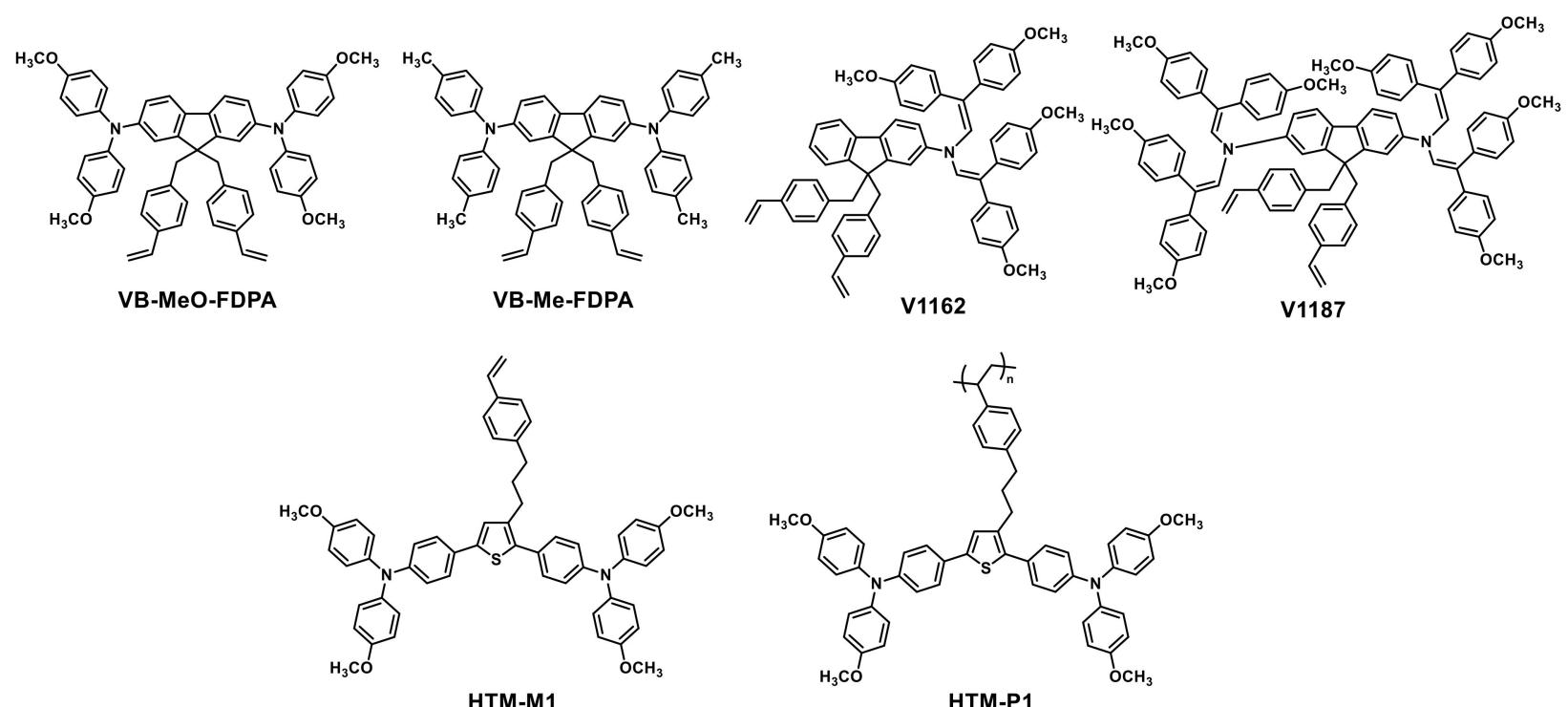

Scheme 3. Classical homopolymeric HTMs and some dopant-free polymeric HTMs (or their monomers).

With P3HT properties in mind, poly[3-(4-carboxybutyl)thiophene] (P3CT) was designed by Zhang and co-workers, transformed into its butylammonium salt (P3CT-BN) to improve its solubility in organic solvents, and finally used in PSC. [84] The presence of the carboxylic acid oxygens helped to passivate the uncoordinated $\mathrm{Pb}^{2+}$ surface traps at the 
perovskite/HTM interface. The P3CT-BnN HTM achieved a PCE of $19.05 \%$ vs. $18.26 \%$ for doped spiro-OMeTAD. The P3CT-BN cells maintained $80 \%$ of PCE after $1800 \mathrm{~h}$ at $25{ }^{\circ} \mathrm{C}$, in the dark and at $40 \%$ of relative humidity.

The P3HT performances were also improved by introducing a polyelectrolyte interlayer based on P3CT-BN between the perovskite active layer and the P3HT [85]. The thin film of P3CT-BN passivated the perovskite surface traps and helped P3HT to achieve a better deposition onto perovskite. As a matter of fact, the PCE of undoped P3HT grew by $13.13 \%$ with no interlayer, up to $19.23 \%$ when the interlayer was present. Finally, this treatment also improved the device stability, which retained $80 \%$ of the original PCE after $2300 \mathrm{~h}$, at room temperature and 50\% relative humidity conditions. The use of polyelectrolytes as HTMs and especially as a thin layer to passivate the perovskite surface Pb traps and to help the perovskite wetting by the HTM increased considerably in the last two years. Several examples will be found during this review.

A modified P3HT, coded POWT, was built from a monomer containing a lateral chain with an amino acid in the fully protonated state [86]. The synthesis of the polyelectrolyte was performed starting from the 2-(3-thiophene)acetic acid, which was reduced to an alcohol and activated as tosylate, which was finally reacted with $N$-t-Boc-L-serine. The final monomer was simply polymerized by the oxidant $\mathrm{FeCl}_{3}$, which at once performed the polymerization and the amino acid deprotection. This polymer showed the HOMO at $-5.48 \mathrm{eV}$ and high hole mobility $\left(5.74 \times 10^{-3} \mathrm{~cm}^{2} \mathrm{~V}^{-1} \mathrm{~s}^{-1}\right)$ and could form very good and homogeneous films. In the inverted PSC architecture, POWT delivered a good PCE, $17.50 \%$, overcoming the reference PEDOT:PSS and showing promising stability, over $54 \mathrm{~d}$ for non-encapsulated cells under nitrogen at room temperature.

Always structurally related to the P3HT polymer, the PEDOT was modified by adding a lateral hydrophobic chain of different lengths, obtaining PEDOT-C6, PEDOTC10 and PEDOT-C14 which were characterized and used as HTM for mesoscopic PSCs with $\left(\mathrm{FAPbI}_{3}\right)_{0.85}\left(\mathrm{MAPbBr}_{3}\right)_{0.15}$ perovskite [87]. These polymers were prepared from the dibrominated monomer which was reacted with further bromine in $\mathrm{CHCl}_{3}$. The $\mathrm{HOMO}$, bandgap, stability (around $250^{\circ} \mathrm{C}$ ) and hole mobility (around $1 \times 10^{-4} \mathrm{~cm}^{2} \mathrm{~V}^{-1} \mathrm{~s}^{-1}$ ) were very similar for all those polymers. Most of the photovoltaic behavior was influenced by the morphology of the solid-state film. AFM measurements showed that PEDOT-C6 was unable to form good compact films, while PEDOT-C10 and PEDOT-C14, being more hydrophobic, showed good homogeneous films. The latter were discriminated by their hole mobility $\left(1.25 \times 10^{-4}\right.$ and $\left.0.92 \times 10^{-4} \mathrm{~cm}^{2} \mathrm{~V}^{-1} \mathrm{~s}^{-1}\right)$. The final PCE was $12.1 \%$ for PEDOT-C6, 16.2\% for PEDOT-C10 and 14.8\% for PEDOT-C14, respectively. The stability was measured only for the best performing PEDOT-C10, showing the retention of 75\% of the pristine PCE after $120 \mathrm{~h}$ at $\mathrm{rt}$ and $80 \%$ of relative humidity).

Xiao and co-workers developed a PSC embodying the homopolymer polyaniline HTM (PANI), deposited by electropolymerization with a two-step Cyclic Voltammetry (CV) process [88]. As a particularity of this PSC architecture, the PANI was electropolymerized onto $\mathrm{m}-\mathrm{TiO}_{2}$ obtaining a "brachyplast", porous, structure in which, finally the perovskite was deposited by infiltration. Due to this specific architecture, this material was shown to behave both as a sensitizer and as an HTM. Different types of devices were prepared. One was doped with $\mathrm{Li}^{+}$salt, LiTFSI, and tBP to improve the conductivity of the hole transporting layer. This final kind of device showed a PCE of 7.34\%. Noteworthy, during a stability test (conditions not specified), those devices maintained more than $90 \%$ of their PCE after $1000 \mathrm{~h}$.

Some other electrochemically synthesized polymers, polythiophene (PT), polyphenylene (PPP) and poly(4,4'-bis( $N$-carbazolyl)-1,10-biphenyl) (PPN), were applied to PSCs, with an ITO/HTM $/ \mathrm{CH}_{3} \mathrm{NH}_{3} \mathrm{PbI}_{3} / \mathrm{C}_{60} / \mathrm{BCP} / \mathrm{Ag}$ architecture (where $\mathrm{BCP}$ is bathocuproine, used as a buffer layer) [89]. The polymers were prepared by electrodeposition on the ITO electrode. The HOMO of the polymers are lying at $-5.18 \mathrm{eV}(\mathbf{P T}),-5.26 \mathrm{eV}(\mathrm{PPN})$ and $-5.31 \mathrm{eV}$ (PPP). The last one is better matching the perovskite valence band. The PCE was 14.70, 12.80, 15.80\% for PT, PPN and PPP, respectively (PPP best cell PCE 16.5\%). All 
these HTMs outperformed the classic PEDOT:PSS (11.0\%) initially used as a reference by those authors.

A peculiar case, in dopant-free polymers, is represented by polyvinyl or polystyrenebased polymers, which bear a pendant arm containing an isolated, not conjugated, HTM moiety. Normally, the conductive polymers are always conjugated polymers since they should accommodate charges and transfer them through the conjugated chain by resonance, and the transfer among different chains is obtained by charge hopping or other mechanisms $[9,25,27]$. In principle, the simple not conjugated polymeric chain with pendant groups is not, per se, a conductive polymer. The crowding of the packed small pendant molecules should maintain them at a very short distance, enhancing $\pi-\pi$ stacking interactions and helping the charge transfer. This kind of polymers was also used recently in the field of Organic Photovoltaic Cells (OPV) by crosslinking divinyl triarylaminobased small molecules to give solvent stability to its layer, enabling a layer-by-layer OPV fabrication [65].

The PVCz-OMeDAD is a polyvinyl polymer with a pendant "small molecule" HTM residue, as the first example of a series of polyvinyl polymers with a pendant carbazole scaffold that will be reviewed just below [90]. The monomer is a carbazole where the nitrogen is substituted by a vinyl moiety and two bis(4-methoxyphenil)amine are bound at its 3 and 6 positions. The monomer was easily polymerized giving a material showing excellent filmforming ability, proper energy levels and high hole mobility $\left(3.44 \times 10^{-4} \mathrm{~cm}^{2} \mathrm{~V}^{-1} \mathrm{~s}^{-1}\right)$. The PSCs based on PVCz-OMeDAD worked with a $30 \mathrm{~nm}$ thick HTM thin film, obtaining a PCE of $16.09 \%$ [90]. This approach has been taken into account for PSC applications, especially looking towards possible flexible devices.

As a further example of pendant carbazole-based polyvinyl polymers, the PVCzOMeTPA was produced and used along with PVCz-OMeDAD, in inverted PSCs with a quasi-2D perovskite [91]. The HOMO levels of PVCz-OMeDAD and PVCz-OMeTPA were -5.24 and $-5.38 \mathrm{eV}$ respectively and the authors mentioned that the last one matching better with the perovskite valence band. Into PSC cells with structure as ITO/HTM/quasi$2 \mathrm{D}$ perovskites $/ \mathrm{PC}_{61} \mathrm{BM} / \mathrm{Cr} /$ gold, the PVCz-OMeDAD and PVCz-OMeTPA showed efficiencies as high as $14.76 \%$ and $17.22 \%$, with the PVCz-OMeTPA slightly overcoming the doped PTAA (17.10\%). These efficiencies complied with the hole mobility values.

In the series of the side-chain polymers, two strictly related analogs of PVCz-OMeDAD were prepared by changing the substituents from DPA to TPA. When substituents are in 2.7 position the molecule (P1-PVCzOMeTAD) is more conjugated than for 3.6 positions (P2-PVCzOMeTAD), as witnessed by the band-gap and $1_{\max }\left(\mathrm{B}_{\mathrm{g}}=2.95 \mathrm{vs} .3 .19 \mathrm{eV}\right.$; $1_{\max }=377 \mathrm{vs.} 333 \mathrm{~nm}$ ) [92].The molecular weight of $9.4 \mathrm{kDa}$ for P1-PVCzOMeTAD and $12.8 \mathrm{kDa}$ for P2-PVCzOMeTAD were obtained. Excellent thermal properties were obtained and $\mathrm{T}_{\mathrm{g}}$ was found at $188^{\circ} \mathrm{C}$ and $191^{\circ} \mathrm{C}$ for P1-PVCzOMeTAD and P2-PVCzOMeTAD, respectively. The hole mobility was $1.12 \times 10^{-4} \mathrm{~cm}^{2} \mathrm{~V}^{-1} \mathrm{~s}^{-1}$ for P1-PVCzOMeTAD and $1.32 \times 10^{-4} \mathrm{~cm}^{2} \mathrm{~V}^{-1} \mathrm{~s}^{-1}$ for P2-PVCzOMeTAD. When those HTMs were applied by spin coating with chlorobenzene onto the Cs-FAMA perovskite, the best PCE obtained was 16.78\% for P1-PVCzOMeTAD and 18.45\% for P2-PVCzOMeTAD. For P2-PVCzOMeTAD. Very interestingly, the authors exploited the substitution of chlorobenzene with nonchlorinated solvent (i.e., 2-methylanisole) aiming at an increase in the greenness of the deposition process. In this case, the best PCE was just a bit lower, $16.42 \%$. The usual doping increased the performances to $18.77 \%$ for P1-PVCzOMeTAD and 19.67\% for P2PVCzOMeTAD. The non-encapsulated devices, maintained over $80 \%$ of their pristine PCE for both HTMs kept for 30 days at ambient temperature and $30 \%$ of relative humidity.

Another polymer, PVP-CZ was prepared as a not conjugated polymer with active pendant groups [93]. The key point was that the molecular HTM was prepared apart and linked to a preformed polymer, poly(4-vinylphenol) by the Mitsunobu reaction. This material was transparent, showed relatively low hole mobility $\left(3.1 \times 10^{-5}\right)$ but attained a promising PCE of $17.75 \%$ a bit lower than undoped PTAA (18.85\%) with an excellent fill factor (81.07). This interesting preparation method showed that it can be possible to rely 
on preformed polymer and make attracting to access to the enormous number of small molecule HTMs and to link them to a good quality polymer. All these characteristics make possible a fine-tuning of both polymeric and HTM properties.

The cross-linkable polymer P1-2 was prepared by polymerizing a TPD methacrylate monomer with a cinnamate-acrylate monomer, which was crosslinked onto the ITO electrode in the PSC device at $130^{\circ} \mathrm{C}$ after the deposition, giving CL1-2 [94]. The HTM was transparent and was ideally exploitable for inverted PSCs. The HTM film on ITO was smooth and homogeneous and promoted the growth of larger grains of perovskite with respect to the standard polyTPD. When used in based PSCs, the PCE of CL1-2 was 18.7\% substantially better than the $16.0 \%$ shown by polyTPD.

Starting from the MeO-FDPA, a small molecule that powered a PCE close to $14 \%$, Zhang et al. prepared similar molecules by appending different cross-linkable residues [95]. A thermal polymerization method without the requirement of additives or initiators ensured the absence of further not predictable impurities and promoted the formation of solid 3D polymeric networks. The DH-MeO-FDPA contained a chain with a terminal alkene, while the other two molecules VB-MeO-FDPA and VB-Me-FDPA had styryl derivatives. It was shown that the alkyl chain gave more conformational freedom with respect to the styryl derivatives, but the latter led to a lowering of the HOMO. The styryl molecules showed a hole mobility one order of magnitude higher than VB-MeO-FDPA and DH-MeO-FDPA, similar to spiroOMeTAD. Finally, in the preparation of planar cells, VB-MeO-FDPA helped to obtain larger perovskite grain thus reducing the charge recombination. As a result, the PCE was 15.9\% for DH-MeO-FDPA, 18.7\% for VB-MeO-FDPA and $17.9 \%$ for VB-Me-FDPA. This remarked the importance of the alkoxy oxygen as a donor group on the DPA structure. These molecules are relatively easy to prepare and can be quickly used for the preparation of HTM films.

Other crosslinkable polymers were prepared on the fluorene scaffold, to which two vinyl groups were attached, obtaining V1162 and V1887 [96]. The V1162 and V1887 HTMs were synthesized by coupling a fluorene diamine with the 2,2-bis(4-methoxyphenyl)acetaldehyde, forming an enamine and the final compounds were prepared by reacting the 4-vinylbenzyl chloride with the fluorene intermediates, benzyltriethylammonium chloride and sodium hydroxide. This way of synthesis was attractive since the materials are considerably cheap (price under 17 euro per gram). The DSC measurements showed that just above the fusion temperature $\left(228^{\circ} \mathrm{C}\right.$ for V1162) an exothermic process takes place, which was identified as polymerization. The V1187 material was amorphous $\left(\mathrm{T}_{\mathrm{g}}\right.$ at $\left.139^{\circ} \mathrm{C}\right)$ and its polymerization started at $190^{\circ}$, with a peak at $239^{\circ} \mathrm{C}$. The full crosslinking was achieved in about $15^{\circ} \mathrm{C}$ of heating. In the PSC based on the $\mathrm{Cs}_{0.05}\left(\mathrm{FA}_{0.83} \mathrm{MA}_{0.17}\right)_{0.95} \mathrm{~Pb}\left(\mathrm{I}_{0.83} \mathrm{Br}_{0.17}\right)_{3}$ perovskite, $\mathrm{V1162}$ and V1887 achieved PCEs of $14.49 \%$ and $15.51 \%$ as small molecules and of $14.71 \%$ and $16.77 \%$ as crosslinked polymers, respectively. An optimization study of V1187, trying to choose the best concentration for the deposition showed that at $1.5 \mathrm{mg} / \mathrm{mL}$, a PCE of $18.14 \%$ was obtained after crosslinking.

Polystyrene containing a pendant triarylamine small molecule was prepared by Wu and coworkers [97]. The monomer was obtained by coupling two $N, N^{\prime}$-bis(4-methoxyphenyl)$N^{\prime \prime}$-phenylamine moieties with thiophene, to which styrene was connected in a not conjugated way. This monomer was polymerized, giving the polymer HTM-P1. It showed the HOMO at $-5.18 \mathrm{eV}$ and LUMO at $-2.35 \mathrm{eV}$, both slightly lower than that of the monomer. The thermal stability was good $\left(317^{\circ} \mathrm{C}\right)$ and the $\mathrm{T}_{\mathrm{g}}$ was relatively high $\left(132{ }^{\circ} \mathrm{C}\right)$, avoiding any HTM modification induced by the heating of the device in operating conditions. The hole mobility was remarkably high, $1.6 \times 10^{-4} \mathrm{~cm}^{2} \mathrm{~V}^{-1} \mathrm{~s}^{-1}$, higher than its monomer $\left(6.1 \times 10^{-5} \mathrm{~cm}^{2} \mathrm{~V}^{-1} \mathrm{~s}^{-1}\right)$ : in cells based on triple cation perovskite $\left(\mathrm{Cs}_{0.05} \mathrm{FA}_{0.81} \mathrm{MA}_{0.14} \mathrm{PbI}_{2.55} \mathrm{Br}_{0.45}\right)$ the HTM-P1 gave a 16.8\% PCE (best cell 17.2\%) while its monomer showed only 9.1\%. The stability of HTM-P1 based cells was evaluated on not encapsulated devices, showing a PCE retention $>80 \%$ after 20 days [97].

These two last examples showed the importance of this approach. The not-conductive polymers can keep a lot of pendant "small molecule" HTMs close to each other so that 
the contact for ensuring hole transport is assured. The efficiencies obtained with PVCzOMeDAD and HTM-P1 account for a possible evolution towards better efficiencies, by modifying both the kind of polymeric skeleton and the small molecule HTM pendant arm.

\subsubsection{D-A Copolymers}

Throughout this section, we will discuss the D-A polymeric HTMs used in PSC, relating the polymer performances to its structural building blocks. The main way to approach this discussion is to evidence a building block and to collect all the polymers containing it, to discuss the differences in structure, properties, morphological behavior, and photovoltaic performance.

We can remark that starting in 2014, just after the beginning of the PSC "story" (in 2012), also the dopant-free HTMs are emerging as an important and necessary component of the solar cell, even because of the strict requirements for HTM and PSC stability [71].

\subsubsection{DPP (2,5-Dihydropyrrolo[3,4]Pyrrole-1,4-Dione)}

In 2013, the first report of dopant-free polymeric HTM used in a perovskite solar cell was a copolymer, PCBTDPP, made by carbazole, thiophene and 2,5-dihydropyrrolo[3,4]pyrrole1,4-dione units (DPP) bearing alkyl chains to increase its synthetic processability (for all polymer of the DPP serie please see Table 2 and Scheme 4) [77]. This material showed a correctly aligned HOMO level $(-5.34 \mathrm{eV})$, and very high hole mobility $\left(0.02 \mathrm{~cm}^{2} \mathrm{~V}^{-1} \mathrm{~s}^{-1}\right)$. The application in both $\mathrm{MAPBr}_{3}$ and $\mathrm{MAPbI}_{3}$ gave $3.3 \%$ and $5.5 \% \mathrm{PCE}$, respectively. While being far from the best results, the ability of polymeric HTMs to work in PSC cells was demonstrated and was greatly improved during the years. The polymer PCDTBT (see below the Section 3.3.2., related to benzothiadiazole) is an analog of PCBTDPP in which the acceptor DPP was substituted by a benzothiadiazole (BTZ) [98]. The substitution of DPP with BTZ did not improve the efficiency of $\mathrm{MAPbI}_{3}$ perovskite solar cells, which remained low $(2.4 \%)$.

Conversely, when PCDTBT and DPP-DTT were used to modify the surface of an ITO/PEDOT:PSS interface, they helped to prepare very good crystalline perovskite by vacuum deposition. In these inverted PSC, the PCDTBT polymer (PCE: 16.5\%) outperformed DPP-DTT (8\%, not optimized), and the other polymers were taken into consideration, namely PCPDTBT and P3HT [99]. The higher performances were ascribed to the better alignment of energy levels of PCDTBT with the perovskite, the higher crystallinity of perovskite and its optimized contact with the polymeric substrate. In this case, the polymer layer was thinner enough (less than the tunneling distance, about $10 \mathrm{~nm}$ ) so that the polymer could not limit the charge transport. This was a different condition with respect to most PSCs studied until now, where the HTM are consistently thicker. This was the first excellent result achieved by polymers in PSCs.

Several polymers, in which the DPP was alternated to a few thiophenes, linked in different ways, were prepared.

As an example, the already cited DPP-DTT was made by connecting a DDP unit with the 2,5-di(thiophen-2-yl)thieno[3,2-b]thiophene. The PDPPT-TT polymer, which has the same structure as DPP-DTT was used on normal PSC, in which PCBM was interposed between $\mathrm{TiO}_{2}$ and the perovskite $\left(\mathrm{MA}_{0.85} \mathrm{FA}_{0.15} \mathrm{PbI}_{0.85} \mathrm{Cl}_{0.15}\right)$ layer. After having created an HTM layer onto the perovskite, the film was exposed to solvent vapor, i.e., the solvent vapor annealing process. This process is an alternative to thermal annealing and can be applied at room temperature and, can save energy and make the production processes easier. The pristine polymer showed an average PCE of $14.3 \%$ and the solvent annealing allowed to increase it up to $16.2 \%$, overcoming the doped spiro-OMeTAD which reached $15.8 \%$. The best device obtained after solvent vapor annealing reached a PCE of $17.8 \%$ [100]. This was an outstanding result that showed that each polymer can behave very differently, depending on several conditions: (i) the kind of cell in which it is applied, (ii) the morphology it adopts at the surface, (iii) post-treatment or post-processing of the deposited film, etc. It is worth mentioning that in several cases it is difficult to relate the photovoltaic properties 
to some molecular properties since often not all the characteristics of the polymers are disclosed, such as molecular weight, regioregularity, if any, sometimes simply because they are commercial materials. Indeed, it is well known to polymer chemists that it is difficult to maintain exactly the same characteristic on different batches, so the disclosing of the exact molecular properties has great importance to establish structure-performance relationships.

To build D-A alternated polymers, the DPP was coupled with bisthiophene (DPP-P1), terthiophene (DPP-P2, also reported as PDPP3T), tetrathiophene (DPP-P3) and the 2,5di(2-thienyl)thieno[3,2-b]thiophene (DPP-P4, analog of PDPPT-TT, with different chain length) [26]. These materials showed HOMO energy level lying at $-5.35 \mathrm{eV}$ (DPP-P1)), -5.20 eV (DPP-P2), -5.25 eV, (DPP-P3), -5.19 eV (DPP-P4) high thermal stability, a lamellar packing obtained by $\pi$-stacking with $\pi-\pi$ contacts as short as $3.6 \AA$ (DPP-P4). In the conditions used in this study, the DPP-P2 and DPP-P4 showed very high hole mobility (4.4 and $\left.3.7 \times 10^{-2} \mathrm{~cm}^{2} \mathrm{~V}^{-1} \mathrm{~s}^{-1}\right)$. The DPP-P2 and DPP-P4 showed a reasonable PCE $(7,1 \%$ and $9.3 \%$ respectively) on $\mathrm{MAPbI}_{3}$ perovskite which only for DPP-P4 (PDPPT-TT with different chain length) became very good on $\mathrm{Cs}(14.2 \%)$ and $\mathrm{Rb}(16.3 \%)$ based perovskite, respectively [26]. It is worth mentioning that the DPP-P3, containing three thiophenes, showed a lower PCE, probably due to a shorter conjugation length, ascribable to the repetition of small aromatic units. The DPP-P4 which contains one thienothiophene can probably extend better the conjugation and promote $\mathrm{p}-\mathrm{p}$ stacking.

In another paper, the polymer PDPP3T, reported above as DPP-P2 and containing three thiophene rings, was prepared and used within mesoscopic PSCs. Its HOMO was lying at $-5.3 \mathrm{eV}$, properly aligned with the perovskite $\mathrm{MAPbI}_{3}$ [101]. Very interestingly, in its pristine state, it showed the same PCE as doped spiro-OMeTAD (12.3\%). The PDPP3T can transport charges faster than spiro-OMeTAD, and since the charge transport is faster than the charge lifetime, both HTMs are working proficiently. Stability tests on nonencapsulated devices at room temperature and $20 \%$ of relative humidity showed a better endurance of the PDPP3T over spiro-OMeTAD, retaining 40\% of the starting efficiency after $172 \mathrm{~h}$, vs. the $17 \%$ of the spiro-OMeTAD.

It is clear that the use of a different number of thiophenes as the spacer between DDP units can tune the properties of the polymer, but it is also evident that when too much conformational ability is given to the different rings, there is a high proneness to tilt them and to reduce the $\mathrm{p}-\mathrm{p}$ stacking ability of the polymer in the solid-state. This negatively influences photovoltaic performances. The general outcome is that by assembling large fused ring systems and limiting the number of single bonds in the "monomeric unit", one should achieve better morphological characteristics of the film and thus higher performances.

A polymer based on a diketopyrrolopyrrole and thiophene, PDPPDBTE, was prepared by surrounding DPP on each side with two thiophenes and the polymeric connections were performed with an ethylene group [102,103]. The material was originally implemented in OFET, showing very high hole mobility $\left(0.32 \mathrm{~cm}^{2} \mathrm{~V}^{-1} \mathrm{~s}^{-1}\right)$ in undoped state and conductivity $\left(10^{-2} \mathrm{~S} \mathrm{~cm}^{-1}\right)$, substantially better than spiro-OMeTAD and P3HT, thus paving the way to a PDPPDBTE application in PSCs. The use in $\mathrm{MAPbI}_{3}$ based mesoscopic PSCs gave a good PCE (9.2\%), exceeding the values obtained by both spiroOMeTAD (7.6\%) and P3HT (6.3\%) in the same configuration. Excellent stability was shown by the PDPPDBTE based PSCs, which maintained $>80 \%$ of the pristine PCE over $1000 \mathrm{~h}$, while spiro-OMeTAD maintained $>70 \%$, for non-encapsulated devices, at rt and $20 \%$ of relative humidity.

The PDVT-10 polymer is the same material as PDPPDBTE. It was used by Liu and co-workers in mesoscopic $\mathrm{MAPbI}_{3}$ PSCs, and showed a great film-forming ability after annealing $5 \mathrm{~min}$ at $150^{\circ} \mathrm{C}$. This characteristic could give good protection of perovskite and increase stability [104]. The material showed suitable $\mathrm{HOMO}$, located at $-5.28 \mathrm{eV}$. The hole mobility of PDVT-10 (doped) was exceptionally high $\left(8.2 \mathrm{~cm}^{2} \mathrm{~V}^{-1} \mathrm{~s}^{-1}\right)$. The PCE (12.97\%, best cell: $13.4 \%$ ) was close to that of a commercial PTAA (11.28\%, best cell: $14.60 \%)$, but with improved reproducibility. The authors attributed the good results to the high coplanarity of the DPP with its two thiophenes on both sides, due to hydrogen bonding of 
the DPP carbonyl groups with the b-hydrogens of the thiophenes. No other information could be found in the related papers [102-104], to establish the different performances of PDPPDBTE and PDVT-10. The stability test evidenced the better performance of PDVT10, which survived to $20 \%$ humidity for 20 days, at room temperature and under the light, without appreciable degradation. On the contrary, PTAA was heavily degraded after 5 days and fully degraded after 20 days.

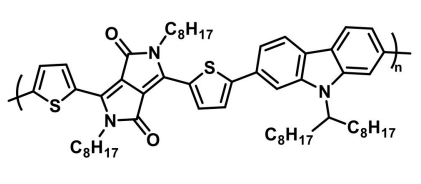

PCBTDPP

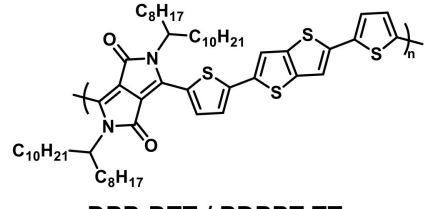

DPP-DTT / PDPPT-TT

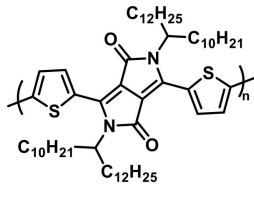

DPP-P1

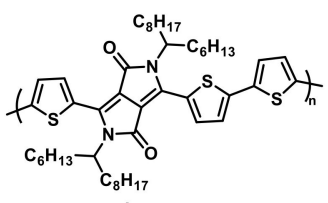

DPP-P2 / PDPP3T

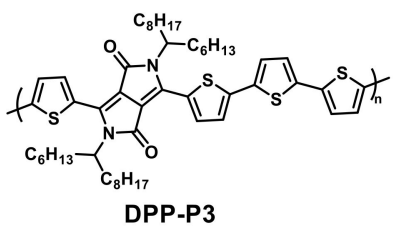

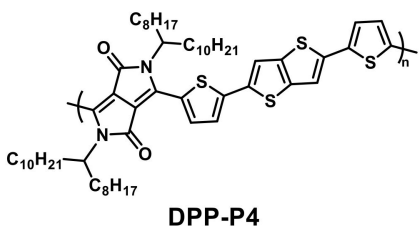

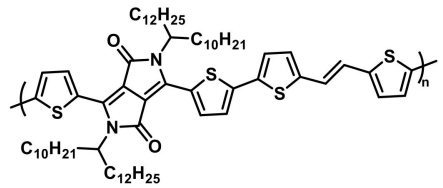

PDPPDBTE / PDVT10
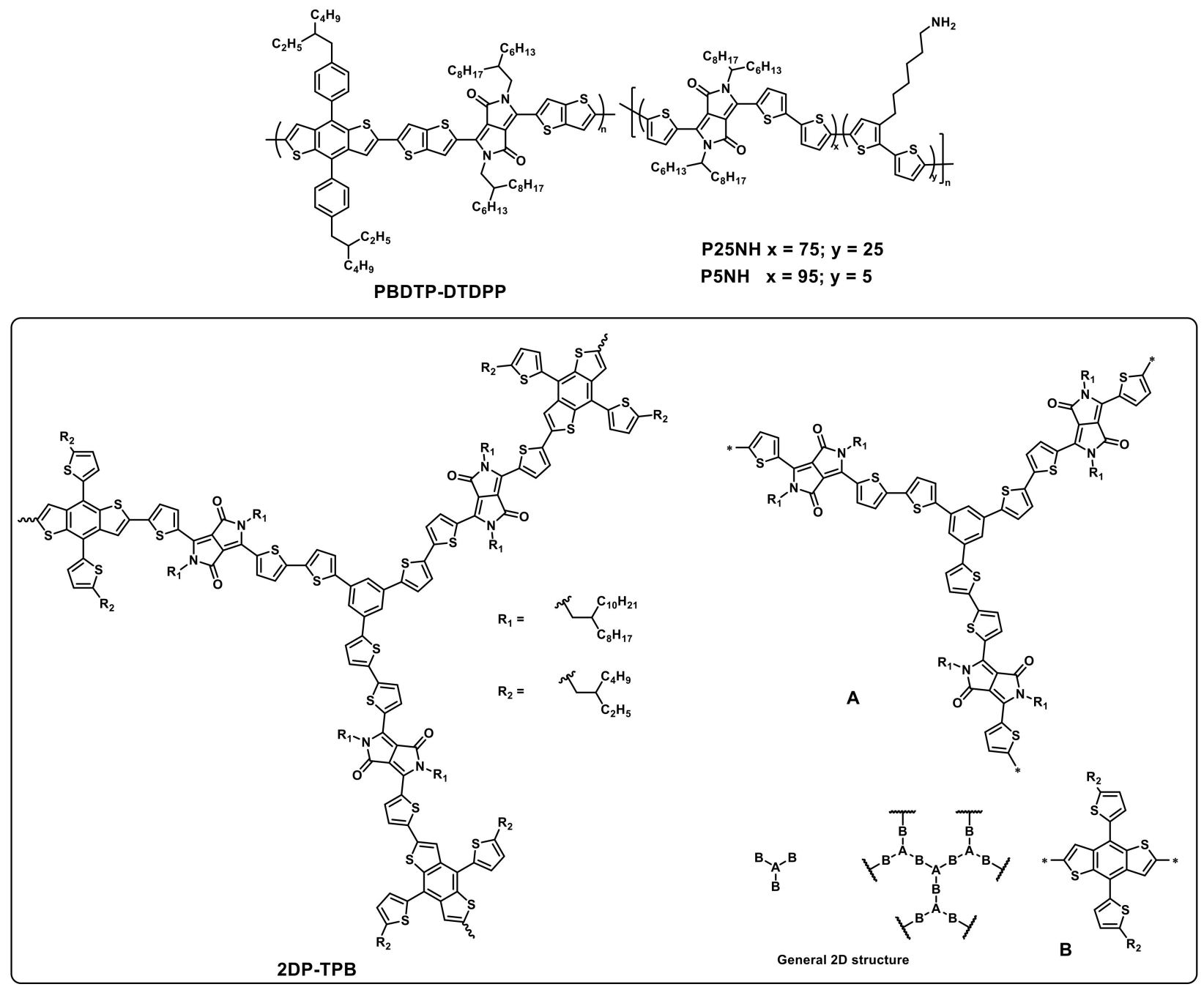

Scheme 4. Polymers containing the 2,5-Dihydropyrrolo[3,4]Pyrrole-1,4-Dione (DDP) group. 
The polymer PBDTP-DTDPP contains both DPP and benzodithiophene (BDT). For more information about BDT-based HTMs please see paragraph 3.4.2.2 on (BDT, Benzo[1,2$\mathrm{b}: 4,5-\mathrm{b}^{\prime}$ ]dithiophene) cores spaced by the bithiophene was prepared and applied on planar PSCs [105]. The presence of two bithiophenes around the DPP core was enhancing the proneness to obtain highly ordered solid-state films, by $\mathrm{p}-\mathrm{p}$ stacking. Photophysical measurements showed an extremely fast separation charge process, in the range of picoseconds. Solar cells based on the triple cation perovskite $\mathrm{Cs}_{0.05}\left(\mathrm{MA}_{0.17} \mathrm{FA}_{0.83}\right)_{0.95} \mathrm{~Pb}\left(\mathrm{I}_{0.83} \mathrm{Br}_{0.17}\right)_{3}$ showing a PCE $14.73 \%$ slightly lower than spiro-OMeTAD. Notably, this material did not show any positive or negative effect ascribable to doping (PCE $14.00 \%$ ).

The DPP based polymer P25NH was produced by reacting the 3,6-bis(5-bromothiophen2-yl)-2,5-bis(2-hexyldecyl)pyrrolo[3,4-c]pyrrole-1,4(2H,5H)-dione monomer with a mixture 4: 1 of 2,5-bis(trimethylstannyl)thiophene and 2-(6-(2,5-Dibromothiophen-3-yl)hexyl)isoindoline1,3-dione, to obtain a polymer in which the amino hexyl pendant chain was present in a average ratio of 3:1 [106]. The skeleton of the P25NH is very similar to the DPP-P3 and the only difference is the presence of further thiophene in P25NH than in DPP-P3; the presence of the aminohexyl chain which is used as a passivating agent for perovskite surface traps is the only other difference. This material gave lamellar films which enabled excellent hole mobility $\left(0.021 \mathrm{~cm}^{2} \mathrm{~V}^{-1} \mathrm{~s}^{-1}\right)$. The amino pendant group was able to passivate surface perovskite hole traps thus increasing the PCE of P25NH, which was $18.1 \%$, higher than the $15.5 \%$ obtained for the standard P3HT.

As an evolution of this work, the authors tried to further improve the hole mobility of this kind of compound, by modulating the ratio between the two monomers, obtaining excellent results with the 95:5 ratio [107]. The increase in hole mobility of $\mathbf{P 5 N H}$ with respect to $\mathbf{P 2 5 N H}$ can afford thicker films to better protecting the perovskite without sacrificing the performances. The XRD analysis showed weaker reflections for the perovskite crystals, due to the passivating effect of the amino group at the surface $\mathrm{Pb}$ atoms, but no reflections were found for the HTM, showing that it is amorphous in the solid-state. The polymer P5NH which contains only 5\% of the 3-aminohexylthiophene monomer showed a hole mobility increase of about $150 \%$ with respect to the polymer P25NH. The final PCE was $18.1 \%$, with a remarkably high fill factor (83.1\%).

A tripodal 2D polymeric HTM, 2DP-TDB, was produced by Fu et al. on the 1,3,5tri(thiophen-2-yl)benzene(TB) scaffold [108]. On this scaffold, the arms were constituted by a DPP monomer with one thiophene at each side. The resulting small molecule (TBDPP) was thus brominated on each terminal thiophene unit and polymerized by the Stille protocol with a BDT monomer. This material showed excellent properties, being prone to $\mathrm{p}-\mathrm{p}$ stacking and organizing as a face-on layer on the perovskite (from GIWAXS measurements and temperature-dependent aggregation from UV spectra) and showing reasonable hole mobility. The $2 \mathrm{D}$ arrangement of this polymer is derived from a concept now largely used for 2D star-shaped small molecules, such a those based on truxenes [23]. The 2D star-shaped polymers can enforce the molecular interactions making the hole transport easier. As evidence, the monomer TB-DPP was substantially less active in PSCs (PCE: $11.61 \%$ ) than 2DP-TDB (PCE: 21.53\%), also due to the better passivation ability of the polymer over the related small molecule. When the perovskite was improved by adding the 4-fluorobenzamide in small quantities to the precursor's mixture, the resulting material was able to push the final PCE of 2DP-TDB up to the record value (22.17\%) obtained up to now for planar PSCs.

\subsubsection{BDT (Benzo[1,2-b:4,5-b']Dithiophene)}

The benzodithiophene core (BDT) is an inherent electron donor group. It was inserted into molecules and polymer with simple synthetic approaches. The starting material is normally the benzo[1,2-b:4,5- $\left.\mathrm{b}^{\prime}\right]$ dithiophene-4,8-dione, which can be modified to insert alkyl $[109,110]$ or alkoxy chains $[109,111,112]$ or further thiophenes bearing alkyl chains $[113,114]$. We will analyze several HTMs structures bearing this group since it was one of the most promising donors used in dopant-free polymers $[115,116]$. 
The first BDT containing HTM in the PSC field appeared in 2014 (for all BDT-based polymers please see Table 3 and Scheme 5). The general characteristic of the PTB7 and related polymers is to have a BDT nucleus, bearing two alkoxy chains, coupled with a thieno[3,4-b]thiophene, the 3-fluorothieno[3,4-b]thiophene-2-carboxylic acid, where the carboxylic acid is normally transformed into an ester group.

The PTB1 and PTB7 polymers were based on BDT and on the fluorinated thieno[3,4]thiophene (TT) [117]. The PTB1 bears octyloxy chains on BDT and a dodecyl ester onto the thieno[3,4]thiophene group, while PTB7 bears 2-ehtylhexyloxy chain and 2-thienylhexyl ester groups. They were used on mesoscopic PSCs based on $\mathrm{MAPI}_{3-\mathrm{x}} \mathrm{Cl}_{\mathrm{x}}$, and compared with PCDTBT, PCPDTBT (PCE for PCDTBT was up to $16.5 \%$, for other data on them, see Section 3.3.2.3 on BTZ (Benzothiadiazole) and Cbz (carbazole), and references cited therein). The undoped spiro-OMeTAD, taken as a standard, gave a PCE of $10.9 \%$, as a result of a lower back electron transfer with respect to the polymers, since the HOMO of spiro-OMeTAD is higher than that of low band-gap polymers. The PTB7 was, however, performing well, with a PCE of 7.5\% higher than the PTB1-based counterpart (6.0\%). The PTB7-Th polymer was used to study the effect of the HTM-perovskite interfacial layer [118]. This HTM belongs to the family of PTB7 and related polymers, and it is an analog of PTB7, where the oxygen of the alkoxy chain moieties on the BDT nucleus is replaced by thiophene. This polymer showed very good hole mobility, and a HOMO with the correct energy to align with the perovskite valence band. The interface between a sol-gel prepared $\mathrm{ZnO}$ (as an electron transport layer, ETL) and the $\mathrm{MAPbI}_{3}$ perovskite was treated with a PCBM layer. The PCBM helped to modify the interface with $\mathrm{ZnO}$, helping to improve the $\mathrm{V}_{\mathrm{OC}}$ of the device. As a consequence, the best PCE obtained was $11.04 \%$ (average PCE: 10.83\%), higher than the value obtained without the PCBM layer, 8.37\% (average PCE: 7.65\%). This demonstrated the better behavior of PTB7-Th when the ETL material was different from the $\mathrm{TiO}_{2}$.

The polymers PTB7 and PTB7-Th were tested recently (along with P3HT and PCDTBT) in $\mathrm{MAPbI}_{3}$ solar cells showing the best PCE for PTB7 (6.30\%) and PTB7-Th (3.48\%) [98]. During a stability test (dark, room temperature, 55-70\% humidity, 66 h) PTB7-Th showed a $60 \%$ increase of its $\mathrm{J}_{\mathrm{sc}}$ and of $40 \%$ of its PCE performance (final PCE around $4.87 \%$ after $66 \mathrm{~h}$ ), which was not clarified by the authors, while for PTB7 the PCE decreased by $40 \%$ (final PCE around 3.78\% after 66 h.). While not being as active as the previously cited works, it seems that PTB7-Th can be more interesting from a stability point of view. Further studies in strictly controlled conditions would be needed to establish what material is the best one.

Three BDT-based polymers, PBDT-N0, PBDT-N5 and PDBT-N20, with pendant amino-terminated alkyl chains $[119,120]$. The main goal was to exploit the amino pendant groups to passivate the perovskite and to link the polymers to the perovskite. Those polymers are based on the skeleton of PTB7 and were obtained by reaction of the BDT monomer with a mixture of octyl 3-fluorothieno[3,4-b]thiophene-2-carboxylate and 8(dimethylamino)octyl 3-fluorothieno[3,4-b]thiophene-2-carboxylate in different proportions [120]. Their energy levels were very similar since the percentage content of amino groups did not influence the HOMO, while the hole mobility increased. These polymers were used in mesoporous PSCs with the $\left(\mathrm{FAPbI}_{3}\right)_{0.85}\left(\mathrm{MAPbBr}_{3}\right)_{0.15}$ perovskite. The PCE increased by following the content of amino groups, being $12.4 \%, 15.5 \%$ and $18.9 \%$ for PBDT-N0, PBDT-N5 and PDBT-N20, respectively. This kind of example explains well that the perovskite needs to be passivated in order to perform better and that an HTM should be built carefully, not only taking into consideration its main intrinsic HTM properties. 
Table 2. Performances of dopant-free polymeric HTMs based on the DDP scaffold. (see legend for details).

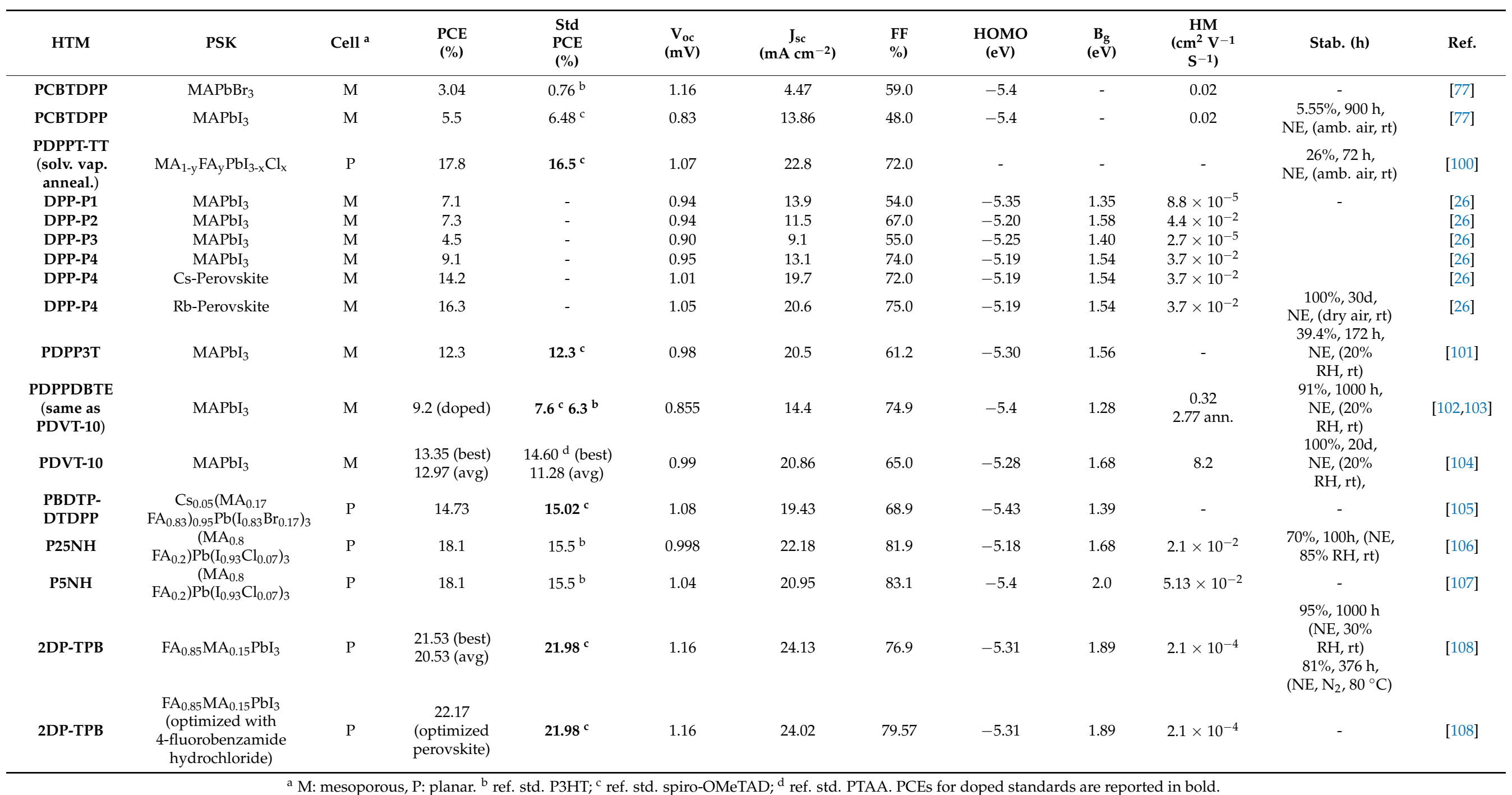


A random copolymer based on BDT, RCP-BTT, was synthesized by the Stille protocol by coupling the stannyl derivative of the BDT partner with a mixture of the 1,3dibromo-5-(8-phenyloctyl)-4H-thieno[3,4-c]pyrrole-4,6(5H)-dione and the 1-(4,6-dibromo3-fluorothieno[3,4-b]thiophen-2-yl)-3-ethylheptan-1-one in a ratio 5:95. [121] The HOMO was found at $-5.28 \mathrm{eV}$ and the hole mobility was high $\left(0.0023 \mathrm{~cm}^{2} \mathrm{~V}^{-1} \mathrm{~s}^{-1}\right)$. In a mesoporous PSC based on the $\mathrm{Cs}_{0.05}\left(\mathrm{FA}_{0.85} \mathrm{MA}_{0.15}\right)_{0.95} \mathrm{~Pb}\left(\mathrm{I}_{0.85} \mathrm{Br}_{0.15}\right)_{3}$ perovskite, RCP-BTT gave a PCE of $8.45 \%$, higher than the reference PTB7 (6.91\%). Under doped conditions, the RCP-BTT obtained a PCE of $14.91 \%$, mainly due to a huge increase of the $\mathrm{J}_{\mathrm{sc}}$ and fill factor (from $53 \%$ to $69 \%$ ) as supported by AFM analysis which showed a better and homogeneous film formation.

Very recently a fully inorganic quantum dot $\alpha \mathrm{CsPbI}_{3}$ perovskite was used with the PTB7 and PTB7-Th polymers, obtaining a minimal $V_{\text {oc }}$ energy loss [122]. The record PCE $12.55 \%$ was obtained by PTB7 with this quantum dot (QD) perovskite. In the same conditions, the P3HT reached $9.82 \%$ and PTB7-Th gave $10.60 \%$. The PTB7 aligns nearly perfectly with the valence band of the QD-perovskite [122]. Strictly related to the PTB7 polymer family, PTB-BO and PTB-DCB21 were synthetized by Lee and co-workers. Three monomers, a BDT and two different fluorinated thieno[3,4]thiophenes (TT), were used in different combinations, to prepare two similar polymers, to be implemented as dopant-free HTMs, namely PTB-BO and PTB-DCB21 [123]. The BDT nucleus is the same as PTB7. The two fluorinated thieno[3,4]thiophene moieties are functionalized with either an alkyl chain (2-butyloctyl) or a dichlorobenzene. The PTB-DCB21 obtained a PCE of $8.7 \%$ while the PTB-BO PCE was a little lower, $7.4 \%$, because of general good hole mobilities. It seems that the dichlorobenzene group gives a faster electron transport and retarded charge recombination, due to possible $\mathrm{p}$ interaction with the component of the perovskite. It is worth noting that the PCE increased upon aging of the devices probably due to better intermolecular interactions between the HTM and the perovskite.

The PBDTTT-C polymer, based on BDT and thieno[3,4]thiophene (TT) moieties, was used to prepare planar PSCs without an ETL material (namely $\mathrm{TiO}_{2}$ ) [124]. This HTM is different from PTB7 only due to the substituent on the moiety. Instead of a 2-ethyhexyl ester, the 2-ethylhexanoyl group was present. The new material showed higher hole mobility $\left(2.4 \times 10^{-4} \mathrm{~cm}^{2} \mathrm{~V}^{-1} \mathrm{~s}^{-1}\right)$ than P3HT $\left(5.1 \times 10^{-5} \mathrm{~cm}^{2} \mathrm{~V}^{-1} \mathrm{~s}^{-1}\right)$, used as a reference, and better alignment of its HOMO with the perovskite valence band level. In the planar PSC configuration, a good PCE (9.95\% best cell PCE, 9.32\% average PCE) was obtained.

After having thoroughly explored this main backbone for the PTB7/PTB7-Th family, further combinations of BDT were approached. A noticeably series of results came from the substitution of the thieno[3,4]thiophene unit with benzothiadiazole, which was always bearing two thiophenes at both sides.

A polymer named $\mathbf{P}$ was obtained as a D- $\pi$-A polymer, by coupling a dodecyloxysubstituted BDT monomer and a bis(thienyl)benzothiadiazole. The polymer was applied in cells with $\mathrm{FTO} / \mathrm{bl}-\mathrm{TiO}_{2} / \mathrm{TiO}_{2} / \mathrm{CH}_{3} \mathrm{NH}_{3} \mathrm{PbI}_{3} / \mathrm{HTM} / \mathrm{Au}$ architecture. It showed a deeper $\mathrm{HOMO}$, as a cause of the strong acceptor character of BTZ. The general parameters, such as increased hole mobility, $\mathrm{V}_{\mathrm{oc}}, \mathrm{J}_{\mathrm{sc}}$, Fill Factor (FF) and PCE, were better than P3HT ones, but far from those needed to obtain a high PCE [125].

A huge breakthrough was obtained by introducing substituents on the BTZ unit and / or on the thiophenes at its sides. An impressive PCE (17.3\%) was obtained by Kim et al. who produced a random copolymer (RCP) by assembling a donor BDT monomer with two acceptor BTZ-based monomers (that here, for homology, will define with the acronyms: M-R and M-OR) [126]. 
Table 3. Performances of dopant-free polymeric HTMs based on the benzodithiophene (BDT) scaffold. (see legend for details).

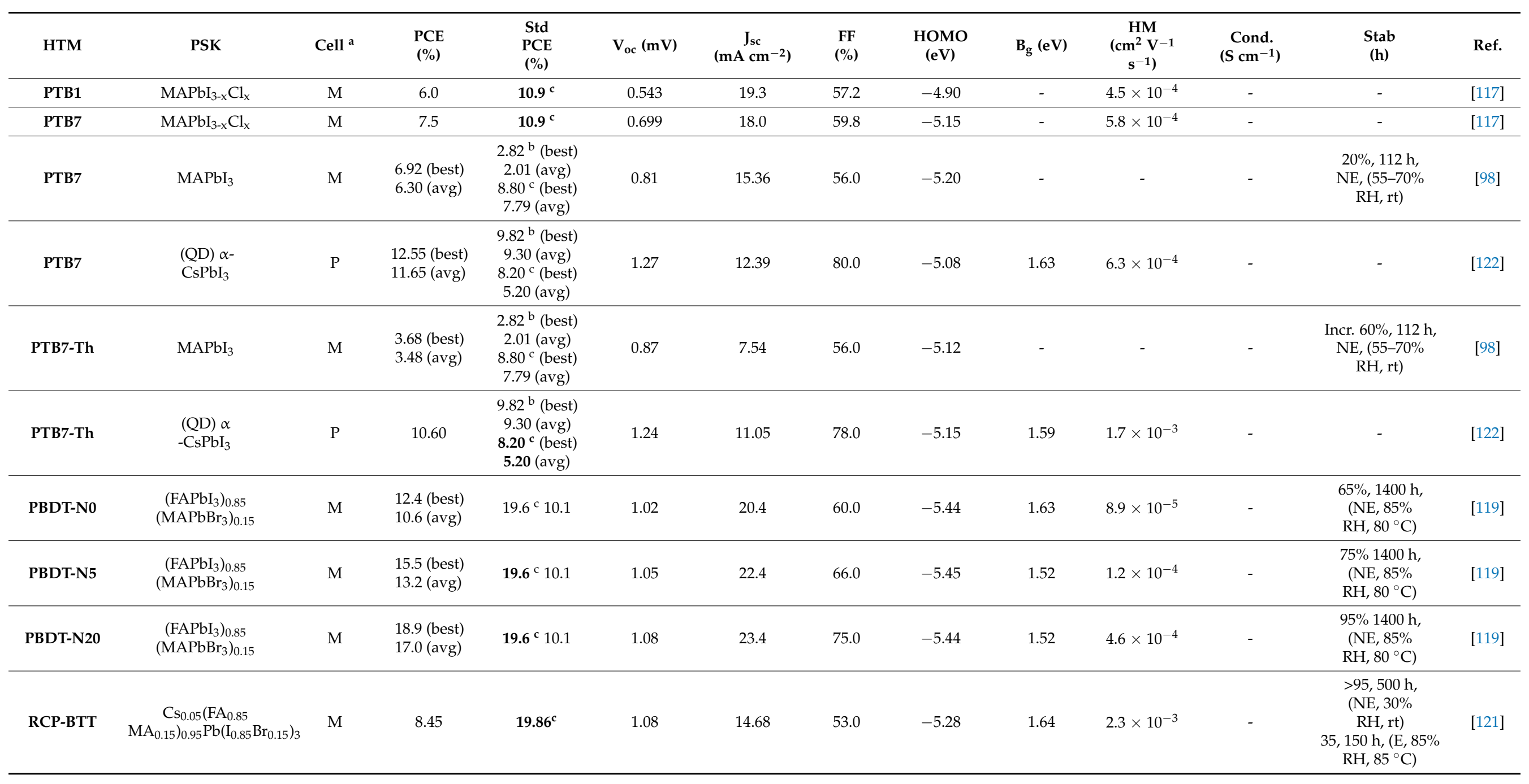


Table 3. Cont

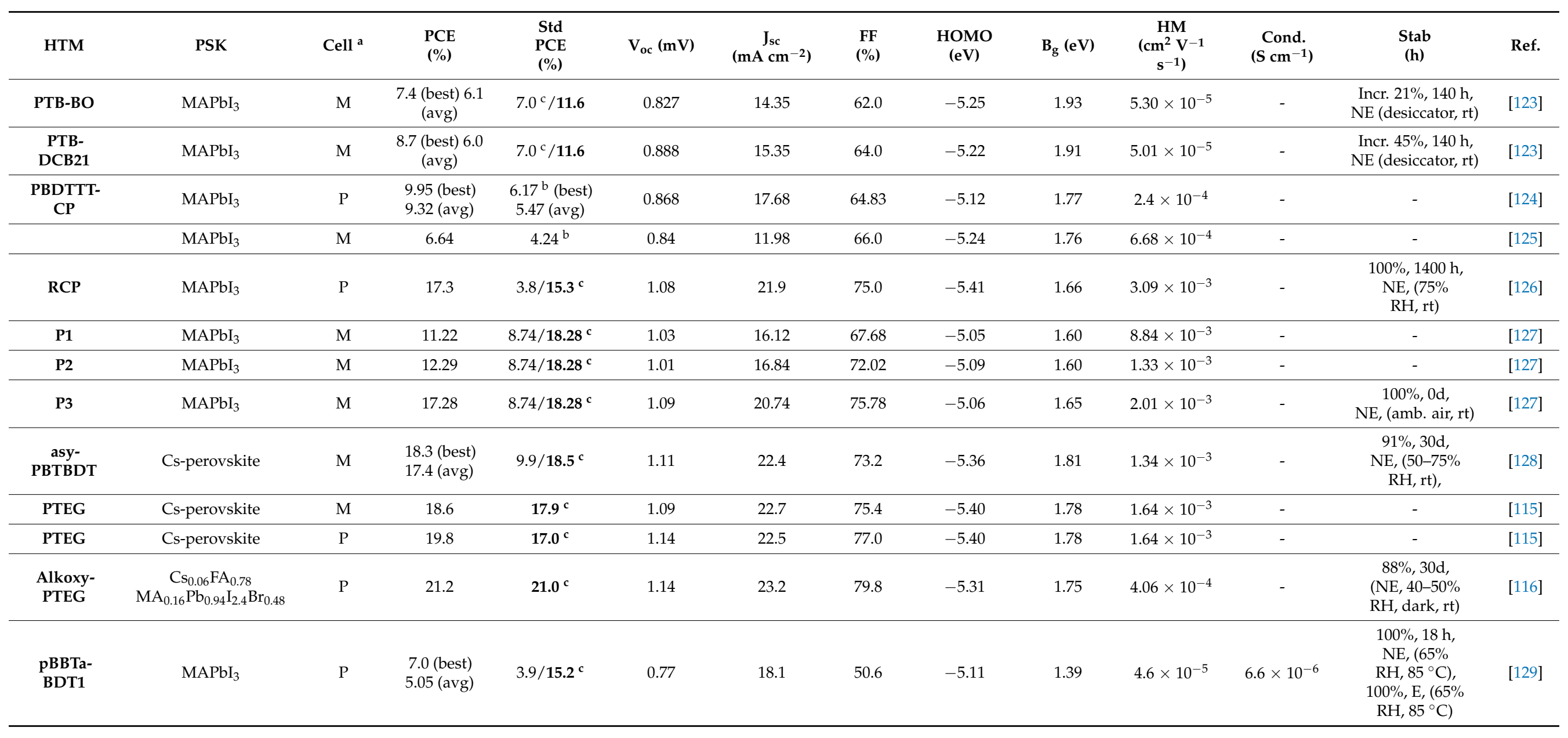


Table 3. Cont

\begin{tabular}{|c|c|c|c|c|c|c|c|c|c|c|c|c|c|}
\hline HTM & PSK & Cell $^{a}$ & $\begin{array}{l}\text { PCE } \\
(\%)\end{array}$ & $\begin{array}{l}\text { Std } \\
\text { PCE } \\
(\%)\end{array}$ & $\mathrm{V}_{\mathrm{oc}}(\mathrm{mV})$ & $\begin{array}{c}\mathrm{J}_{\mathrm{sc}} \\
\left(\mathrm{mA} \mathrm{cm} \mathrm{cm}^{-2}\right)\end{array}$ & $\begin{array}{l}\mathrm{FF} \\
(\%)\end{array}$ & $\begin{array}{c}\text { HOMO } \\
(\mathrm{eV})\end{array}$ & $B_{g}(e V)$ & $\begin{array}{c}\mathrm{HM} \\
\left(\mathrm{cm}^{2} \mathrm{~V}^{-1}\right. \\
\left.\mathrm{s}^{-1}\right)\end{array}$ & $\begin{array}{l}\text { Cond. } \\
\left(\mathrm{S} \mathrm{cm}^{-1}\right)\end{array}$ & $\begin{array}{c}\text { Stab } \\
\text { (h) }\end{array}$ & Ref. \\
\hline $\begin{array}{l}\text { pBBT- } \\
\text { BDT2 }\end{array}$ & $\mathrm{MAPbI}_{3}$ & $\mathrm{P}$ & $\begin{array}{r}14.5 \text { (best) } \\
12.05 \text { (avg) }\end{array}$ & $3.9 / 15.2^{c}$ & 0.95 & 20.3 & 75.2 & -5.21 & 1.37 & $2.0 \times 10^{-3}$ & $1.3 \times 10^{-5}$ & $\begin{array}{c}100 \%, 18 \mathrm{~h}, \\
\mathrm{NE},(65 \% \\
\left.\mathrm{RH}, 85^{\circ} \mathrm{C}\right), \\
100 \%, \mathrm{E},(65 \% \\
\left.\mathrm{RH}, 85^{\circ} \mathrm{C}\right)\end{array}$ & [129] \\
\hline P1-0F & $\mathrm{MAPbI}_{3}$ & $\mathrm{M}$ & 9.80 & $8.74 / \mathbf{1 8 . 4 7 ^ { c }}$ & 1.00 & 17.85 & 54.66 & -5.41 & 1.82 & $2.51 \times 10^{-5}$ & - & $\begin{array}{c}>75 \%, 720 \mathrm{~h}, \\
\mathrm{NE},(\mathrm{amb} . \text { air, rt) }\end{array}$ & [130] \\
\hline P2-2F & $\mathrm{MAPbI}_{3}$ & $\mathrm{M}$ & 14.94 & $8.74 / 18.47^{c}$ & 1.04 & 20.17 & 70.65 & -5.43 & 1.82 & $9.32 \times 10^{-5}$ & - & $\begin{array}{c}>75 \%, 720 \mathrm{~h}, \\
\mathrm{NE},(\mathrm{amb} . \text { air, rt) }\end{array}$ & [130] \\
\hline P3-4F & $\mathrm{MAPbI}_{3}$ & $\mathrm{M}$ & 10.35 & $8.74 / 18.47^{c}$ & 1.03 & 18.58 & 53.81 & -5.50 & 1.82 & $4.06 \times 10^{-5}$ & - & $\begin{array}{c}>75 \%, 720 \mathrm{~h}, \\
\mathrm{NE},(\mathrm{amb} . \text { air, rt) }\end{array}$ & [130] \\
\hline P-TT-TPD & CsFAMA & $\mathrm{M}$ & $\begin{array}{l}17.10 \text { (best) } \\
\text { (16.96 (avg) }\end{array}$ & $21.5^{c}$ & 1.04 & 21.86 & 74.25 & -5.42 & 1.79 & $1.29 \times 10^{-4}$ & - & - & [131] \\
\hline K1 & $\mathrm{MAPbI}_{3}$ & $\mathrm{P}$ & $\begin{array}{l}16.02 \text { (best) } \\
15.19 \text { (avg) }\end{array}$ & - & 1.06 & 19.22 & 78.0 & -5.29 & 1.96 & $2.96 \times 10^{-5}$ & - & $\begin{array}{c}85 \%, 200 \mathrm{~h}, \\
\mathrm{NE},(\mathrm{amb} . \text { air, rt) }\end{array}$ & [132] \\
\hline $\mathrm{K} 2$ & $\mathrm{MAPbI}_{3}$ & $\mathrm{P}$ & $\begin{array}{l}3.85 \text { (best) } \\
2.9 \text { (avg) }\end{array}$ & - & 0.92 & 7.69 & 55.0 & -5.35 & 1.48 & $2.55 \times 10^{-7}$ & - & - & [132] \\
\hline K3 & $\mathrm{MAPbI}_{3}$ & $\mathrm{P}$ & $\begin{array}{l}12.50 \text { (best) } \\
11.98 \text { (avg) }\end{array}$ & - & 1.02 & 16.94 & 73.0 & -5.40 & 1.97 & $1.41 \times 10^{-6}$ & - & - & [132] \\
\hline K4 & $\mathrm{MAPbI}_{3}$ & $\mathrm{P}$ & $\begin{array}{l}6.45 \text { (best) } \\
5.84 \text { (avg) }\end{array}$ & - & 0.94 & 11.07 & 63.0 & -5.31 & 1.53 & $9.67 \times 10^{-7}$ & & - & [132] \\
\hline K5 & $\mathrm{MAPbI}_{3}$ & $\mathrm{P}$ & $\begin{array}{l}14.65 \text { (best) } \\
13.83 \text { (avg) }\end{array}$ & - & 1.05 & 18.32 & 76.0 & -5.40 & 1.92 & $5.68 \times 10^{-6}$ & - & - & [132] \\
\hline K6 & $\mathrm{MAPbI}_{3}$ & $\mathrm{P}$ & $\begin{array}{c}13.77 \text { (bes) } \\
13.06 \text { (avg) }\end{array}$ & - & 1.04 & 17.75 & 75.0 & -5.42 & 1.92 & $4.89 \times 10^{-6}$ & - & - & [132] \\
\hline R1 & $\mathrm{MAPbI}_{3}$ & $\mathrm{M}$ & 15.88 & - & 0.98 & 23.70 & 68.3 & -5.42 & 1.60 & $3.7 \times 10^{-3}$ & - & $\begin{array}{c}100 \%, 500 \mathrm{~h}, \\
\mathrm{NE}(75 \% \\
\mathrm{RH}, \mathrm{rt})\end{array}$ & [133] \\
\hline
\end{tabular}


Table 3. Cont

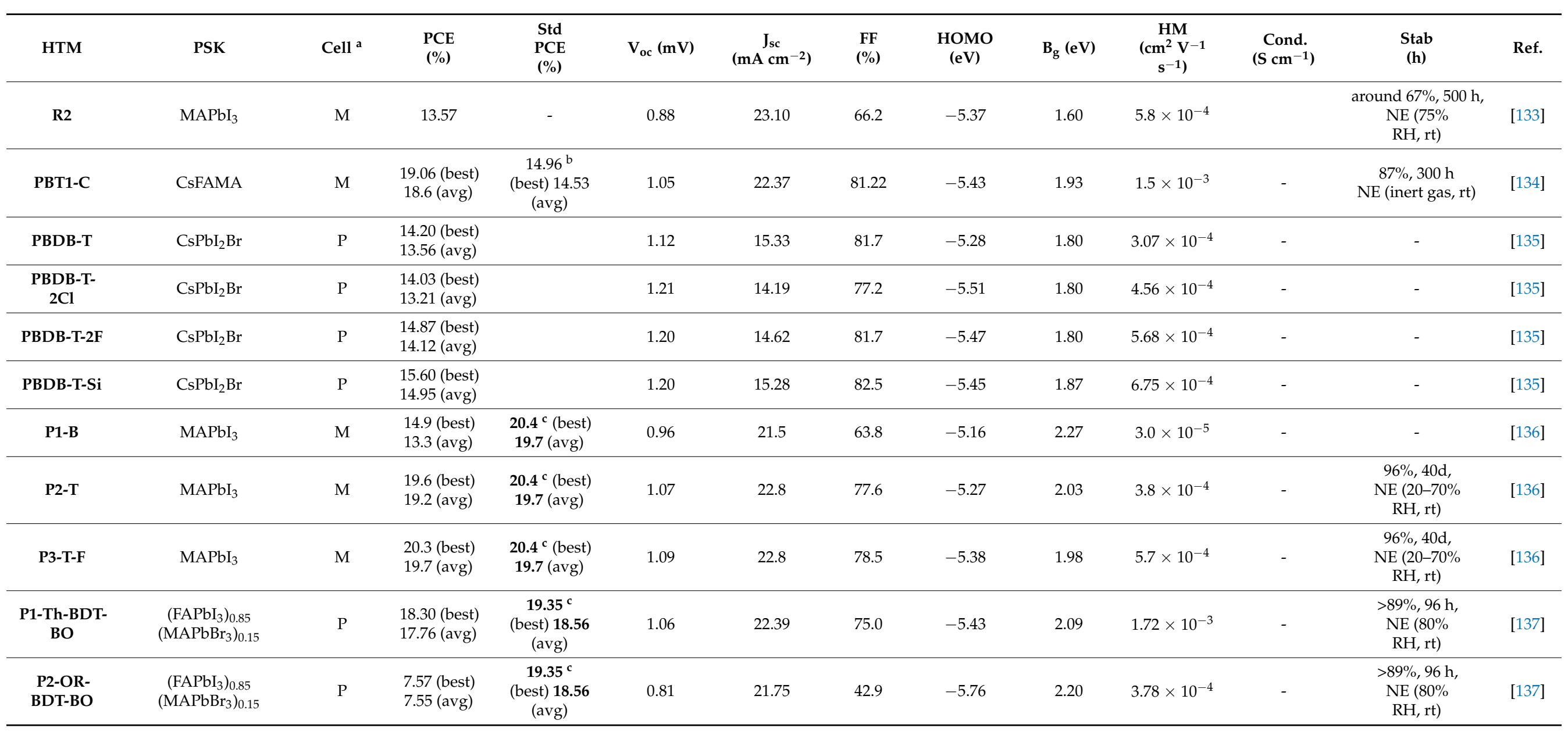


Table 3. Cont

\begin{tabular}{|c|c|c|c|c|c|c|c|c|c|c|c|c|c|}
\hline HTM & PSK & Cell $^{a}$ & $\begin{array}{l}\text { PCE } \\
(\%)\end{array}$ & $\begin{array}{l}\text { Std } \\
\text { PCE } \\
(\%)\end{array}$ & $\mathrm{V}_{\mathrm{oc}}(\mathrm{mV})$ & $\begin{array}{c}\mathrm{J}_{\mathrm{sc}} \\
(\mathrm{mA} \mathrm{cm}-2)\end{array}$ & $\begin{array}{l}\mathrm{FF} \\
(\%)\end{array}$ & $\begin{array}{c}\text { HOMO } \\
(\mathrm{eV})\end{array}$ & $B_{g}(e V)$ & $\begin{array}{c}\mathrm{HM} \\
\left(\mathrm{cm}^{2} \mathrm{~V}^{-1}\right. \\
\left.\mathrm{s}^{-1}\right)\end{array}$ & $\begin{array}{l}\text { Cond. } \\
\left(\mathrm{S} \mathrm{cm}^{-1}\right)\end{array}$ & $\begin{array}{c}\text { Stab } \\
\text { (h) }\end{array}$ & Ref. \\
\hline $\begin{array}{l}\text { P3-OR- } \\
\text { BDT-T }\end{array}$ & $\begin{array}{c}\left(\mathrm{FAPbI}_{3}\right)_{0.85} \\
\left(\mathrm{MAPbBr}_{3}\right)_{0.15}\end{array}$ & $\mathrm{P}$ & $\begin{array}{l}13.03 \text { (best) } \\
12.92 \text { (avg) }\end{array}$ & $\begin{array}{c}19.35^{\mathrm{c}} \\
\text { (best) } 18.56 \\
\text { (avg) }\end{array}$ & 0.93 & 22.03 & 63.3 & -5.30 & 2.13 & $2.54 \times 10^{-4}$ & - & $\begin{array}{c}>89 \%, 96 \mathrm{~h}, \\
\mathrm{NE}(80 \% \\
\mathrm{RH}, \mathrm{rt})\end{array}$ & [137] \\
\hline PBDT[2F]T & $\mathrm{MAPbI}_{3}$ & $\mathrm{P}$ & $\begin{array}{l}17.52 \text { (best) } \\
16.55 \text { (avg) }\end{array}$ & $20.20_{\mathrm{d}}^{\mathrm{c}} 15.59$ & 1.06 & 22.64 & 72.60 & -5.29 & 2.1 & $9.2 \times 10^{-6}$ & - & $\begin{array}{c}91 \%, 16 \mathrm{~d}, \\
\mathrm{NE}(30 \% \\
\left.\mathrm{RH}, 30^{\circ} \mathrm{C}\right)\end{array}$ & [138] \\
\hline $\operatorname{PBDT}(\mathrm{T})[2 \mathrm{~F}] \mathrm{T}$ & $\mathrm{MAPbI}_{3}$ & $\mathrm{P}$ & $\begin{array}{l}11.63 \text { (best) } \\
10.25 \text { (avg) }\end{array}$ & $\begin{array}{c}20.20^{\mathrm{c}} 15.59 \\
\mathrm{~d}\end{array}$ & 1.03 & 16.59 & 67.95 & -5.22 & 2.0 & - & - & - & [138] \\
\hline PBDT[2H]T & $\mathrm{MAPbI}_{3}$ & $\mathrm{P}$ & $\begin{array}{l}14.24 \text { (best) } \\
13.50 \text { (avg) }\end{array}$ & $20.20_{\mathrm{d}}^{\mathrm{c}} 15.59$ & 1.05 & 20.89 & 64.97 & -5.03 & 2.1 & $\begin{array}{c}2.2 \times 10^{-6} \\
{[139]}\end{array}$ & - & - & [138] \\
\hline
\end{tabular}

${ }^{a}$ M: mesoporous, P: planar. ${ }^{b}$ ref. std. P3HT; ${ }^{c}$ ref. std. spiro-OMeTAD; ${ }^{d}$ ref. std. PTAA. PCEs for doped standards are reported in bold. 


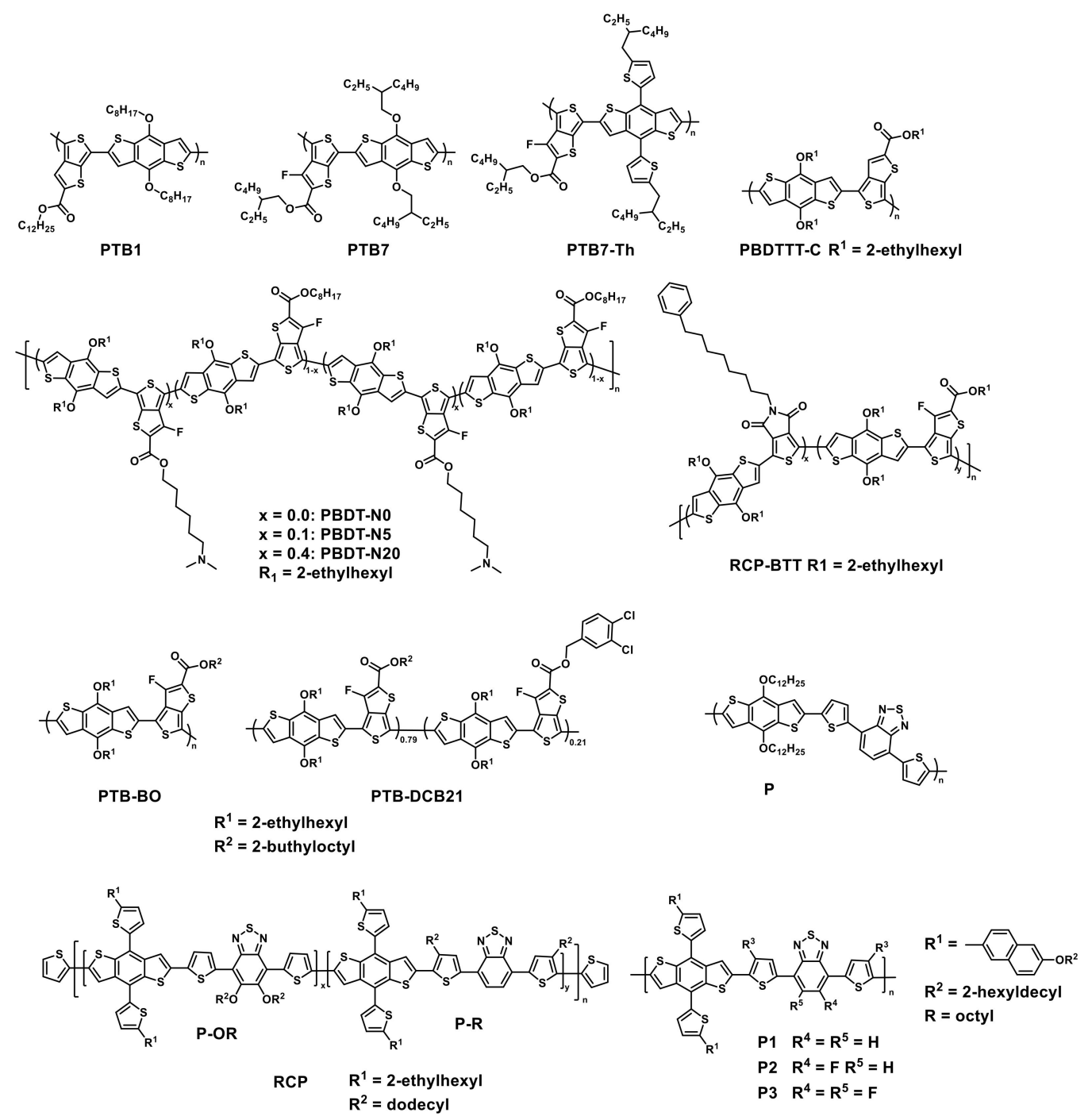

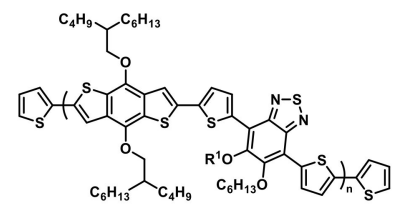

PBTBDT $\mathbf{R}^{\mathbf{1}}=$ hexyl

asy-PBTBDT $\mathbf{R}^{1}=$ ethyl

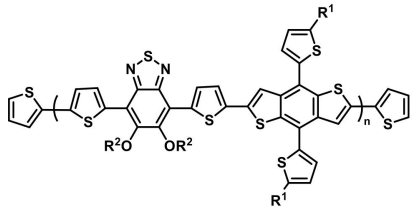

PTEG $\mathbf{R}^{1}=$ 2-ethylhexyl

$\mathrm{R}^{2}=$ * 0 ○佂

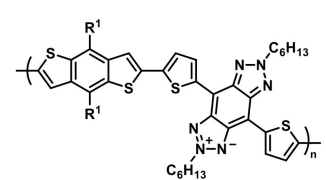

PBBTa-BDT1 R1 =

pBBTa-BDT2 R1 $=-O R^{2}$

R1 = 2-hexyldecy

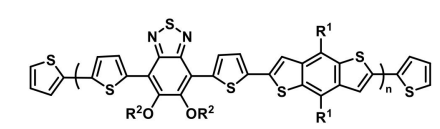

Alkoxy-PC8 $\mathrm{R}^{1}=$ *-O $\mathrm{R}^{1}=$

Thiophenyl-PTEG $R^{1}=$ *

Alkoxy-PTEG $\mathrm{R}^{1}=$, o $\mathrm{R}^{2}=$ *

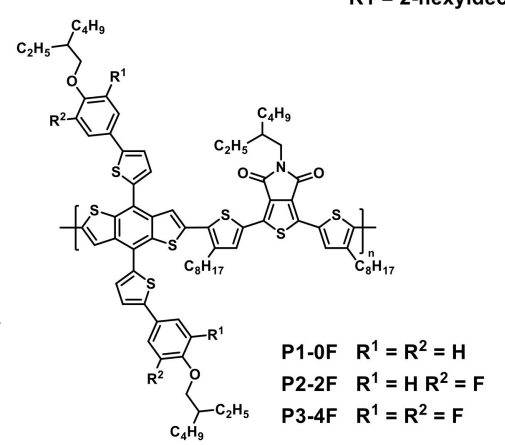

Scheme 5. Cont. 

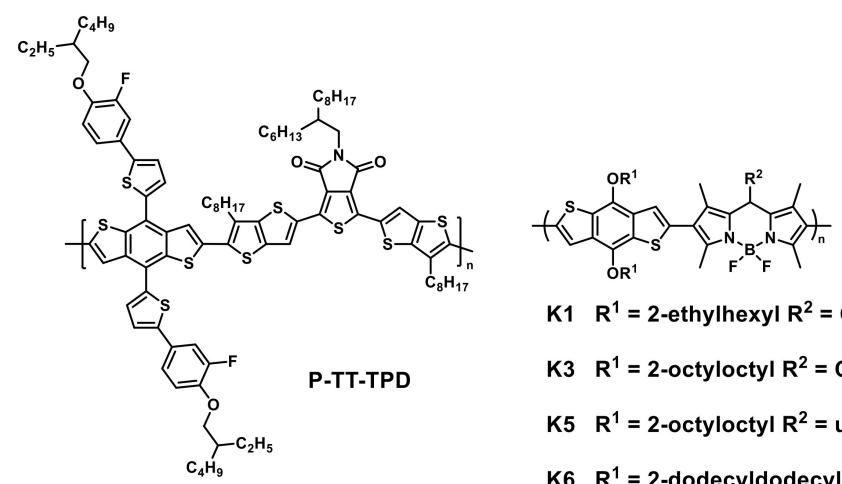

K1 $R^{1}=$ 2-ethylhexyl $R^{2}=\mathrm{CH}_{3}$

K3 $R^{1}=2$-octyloctyl $R^{2}=\mathrm{CH}_{3}$

K5 $R^{1}=2$-octyloctyl $R^{2}=$ undecyl

K6 $R^{1}=$ 2-dodecyldodecyl $R^{2}=\mathrm{CH}_{3}$

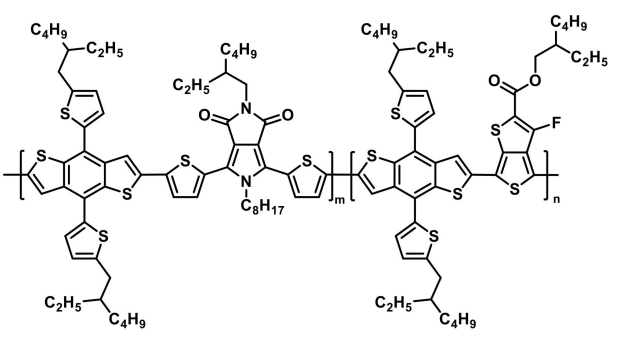

R1

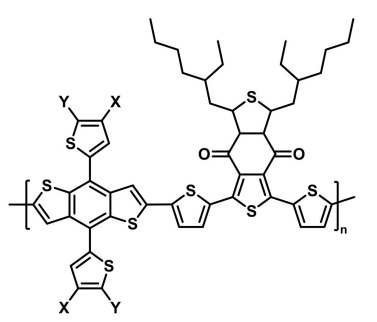

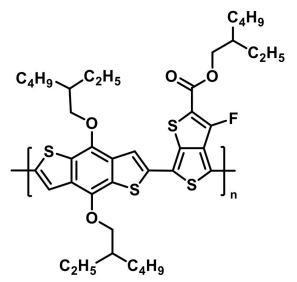

R2

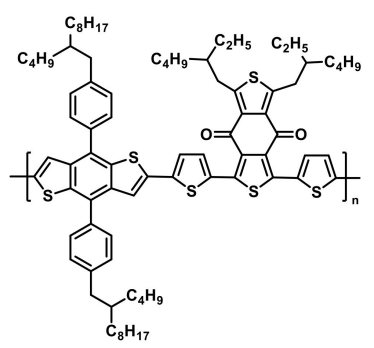

PBT1-C
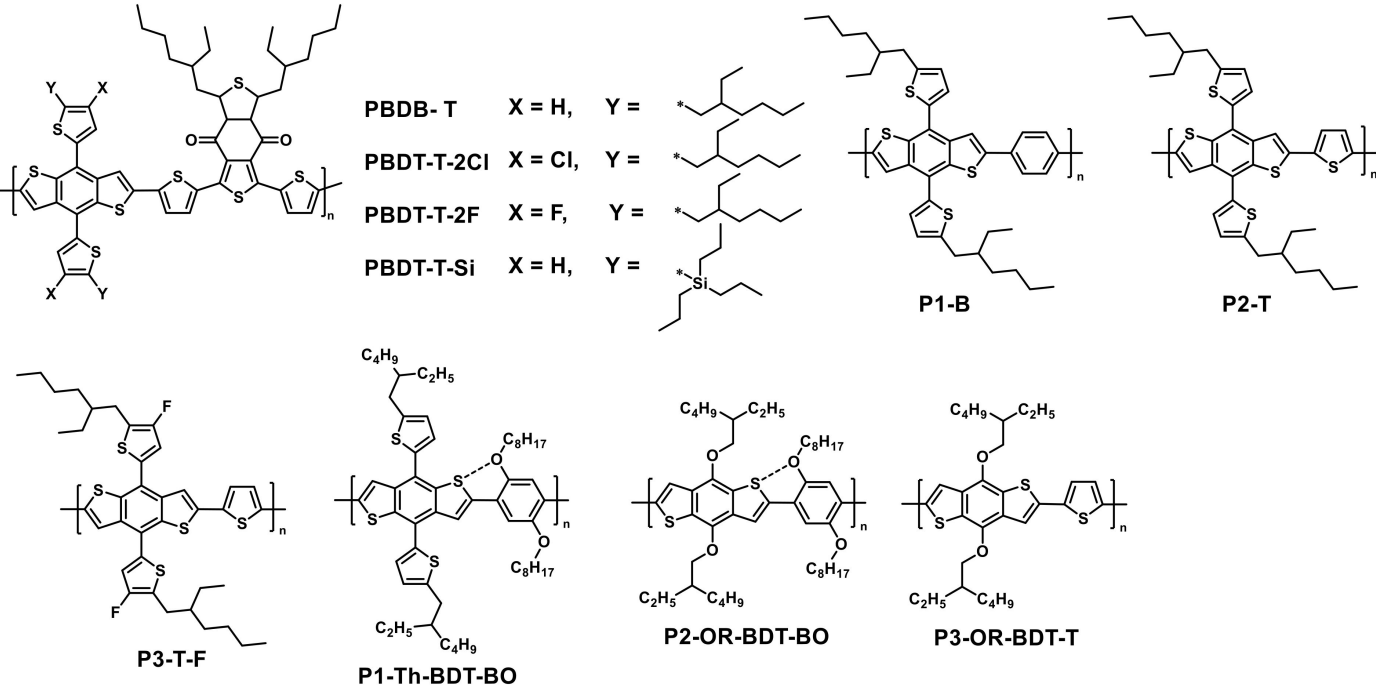

P1-Th-BDT-BO
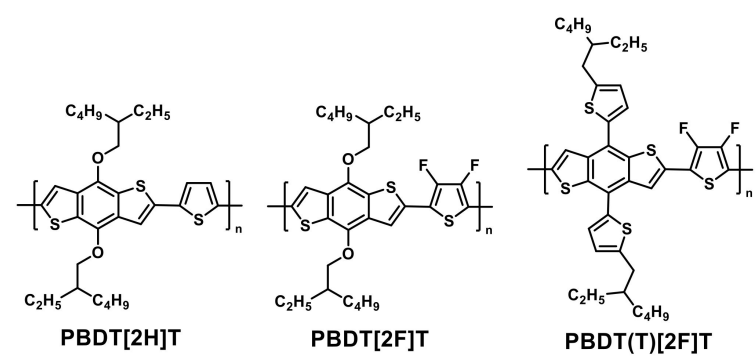

Scheme 5. HTMs containing the BDT group.

Small differences are present on the monomers. The BDT monomer contains two thiophenes with a 2-ethylhexyl chain. One BTZ monomer possesses two 2-ethylhexyl chains on the two thiophenes present at both sides of BTZ (M-R) and the other BTZ monomer has the dodecyloxy chains positioned on the BTZ, (M-OR). The random copolymerization of the two monomers by Stille coupling yielded the RCP polymer. Both M-R and M-OR 
were polymerized with the BDT monomer, giving their respective "homopolymers" P-R and P-OR. These two homopolymers were reasonably similar to the molecular weight of the RCP, since the synthetic methods requested for every polymer a few microwave heating steps $\left(120^{\circ} \mathrm{C}, 5 \mathrm{~min}, 140{ }^{\circ} \mathrm{C} 5 \mathrm{~min}, 170{ }^{\circ} \mathrm{C}, 1 \mathrm{~h}\right)$ and two end-capping steps with 2-tributylstannylthiophene at $140^{\circ} \mathrm{C} 20 \mathrm{~min}$ and with 2-bromothiophene for $140^{\circ}, 20 \mathrm{~min}$ ). Microwave heating applied to organic reactions normally improves the repeatability and homogeneity of products obtained in different batches and often reduces byproducts [140]. It is however a problem to use this method for industrial production since, for technical reasons, one cannot scale-up easily the system [141]. P-OR has the HOMO (-5.51 eV) lying below the $\mathrm{MAPbI}_{3}$ perovskite valence band $(-5.43 \mathrm{eV})$, while the $\mathbf{P}-\mathbf{R} \mathrm{HOMO}(-5.40 \mathrm{eV})$ is better aligned with the perovskite. As a result, the RCP HTM has the HOMO at $-5.41 \mathrm{eV}$, still correctly aligned with the perovskite VB. The hole mobility of RCP was higher than the P-R and P-OR homopolymers. It is worth and essential mentioning that while the P-OR homopolymer shows a face-on organization of the polymer onto the perovskite, $\mathbf{P}-\mathbf{R}$ does not show this ability. The RCP copolymer improved this property and the ability to order itself at the surface in a face-on way, which is well known to promote an easy hole transfer in the vertical direction, from the perovskite to the metal electrode. All these facts evidence that the RCP polymer is beneficial for the PSC application and, consequently, that a possible random copolymerization strategy can be used fruitfully to improve polymer properties. While the PCE of the single homopolymers was low (1.9\% for P-R and $2.6 \%$ for P-OR), the combination of the two monomers was strongly synergistic (PCE 17.3\%), also overcoming the doped spiro-OMeTAD (15.3\%). The doped RCP-based PSCs showed a PCE of $16.5 \%$, denoting the better performance for RCP in the undoped state. Stability tests on not encapsulated devices (over $1400 \mathrm{~h}$ at room temperature and $75 \%$ relative humidity) demonstrated the absolute stability of the cells containing only RCP while the doped RCP decreased their performances (maintaining around $40 \%$ of the pristine PCE) still being however higher than spiro-OMeTAD, which fully decomposed and deactivated after just less than $900 \mathrm{~h}$. A stable PCE of 17.3\% maintained for longtime exposure to high humidity showed that PSC can be improved to be amenable to the market, in the next future. Starting from these excellent results, the research further explored the application of polymers based on BDT and BTZ.

Three polymers, named P1, P2 and P3, were based on a BDT nucleus monomer, substituted with a 2-(6-((2-hexyldecyl)oxy)naphthalen-2-yl)thienyl group and on a benzothiadiazole (BTZ) surrounded by two 3-octylthiophenes [127]. The only difference among the polymers is the presence of a variable number of fluorine substituents on the BTZ moiety, absent for P1, 1 for P2 and 2 for P3. The absorption of the polymers covers the range between 300 and $800 \mathrm{~nm}$. Their stability was above $400{ }^{\circ} \mathrm{C}$. The fluorine content progressively lowered the HOMO energy level for P1, P2 and P3 to $-5.18 \mathrm{eV},-5.23 \mathrm{eV}$ and $-5.30 \mathrm{eV}$ (calculated values), respectively. The number of fluorine atoms added to the BTZ counterparts increases the acceptor properties of the monomer, enhancing the difference with the BDT monomer and this was fruitful for the photovoltaic properties. The hole mobility was high (up to $2.01 \times 10^{-3} \mathrm{~cm}^{2} \mathrm{~V}^{-1} \mathrm{~s}^{-1}$ ) and followed the same order, P1 < P2 $<$ P3. The average PCE for the polymers P1-P3 was $11.05 \%, 12.22 \%, 17.24 \%$, respectively. The stability of the P3-based devices was evaluated over 30 days, in which it maintained a PCE of about $16.0 \%$, with more than $92 \%$ of PCE retention.

The polymers PBTBDT and asy-PBTBDT contain the same structural motifs and were prepared by assembling a BDT and a BTZ moiety surrounded by two thiophenes. The polymers are made on the basis of a BDT bearing two 2-butyloctyloxy chains, and in PBTBDT the BTZ monomer contains two hexyloxy substituents, whereas in asy-PBTBDT an ethoxy and a decyloxy substituents, being thus asymmetric [128]. This asymmetry has an essential influence on the solubility of the polymers. The PBTBDT shows a reduced solubility in organic solvents, while asy-PBTBDT is highly soluble and easily processable. This asymmetric feature became further important based on the choice of 2-methylanisole (2-MA) as a deposition solvent, which is also certified for food use and also considered a 
green solvent. The solubility of the asymmetric polymer into this solvent was very high, while PBTBDT is not, leading to obtaining an optimized deposition of the HTM film. The hole mobility was high $\left(1.34 \times 10^{-3} \mathrm{~cm}^{2} \mathrm{~V}^{-1} \mathrm{~s}^{-1}\right)$ and the HOMO energy level is at $-5.36 \mathrm{eV}$, properly aligned with the perovskite. The PCE reached the $18.3 \%$ outstanding value in the pristine state and $20.0 \%$ in the doped state. This was one the best results ever obtained until now, and it opened the way to a greener production of PSCs, avoiding, in turn, the use of chlorinated solvents.

An exceptional result in terms of PCE was obtained again by Kim et al. with another BDT-BTZ based polymer, named PTEG [115]. They produced two polymers containing the same BDT monomer, bearing 2-(2-ethylhexyl)thienyl substituents, and a BTZ monomer, in which BTZ is further surrounded by two thiophenes. The difference between the two polymers is related to the two alkoxy substituents on the BTZ ring. One polymer brings two dodecyloxy chains, and the other, named PTEG, contains two triethylene glycol monomethyl ether chains (TEG). The PTEG showed a high proneness to give films with a face-on orientation on the perovskite surface, probably due to the presence of triethylene glycol chains, which avoid the backbone twisting and, at the same time, ensure good interaction with the perovskite surface due to the higher energy of the TEG chains with respect to the classic alkyl chains [115]. Moreover, the TEG chains gave PTEG higher solubility $(39.87 \mathrm{mg} / \mathrm{mL}$, in chlorobenzene) than the alkyl-substituted polymer $(2.73 \mathrm{mg} / \mathrm{mL})$, improving its processability and reducing the amount of solvent required for the deposition. The presence of the TEG chain helps also to obtain high hole mobility, and very good contact with the perovskite as proved by the higher surface energy of the TEG group. In a PSC with $\mathrm{FTO} / \mathrm{TiO}_{2} / \mathrm{m}-\mathrm{TiO}_{2} / \mathrm{Cs}$-perovskite/HTL/Au structure, the PTEG gave a PCE of $18.6 \%$ while in a planar architecture $\left(\mathrm{FTO} / \mathrm{SnO}_{2} / \mathrm{Cs}\right.$-perovskite/HTL/ Au) the PCE was even higher (19.8\%, a really outstanding value). Upon addition of tBP and LiTFSI, the PCE increased in the first case to $19.1 \%$ but decreased in the second case to $19.0 \%$. Further papers showed that one of the more important features of the TEG group is to act as a complexing agent for $\mathrm{Pb}^{2+}$ and that this was beneficial since the TEG chain can interact directly with lead in the perovskite [116,142].

An evolution of the PTEG polymer was the topic of an extremely interesting paper from Lee et al. [116]. Differently from the original PTEG, the authors replaced the substituent on the BDT monomer, from the 5-(2-ethylhexyl)thiophene to the 2-ethylhexyloxy one. A few polymers were obtained, named alkoxy-PC8 $\left(\mathrm{M}_{\mathrm{n}}=25 \mathrm{kDa}\right)$, thiophenylPTEG $\left(M_{n}=57 \mathrm{kDa}\right)$ and alkoxy-PTEG $\left(\mathrm{M}_{\mathrm{n}}=50 \mathrm{kDa}\right)$. The use of green solvent alternative to chlorobenzene $(\mathrm{CB})$ provided an improvement to both the efficiency and the sustainability of the deposition process. In particular, the 2-methyl anisole (MA) and the 3-methylcycloesanone (MC) were not able to dissolve well the original PTEG while they dissolved very well the alkoxy-PTEG. The films given by MA and MC were thinner than those produced by CB and, in particular, MA gave more uniform films. GIWAXS analysis showed a face-on arrangement at the surface for both alkoxy-PC8 and alkoxy-PTEG, but the former was less soluble in MA and MC. The final PSCs were thus prepared with alkoxy-PTEG only. In planar PSC, with $\mathrm{Cs}_{0.06} \mathrm{FA}_{0.78} \mathrm{MA}_{0.16} \mathrm{~Pb}_{0.94} \mathrm{I}_{2.4} \mathrm{Br}_{0.48}$ perovskite, the alkoxy-PTEG gave a 20.6\% efficiency when deposited from CB, 21.2\% from MA and 19.9\% from MC. The long-term stability was assessed for 20 non-encapsulated devices at room temperature and 40-50\% relative humidity for 30 days. The alkoxy-PTEG showed retention of $88 \%$ of PCE. Moreover, encapsulated devices in the same conditions fully saved the PCE. Thermal stability at $100{ }^{\circ} \mathrm{C}$ was excellent for 4 days (94\% PCE retention) but it decreased at $29 \%$ retention after 30 days. However, this was due mainly to the perovskite thermal stability issues in the trial conditions more than to HTM.

Further modifications in the polymeric skeleton were recently exploited by using different acceptor groups other than BTZ.

The polymers pBBTa-BDT1 and pBBTa-BDT2 were prepared and used with success in PSCs [129]. The two moieties coupled to form the polymers were the 4,8-dithien-2-ylbenzo[1,2-d;4,5- $\left.\mathrm{d}^{\prime}\right]$ bistriazole with two hexyl chains and the benzo[1,2-b:4,5- $\left.\mathrm{b}^{\prime}\right]$ dithiophene 
bearing two 2-hexyldexyloxy chains. These polymers show a great interchain interaction and, besides, both form films with a face-on orientation on the deposition surface. The polymer pBBTa-BDT2 is face-on oriented for a large extent, greatly helping the charge transfer, as shown by a higher vertical conductivity and the hole mobility. This could explain the difference in PCE (7.0\% for pBBTa-BDT1 and 14.5\% for pBBTa-BDT2). The devices were also tested for stability: pBBTa-BDT2 retained about $30 \%$ of the initial PCE after 18h, while spiro-OMeTAD, employed as a reference, lost any activity in 5h [129].

The polymers P1-0F, P2-2F and P3-4F were prepared by coupling a BDT monomer containing phenylthiophene moieties with two 2-ethylhexyloxy chains and a thieno[3,4c]pyrrole-4,6(5H)-dione central ring bearing one 2-ethylhexyl chain and surrounded by two thiophenes [130]. In these polymers, the degree of fluorination in the side chain benzene rings was tuned. The HOMO of the P-0F, P2-2F and $\mathbf{P 3 - 4 F}$ polymers $(-5.41 \mathrm{eV},-5.43 \mathrm{eV}$ and $-5.50 \mathrm{eV}$, respectively) was tuned by the introduction of the fluorine atoms and the LUMO behaved accordingly $(-3.59 \mathrm{eV},-3.61 \mathrm{eV}$ and $-3.68 \mathrm{eV})$. The fluorination degree seemed to alter the energy levels without altering the band gap $(1.82 \mathrm{eV})$. The thermal stability showed to be higher than $400{ }^{\circ} \mathrm{C}$ for all the polymers. The dipole moment was higher for the fluorinated polymers with respect to the nonfluorinated one, P1-0F (1.44 D, 4.44 D and 2.75 D for P1-0F, P2-2F and P3-4F respectively), and this was also a measure of a higher molecular packing and order. In this paper, the P1-0F, P2-2F and P3-4F polymers showed hole mobility of $2.51 \times 10^{-5}, 4.06 \times 10^{-5}$ and $9.32 \times 10^{-5} \mathrm{~cm}^{2} \mathrm{~V}^{-1} \mathrm{~s}^{-1}$ respectively, while flash photolysis time-resolved microwave conductivity measurements showed that the hole transfer yield (from perovskite to the HTM) decreased according to the fluorination degree, 0.88, 0.80 and 0.54 for P1-0F, P2-2F and P3-4F respectively. The hole transfer yield $(0.88 \%$ for $\mathrm{P} 1-0 \mathrm{~F}, 0.80 \%$ for $\mathrm{P} 2-2 \mathrm{~F}$ and $0.54 \%$ for $\mathrm{P} 3-4 \mathrm{~F})$ as measured by flash photolysis and time-resolved microwave conductivity is mainly governed by thermodynamic factors, i.e., by the energy offset between the HTM HOMO and the perovskite valence band and thus the higher the HOMO energy level the higher the transfer yield. This helps to focus on the fact that the best PCE and, in general, the best performance is a balance between the different phenomena, such as charge separation, hole transfer and hole mobility. Into cells with an $\mathrm{FTO} / \mathrm{c}-\mathrm{TiO}_{2} / \mathrm{m}-\mathrm{TiO}_{2} /$ perovskite/HTM/Ag architecture, the PCEs obtained for P1-0F, P2-2F and P3-4F were $9.80 \%, 14.94 \%$ and $10.35 \%$, with minimal hysteresis [130].

The P-TT-TPD copolymer was produced by Kranthiraja et al. coupling a donor unit (based on benzodithiophene, BDT) with an acceptor building block (composed by thieno[3,2-b]thiophene and $4 \mathrm{H}$-thieno[3,4-c]pyrrole-4,6(5H)-dione) [131]. The structure is quite complex, but it closely resembles the already cited P2-2F [130], in which the thiophene spacer was substituted by a thieno[3,2-b]thiophene. The HOMO was estimated to lie at $-5.46 \mathrm{eV}$ and a reduced band-gap of $1.79 \mathrm{eV}$ was found. For the monomer and dimer, the DFT calculations showed that the dipole moment is very high and this probably is inducing the building blocks to pack closely also in the polymer. The P-TT-TPD was used as dopantfree HTM onto a mesoporous $\left(\mathrm{FAPbI}_{3}\right)_{0.85}\left(\mathrm{MAPbBr}_{3}\right)_{0.15}$ based PSC and gave a PCE of $17.0 \%$. The simple substitution of the spacer from thiophene to thieno[3,2-b]thiophene caused an efficiency increase of more than 3\%. By using the tris(pentafluorophenyl)borane (BCF) as an additive, which enhances the quantity of induced holes in the polymer, the PCE of $17.56 \%$ was obtained. Remarkably, also this HTM allowed to obtain devices showing a minimal hysteresis.

A series of polymers based on BDT and BODIPY units was prepared by Kyeong and co-workers, K1-K6 [132]. The modification of the alkyl chains on the BDT moiety and of the meso substituent on the BODIPY unit helped to tune HOMO and LUMO, respectively. Previous studies demonstrated that both the energy levels of molecular orbitals in the HTMs were changed simultaneously by chemical modifications of polymer structure [143-145]. Since the LUMO of the HTM should be ideally well higher in energy than the conduction band of the perovskite, to minimize the recombination probability at the perovskite/HTM interface (i.e., the back-transfer of an electron in the HTM from the PSK), chemical modification of polymers was applied to tune the energy levels. The 
connection between the BDT and BODIPY is away from planarity and this helps the HTM to better cover the perovskite. The HOMO and LUMO energy level range is in between -5.29 and -5.42 eVand -3.33 and $-3.37 \mathrm{eV}$, respectively. The modification of HOMO is ascribable to the different alkyl chains on BDT moiety, whose effect is however quite limited. Those HTMs were used for the preparation of inverted p-i-n PSCs. The presence of a meso $\mathrm{CF}_{3}$ containing BODIPY deepens (too much) the LUMO energy level and, in turns, sensibly reduced the PCE, while the presence of a meso $\mathrm{CH}_{3}$ BODIPY lead to the opposite behaviour (more energetic LUMO and increased PCE increased up to $15.19 \%$ for K1, with the best cell showing 16.02\%). Some perovskite ionic precursors were incompatible with the hydrophobic surface of the HTM and thus the polymers showed unwetting behavior towards perovskite; thus, the conjugated polyelectrolyte poly[ $\left(9,9-\mathrm{bis}\left(3^{\prime}-(N, N-\right.\right.$ dimethylamino)propyl)-2,7-fluorene)-alt-2,7-(9,9-dioctylfluorene)] (PFN) was used as a wetting conductive polymer to help the deposition of the K1-K6 polymers. The PCBM was used as ETL layer and zirconium acetylacetonate as the cathode interface layer. $\mathbf{K} \mathbf{1}$ reached the best PCE result since it has higher hole mobility $\left(2.96 \times 10^{-5} \mathrm{~cm}^{2} \mathrm{~V}^{-1} \mathrm{~cm}^{-1}\right)$. Stability tests under open air, showed that K1 based devices maintained $80 \%$ of the pristine PCE over 10 days [132].

A few different acceptor groups were coupled with BDT, the pyrrolo[3,4-c]pyrrole-1,3dione (DPPD) and the 4H,8H-benzo[1,2-c:4,5-c']dithiophene-4,8-dione (BDD).

Two polymers $\mathbf{R} \mathbf{1}$ and $\mathbf{R} \mathbf{2}$ were prepared by Rana and co-workers. R2 was a typical DA polymer, just the already cited PTB-BO, while R1 was made of two D-A monomers [133]. In R1, the donor portion in both monomers was the 4,8-bis(5-(2-ethylhexyl)thiophen2-yl)benzo[1,2-b:4,5- $\mathrm{b}^{\prime}$ ]dithiophene (BDTT), which was coupled either with pyrrolo[3,4c]pyrrole-1,3-dione (DPPD) and [3-fluoro-2-[(2-ethylhexyl)carbonyl]thieno[3,4-b]thiophene] (TT) as the two acceptor units. R2 is simply built on BDTT and TT. The HOMO levels lie at $-5.42 \mathrm{eV}$ and $-5.37 \mathrm{eV}$ for $\mathbf{R} \mathbf{1}$ and $\mathbf{R} \mathbf{2}$ respectively, nearly well aligned with the $\mathrm{MAPbI}_{3}$ perovskite's valence band. The hole mobility was higher for $\mathbf{R} \mathbf{1}\left(3.7 \times 10^{-3} \mathrm{~cm}^{2} \mathrm{~V}^{-1} \mathrm{~s}^{-1}\right)$ than for $\mathbf{R} 2\left(5.8 \times 10^{-4} \mathrm{~cm}^{2} \mathrm{~V}^{-1} \mathrm{~s}^{-1}\right)$. The polymer $\mathbf{R} \mathbf{1}$ showed the best efficiency in the PSCs, approaching 16\%, while R2 achieved 13.6\%. The lower performance of R2 was mainly ascribed to its shallower $\mathrm{HOMO}$ which reduces the $\mathrm{V}_{\mathrm{oc}}$. Once more, it appears evident that the mixing of different D-A monomers can help to better tune the polymer characteristics, e.g., the hole mobility, improving its behavior towards efficiency. The PSCs were fully stable (they saved $100 \%$ of the original PCE) at $25{ }^{\circ} \mathrm{C}, 75 \%$ of relative humidity, for 500 h.The PBT1-C D-A copolymer was obtained from the copoylmerization of benzodithiophene (BDT) with 1,3-bis(4-(2-ethylhexyl)thiophen-2-yl)-5,7-bis(2-alkyl) benzo[1,2-c:4,5-c']dithiophene-4,8-dione (BDD) [134]. This last moiety showed to be an efficient Lewis base that can work to passivate the surface traps, often occurring at the PSK surface due to uncoordinated $\mathrm{Pb}$ surface sites. This coupling led to a polymer whose hole mobility and properties were undoubtedly promising. When it was applied by spin coating onto perovskite, it mostly self-organized in a face-on way thus passivating the uncoordinated $\mathrm{Pb}^{2+}$ centers. On the other side, the preferred orientation of PBT1-C is in an edge-on way and gave smoother film than P3HT, used as a reference. On mesoporous PSCs PBT1-C showed a very high PCE (19.06\%) while the P3HT reached a notably 14.96\%, in its undoped state. As a final remark, the devices retained $80 \%$ of their PCE after storage at $25^{\circ} \mathrm{C}$ under inert gas for $300 \mathrm{~h}$.

Four BDT based polymers were obtained by coupling with benzo-[1,2-c:4,5-c0]dithiophene4,8-dione (BDD), PBDB-T, PBDB-T-2Cl, PBDB-T-2F, PBDB-T-Si, that were very similar to PBT1-C. [135] The introduction of chlorine, fluorine atoms or an organosilyl substituent tried to modulate the properties. The molecular distance for the $\mathrm{p}-\mathrm{p}$ stacking in the crystals diminishes in the order PBDB-T > PBDB-T-2Cl > PBDB-T-2F > PBDB-T-Si, and this is in agreement with the increase of the resistance to the recombination and with the PCE order.

Three new polymers (originally named P1, P2 and P3, here renamed P1-B, P2-T and P3-T-F respectively, to avoid misunderstanding and homonymy with other polymers reported in this review) were prepared by Zhang et al. exploiting a bis(2-EH-Th)BDT as the 
central core [136]. The latter was copolymerized with a phenyl (P1-B) or thiophene (P2-T) group. Moreover, as a slight but substantial modification, a fluorine atom was inserted on the lateral thiophenes on the BDT (P3-T-F). The thiophene spacer helped to planarize the polymeric skeleton, as demonstrated by DFT calculations and the appearance of a red-shifted shoulder in the UV spectra, which also accounts for promoted aggregation phenomena in solution. The different structures among the three polymers helped to finely tune the HOMO energy level: $-5.16 \mathrm{eV}$ for P1-B, $-5.27 \mathrm{eV}$ for P2-T and $-5.38 \mathrm{eV}$ for P3-T-F. GIWAXS study showed that P1-B organizes at the PSK's surface in an edge-on way while both P2-T and P3-T-F, which are more planar, adopt a face-on orientation. The latter outperformed P1-B $(\mathrm{PCE}=14.9 \%)$ in PSCs $\left(\mathrm{FTO} / \mathrm{mp}-\mathrm{SnO}_{2} / \mathrm{MAPbI}_{3} / \mathrm{HTM} / \mathrm{Au}\right)$, leading to an efficiency of $19.6 \%$ (P2-T) and 20.3\% (P3-T-F). This shows that the insertion of fluorine on the side chain portion of the BDT still improved the performance of the BDT-T polymer by just less than $1 \%(+4 \%)$. When the non-encapsulated PSCs were kept at $25{ }^{\circ} \mathrm{C}$ in 20-70\% relative humidity conditions, those made with P2-T and P3-T-F HTMs survived for 40 days, maintaining 97\% of their pristine PSC whereas P1-B based devices were not tested for stability. Very interestingly, the most efficient HTM (P3-T-F) was also implemented in a flexible PSC with a PET/ITO/mp-SnO $/ \mathrm{MAPbI}_{3} / \mathrm{HTM} / \mathrm{Au}$ architecture, providing an excellent PCE: $16.2 \%$, thus envisaging potential application in view of a "roll-to-roll" PSC production. This really elegant screening clarified that sometimes it is not mandatory to build an HTM by coupling "very strong" complex donor and acceptor monomers, but simpler structures can give excellent results and can greatly simplify the access to highly performant HTMs, reducing the cost and improve the sustainability of the material.

In a recent paper, the P1-Th-BDT-BO, P2-OR-BDT-BO and P3-OR-BDT-T BDT based polymers were prepared to exploit the sulfur-oxygen interaction in order to force a planarity on the main conjugated chain [137]. They showed good thermal stability with decomposition temperature over $300{ }^{\circ} \mathrm{C}$. P1-Th-BDT-BO and P2-OR-BDT-BO, which only differ for the substitution on the central ring of BDT (thiophene vs. alkoxy substituent, respectively) showed remarkable differences for the HOMO energy level ( $-5.43 \mathrm{vs} .-5.76 \mathrm{eV}$ respectively). On the basis of the excellent efficiencies of P1-Th-BDT-BO, one can imagine that due to the bad alignment with the perovskite $(-5.48 \mathrm{eV})$ used in this work, P2-ORBDT-BO could be effectively employed with a deeper valence band perovskite. In the planar cell arrangement, P1-Th-BDT-BO gave a PCE of $18.30 \%$, slightly lower than doped spiro-OMeTAD. At $20{ }^{\circ} \mathrm{C}$ and $80 \%$ of relative humidity, the P1-Th-BDT-BO based PSCs saved $89 \%$ of its pristine PCE after $96 \mathrm{~h}$.

The BDT was copolymerized with thiophene and/or the 3,4-difluorothiophene to obtain some polymeric HTMs named PBDT[2H]T, PBDT[2F]T and PBDT(T)[2F]T [138]. The energy levels were around $-5.29 \mathrm{eV}$ and the hole mobility was not so high $[138,139]$. GIWAXS studies showed a high proneness to adopt a face-on arrangement at the surface for PBDT[2F]T and lower for PBDT(T)[2F]T, while no clear evidence was found for PBDT[2H]T. The face-on arrangement is the reason behind the overcoming of the low hole mobility since the PBDT[2F]T reached an efficiency of $17.25 \%$ in a planar PSC. It is noteworthy that the best performing polymer PBDT[2F]T was also the lightest one (28 vs. 48-49 kDa), which often is uncommon. When exposed to a $30 \%$ relative humidity and $30^{\circ} \mathrm{C}$ the PBDT[2F]T cell retained $91 \%$ of PCE after 16 days.

\subsubsection{BTZ (Benzothiadiazole) and Cbz (Carbazole)}

Often, the carbazole (Cbz) was used as a donor [146,147] and the benzothiadiazole (BTZ) was used as an acceptor in solar cells $[11,148,149]$. They were combined with other comonomers with different approaches in PSCs. By limiting the discussion to the dopant-free topic and to 15\% PCE cut-off limit, we can recall that several polymers were already shown in this review, containing benzothiadiazole (P [125], RCP [126], P1, P2, P3 [127], PBTBDT [128], asy-PBTBDT [128], PTEG [115], Alkoxy-PTEG,[116], Thiophenyl-PTEG [116], AlkoxyPC8 [116]) and carbazole (PPN [89], PVCz-OMeDAD [90], PVCz-OMeTPA [91], P1-PVCzOMeTAD [92], P2-PVCz-OMeTAD [92], PVP-CZ [93], PCBTDPP [77]). 
Those benzothiadiazole (BTZ) based polymers achieved excellent photovoltaic efficiencies, up to $21.2 \%$ for the Alkoxy-PTEG polymer [116]. This comes out from a series of improvements, such as the combination of donors and acceptors, modification of BDT with alkoxy chains or alkyl thienyl moieties, insertion on the BTZ residue of the triethylene glycol chains as passivator for $\mathrm{Pb}^{2+}$ surface traps. The BTZ acceptor was thus tuned in its acceptor strength due to the alkoxy/TEG chains and this contributed to the optimization of the photovoltaic performances.

Interestingly, carbazole and benzothiadiazole were coupled together to give the PCDTBT family of polymers (for all benzothiadiazole-based and carbazole-based polymers please see Table 4, Figure 4 and Scheme 6).

A few polymers were used to modify the surface of an ITO/PEDOT:PSS interface. Among PCDTBT, PCPDTBT, P3HT and DPP-DTT, the PCDTBT polymer outperformed the others [99]. Since the perovskite was grown on a very thin polymer layer, it was demonstrated that the more crystalline perovskite was obtained with PCDTBT, and the higher PCE performances (up to 16.5\%) were ascribable to this feature [99]. However, since the tunneling distance for hole transport is larger than the polymer layer thickness, the polymer did not mediate the hole transport. This was a different condition with respect to most PSCs studied until now.

The effect on the alkylation of the benzothiadiazole moiety in the PCDTBT polymers was studied in different papers. The polymers PCDTBT1 and PCDTBT8 were synthetized by inserting methoxy and octyloxy substituents on the BTZ scaffold [150]. The HOMO energy levels were $-5.35 \mathrm{eV},-5.38 \mathrm{eV}$ and $-5.40 \mathrm{eV}$ for PCDTBT, PCDTBT1 and PCDTBT8, respectively. The PCDTBT was already shown to easily pack with $\pi-\pi$ stacking and adopting a face-on orientation towards the perovskite surface [151]. This stacking is severely modified by the presence of further chains like the alkoxy one, which can compromise the coplanarity of rings. This effect was less severe for the very short methoxy group. Based on this effect, the PCDTBT1 showed a PCE improvement with respect to PCDTBT while the PCDTBT8 long chains gave a hindrance that negatively affected the PCE. This evidences that the ability to transport charges is not the only parameter determining the device's efficiency. The PCDTBT1 showed an excellently fast charge transport with respect to the other two polymers (proved by the very low dark current). The PCE were as follows: 16.43\% for PCDTBT (best cell: 17.1\%), 18.67\% for PCDTBT1 (best cell: 19.1\%) and 14.81\% for PCDTBT8 (best cell: 15.4\%) [150].

Three conjugated polyelectrolytes, $\mathbf{B F}-\mathrm{NMe}_{3}, \mathbf{B F ~} \mathbf{S O}_{3}$ and $\mathbf{B F}-\mathbf{N H}_{3}$ were prepared on the basis of a fluorene monomer, which contained two electrolyte moieties and a bis(thieno)thiazole (4,7-di(thiophen-2-yl)benzo[c][1,2,5]thiadiazole) monomer by the Stille method [152]. These HTMs are very similar to PCDTBT8, PCDTBT1 and PCDTBT8 and were applied in inverted PSCs with $\mathrm{MAPbI}_{3}$ perovskite. With respect to PEDOT:PSS they improved the preparation of the perovskite, obtaining larger grains (in the order $\mathbf{B F}-\mathbf{N M e}_{3}$ $<\mathrm{BF} \mathrm{SO}_{3}<\mathrm{BF}-\mathrm{NH}_{3}$ ) and the related charge mobility, which was reflected onto the final $\mathrm{J}_{\mathrm{sc}}$ in the PSCs. Moreover, the recombination resistance showed the reverse order. The PCE obtained in inverted PSCs based on the $\mathrm{MAPbI}_{3}$ perovskite were $14.92 \%, 17.14 \%$ and $17.71 \%$ for $\mathrm{BF}-\mathrm{NMe}_{3}, \mathrm{BF} \mathrm{SO}_{3}$ and $\mathrm{BF}-\mathrm{NH}_{3}$ respectively.

The BTZ core was also used in a D- $\pi$-A polymer, TTB-TTQ, that was prepared by assembling two monomers, TTB and TTQ, in which two thiophene rings are coupled with either alkoxylated benzothiadiazole (BTZ) or Quinoxaline (Q) [153]. Since the homopolymer of TTB is highly crystalline and gives bad and inefficient HTM films on perovskite, the incorporation of TTQ broke the molecular symmetry, reducing the $\pi-\pi$ strong interactions, and the resulting polymer showed an excellent solubility in organic solvents and reasonable $(6.2 \%)$ to good $(14.1 \%)$ performance in PSC in its pristine and doped state, respectively. While both homopolymers obtained for TTB and TTQ have too deep HOMOs, to be correctly aligned with perovskite valence band level, the copolymer possesses a more energetic HOMO that matches well the perovskite energy level. Very interestingly, the hole mobility of TTB-TTQ in its pristine state was close to that of spiro-OMeTAD. 
Table 4. Dopant-free benzothiadiazole and carbazole polymeric HTM performances. (see legend for details).

\begin{tabular}{|c|c|c|c|c|c|c|c|c|c|c|c|c|}
\hline HTM & PSK & Cell $^{a}$ & $\begin{array}{l}\text { PCE } \\
(\%)\end{array}$ & $\begin{array}{l}\text { Std } \\
\text { PCE } \\
(\%)^{b}\end{array}$ & $\begin{array}{l}\mathrm{V}_{\mathrm{oc}} \\
(\mathrm{mV})\end{array}$ & $\begin{array}{c}\mathrm{J}_{\mathrm{sc}} \\
\left(\mathrm{mA} \mathrm{cm}^{-2}\right)\end{array}$ & $\begin{array}{l}\text { FF } \\
(\%)\end{array}$ & $\begin{array}{c}\text { HOMO } \\
\text { eV) }\end{array}$ & $\begin{array}{l}B_{g} \\
(e V)\end{array}$ & $\begin{array}{c}\mathrm{HM} \\
\left(\mathrm{cm}^{2} \mathrm{~V}^{-1}\right. \\
\left.\mathrm{S}^{-1}\right)\end{array}$ & $\begin{array}{l}\text { Stab. } \\
\text { (h) }\end{array}$ & Ref. \\
\hline PCDTBT & $\mathrm{MAPbI}_{3}$ & $\mathrm{P}$ & 16.5 & - & 1.05 & 21.9 & 72.0 & -5.3 & - & - & - & [99] \\
\hline PCDTBT & $\mathrm{MAPbI}_{3}$ & $\mathrm{P}$ & $\begin{array}{r}17.1 \text { (best) } \\
16.43 \text { (avg) } \\
\end{array}$ & $\begin{array}{l}19.4^{\mathrm{b}} \text { (best) } \\
18.81 \text { (avg) }\end{array}$ & 1.05 & 21.62 & 72.34 & -5.35 & - & - & $\begin{array}{c}>90 \%, 30 \mathrm{~d}, \mathrm{E}, \\
\left(\mathrm{RH} 40-70 \%, 25-35{ }^{\circ} \mathrm{C}\right)\end{array}$ & [150] \\
\hline PCDTBT1 & $\mathrm{MAPbI}_{3}$ & $\mathrm{P}$ & $\begin{array}{r}19.1 \text { (best) } \\
18.67 \text { (avg) } \\
\end{array}$ & $\begin{array}{l}19.4^{\mathrm{b}} \text { (best) } \\
18.81 \text { (avg) }\end{array}$ & 1.10 & 21.78 & 77.63 & -5.38 & - & - & $\begin{array}{c}>90 \%, 30 \mathrm{~d}, \mathrm{E}, \\
\left(\mathrm{RH} 40-70 \%, 25-35{ }^{\circ} \mathrm{C}\right)\end{array}$ & [150] \\
\hline РCDTBT8 & $\mathrm{MAPbI}_{3}$ & $\mathrm{P}$ & $\begin{array}{r}15.4 \text { (best) } \\
14.81 \text { (avg) }\end{array}$ & $\begin{array}{l}19.4^{\mathrm{b}} \text { (best) } \\
18.81 \text { (avg) }\end{array}$ & 1.02 & 21.29 & 67.31 & -5.40 & - & - & $\begin{array}{c}25 \%, 30 \mathrm{~d}, \mathrm{E} \\
\left(\mathrm{RH} 40-70 \%, 25-35^{\circ} \mathrm{C}\right)\end{array}$ & [150] \\
\hline BF-NMe 3 & $\mathrm{MAPbI}_{3}$ & I & $\begin{array}{l}14.92 \text { (best) } \\
14.65 \text { (avg) }\end{array}$ & $\begin{array}{c}12.81 \\
\text { PEDOT: } \\
\text { PSS }\end{array}$ & 1.01 & 18.51 & 79.7 & -5.40 & 1.88 & - & $\begin{array}{c}>90 \% 960 \mathrm{~h}, \\
(\mathrm{NE}, 25 \% \\
\text { RH, rt) }\end{array}$ & [152] \\
\hline $\mathrm{BF} \mathrm{SO}_{3}$ & $\mathrm{MAPbI}_{3}$ & I & $\begin{array}{l}17.14 \text { (best) } \\
16.85 \text { (avg) }\end{array}$ & $\begin{array}{l}12.81 \\
\text { PEDOT: } \\
\text { PSS }\end{array}$ & 1.05 & 19.92 & 82.1 & -5.40 & 1.88 & - & $\begin{array}{c}>90 \% 960 \mathrm{~h}, \\
(\mathrm{NE}, 25 \% \\
\mathrm{RH}, \mathrm{rt})\end{array}$ & [152] \\
\hline TTB-TTQ & $\mathrm{MAPbI}_{3-\mathrm{x}} \mathrm{Cl}_{\mathrm{x}}$ & M & 6,2 & $\begin{array}{c}11.5^{\mathrm{c}} \text { (best) } \\
10.1 \text { (avg) }\end{array}$ & 0.94 & 11.8 & 55.4 & -5.11 & 1.61 & $1.01 \times 10^{-4}$ & - & [153] \\
\hline BTTP & $\mathrm{MAPbI}_{3}$ & M & 3.80 & $7.55^{c} / 12.53^{c}$ & 0.78 & 10.11 & 48.2 & -5.40 & 2.2 & - & - & [154] \\
\hline BTTP-CN & $\mathrm{MAPbI}_{3}$ & $\mathrm{M}$ & 3.48 & $7.55^{c} / 12.53^{c}$ & 0.69 & 10.01 & 50.3 & -5.25 & 2.13 & - & - & [154] \\
\hline $\mathrm{PVBT}^{-\mathrm{SO}_{3}}$ & $\mathrm{MAPbI}_{3}$ & I & $\begin{array}{r}18.4 \text { (best) } \\
17.57 \text { (avg) }\end{array}$ & - & 1.06 & 22.5 & 77.0 & -5.27 & 1.72 & - & - & [155] \\
\hline $\begin{array}{l}\text { PVF2BT- } \\
\mathrm{SO}_{3}\end{array}$ & $\mathrm{MAPbI}_{3}$ & I & $\begin{array}{l}13.6 \text { (best) } \\
13.2 \text { (avg) }\end{array}$ & - & 1.05 & 18.89 & 69.0 & -5.40 & 1.78 & - & - & [155] \\
\hline $\mathrm{PVF}_{-}-\mathrm{SO}_{3}$ & $\mathrm{MAPbI}_{3}$ & I & $\begin{array}{l}7.3 \text { (best) } \\
6.69 \text { (avg) }\end{array}$ & - & 0.99 & 12.9 & 56.0 & -5.66 & 2.16 & - & - & [155] \\
\hline
\end{tabular}


Table 4. Cont.

\begin{tabular}{|c|c|c|c|c|c|c|c|c|c|c|c|c|}
\hline HTM & PSK & Cell $^{a}$ & $\begin{array}{l}\text { PCE } \\
(\%)\end{array}$ & $\begin{array}{l}\text { Std } \\
\text { PCE } \\
(\%)^{b}\end{array}$ & $\begin{array}{l}\mathrm{V}_{\mathrm{oc}} \\
(\mathrm{mV})\end{array}$ & $\begin{array}{c}\mathrm{J}_{\mathrm{sc}} \\
\left(\mathrm{mA} \mathrm{cm}^{-2}\right)\end{array}$ & $\begin{array}{l}\text { FF } \\
(\%)\end{array}$ & $\begin{array}{c}\text { HOMO } \\
\text { eV) }\end{array}$ & $\begin{array}{l}B_{g} \\
(e V)\end{array}$ & $\begin{array}{c}\mathrm{HM} \\
\left(\mathrm{cm}^{2} \mathrm{~V}^{-1}\right. \\
\left.\mathrm{S}^{-1}\right)\end{array}$ & $\begin{array}{l}\text { Stab. } \\
\text { (h) }\end{array}$ & Ref. \\
\hline PDTIDTBT & CsFAMA & $\mathrm{M}$ & 17.9 & 18.63 (spiro) & 1.09 & 22.5 & 79.0 & -5.35 & 2.06 & $5.24 \times 10^{-4}$ & & [156] \\
\hline PDTIDTBT & $\begin{array}{l}\text { CsFAMA } \\
\text { (PMMA) }\end{array}$ & M & 19.89 & 19.28 (spiro) & 1.14 & 22.6 & 77.2 & -5.35 & 2.06 & $5.24 \times 10^{-4}$ & $\begin{array}{c}>93 \%, 42 \mathrm{~d}, \\
(\mathrm{NE}, 42 \% \\
\mathrm{RH}, \mathrm{rt})\end{array}$ & [156] \\
\hline DTS & $\mathrm{MAPbI}_{3}(\mathrm{Cl})$ & I & 17.27 & $16.92^{c}$ & 1.01 & 21.97 & 77.46 & -5.01 & 1.67 & $8.83 \times 10^{-5}$ & - & [157] \\
\hline DTS & $\begin{array}{c}\operatorname{MAPbI}_{3}(\mathrm{Cl}) / \\
\text { (PSBMA) }\end{array}$ & I & 20.17 & $18.02^{\mathrm{c}}$ & 1.10 & 22.44 & 81.67 & -5.01 & 1.67 & $8.83 \times 10^{-5}$ & $\begin{array}{c}>83 \%, 400 \mathrm{~h} \\
\left(\mathrm{NE}, \mathrm{N}_{2}, 85^{\circ} \mathrm{C}\right) \\
>94 \%, 1500 \mathrm{~h} \\
(\mathrm{NE}, 20 \% \\
\text { RH, rt) }\end{array}$ & [157] \\
\hline CDT & $\mathrm{MAPbI}_{3}(\mathrm{Cl})$ & I & 17.02 & $16.92^{c}$ & 0.98 & 22.23 & 78.17 & -5.14 & 1.54 & $8.43 \times 10^{-5}$ & - & [157] \\
\hline CDT & $\begin{array}{c}\mathrm{MAPbI}_{3}(\mathrm{Cl}) / \\
\left(\mathrm{PSBMA}^{2}\right)\end{array}$ & I & 20.05 & $18.02^{c}$ & 1.08 & 22.75 & 81.59 & -5.14 & 1.54 & $8.43 \times 10^{-5}$ & $\begin{array}{c}>83 \%, 400 \mathrm{~h} \\
\left(\mathrm{NE}, \mathrm{N}_{2}, 85^{\circ} \mathrm{C}\right) \\
>94 \%, 1500 \mathrm{~h} \\
(\mathrm{NE}, 20 \% \\
\mathrm{RH}, \mathrm{rt})\end{array}$ & [157] \\
\hline DTP & $\mathrm{MAPbI}_{3}(\mathrm{Cl})$ & I & 14.87 & 16.92 & 1.10 & 21.44 & 63.05 & -5.23 & 1.45 & $4.96 \times 10^{-5}$ & - & [157] \\
\hline DTP & $\begin{array}{c}\mathrm{MAPbI}_{3}(\mathrm{Cl}) / \\
\left(\mathrm{PSBMA}^{2}\right)\end{array}$ & I & 17.60 & $18.02^{c}$ & 1.04 & 21.59 & 78.38 & -5.23 & 1.45 & $4.96 \times 10^{-5}$ & $\begin{array}{c}>83 \%, 400 \mathrm{~h} \\
\left(\mathrm{NE}, \mathrm{N}_{2}, 85^{\circ} \mathrm{C}\right) \\
>94 \%, 1500 \mathrm{~h} \\
(\mathrm{NE}, 20 \% \\
\mathrm{RH}, \mathrm{rt})\end{array}$ & [157] \\
\hline 3,6PCzTPA & $\begin{array}{c}\left(\mathrm{FAPbI}_{3}\right)_{0.85} \\
\left(\mathrm{MAPbBr}_{3}\right)_{0.15}\end{array}$ & I & 16.4 & $18.1^{\mathrm{c}}$ & 0.96 & 21.93 & 77.9 & -5.18 & 3.18 & $1.46 \times 10^{-5}$ & - & [158] \\
\hline 2,7PCzTPA & $\begin{array}{c}\left(\mathrm{FAPbI}_{3}\right)_{0.85} \\
\left(\mathrm{MAPbBr}_{3}\right)_{0.15}\end{array}$ & I & 17.1 & $18.1^{\mathrm{c}}$ & 1.07 & 21.78 & 73.2 & -5.23 & 2.86 & $1.49 \times 10^{-6}$ & - & [158] \\
\hline $\begin{array}{r}\text { 3,6-2,7- } \\
\text { PCzTPA }\end{array}$ & $\begin{array}{c}\left(\mathrm{FAPbI}_{3}\right)_{0.85} \\
\left(\mathrm{MAPbBr}_{3}\right)_{0.15}\end{array}$ & I & 18.4 & $18.1^{\mathrm{c}}$ & 1.04 & 22.66 & 77.9 & -5.22 & 3.00 & $1.74 \times 10^{-5}$ & - & [158] \\
\hline
\end{tabular}


Table 4. Cont.

\begin{tabular}{|c|c|c|c|c|c|c|c|c|c|c|c|c|}
\hline HTM & PSK & Cell $^{\mathrm{a}}$ & $\begin{array}{l}\text { PCE } \\
(\%)\end{array}$ & $\begin{array}{c}\text { Std } \\
\text { PCE } \\
(\%)^{b}\end{array}$ & $\begin{array}{c}\mathrm{V}_{\mathrm{oc}} \\
(\mathrm{mV})\end{array}$ & $\begin{array}{c}\mathrm{J}_{\mathrm{sc}} \\
\left(\mathrm{mA} \mathrm{cm}^{-2}\right)\end{array}$ & $\begin{array}{l}\text { FF } \\
(\%)\end{array}$ & $\begin{array}{c}\text { HOMO } \\
\text { eV) }\end{array}$ & $\begin{array}{c}\mathbf{B}_{\mathrm{g}} \\
(\mathrm{eV})\end{array}$ & $\begin{array}{c}\mathrm{HM} \\
\left(\mathrm{cm}^{2} \mathrm{~V}^{-1}\right. \\
\left.\mathrm{S}^{-1}\right)\end{array}$ & $\begin{array}{l}\text { Stab. } \\
\text { (h) }\end{array}$ & Ref. \\
\hline PC1 & $\mathrm{MAPbI}_{3}$ & M & 8.8 & 20.3 spiro & 0.85 & 21.3 & 49.1 & -5.37 & 2.37 & $4.2 \times 10^{-5}$ & - & [159] \\
\hline PC2 & $\mathrm{MAPbI}_{3}$ & $\mathrm{M}$ & 18.3 & 20.3 spiro & 1.06 & 21.7 & 76.2 & -5.17 & 2.13 & $7.3 \times 10^{-4}$ & - & [159] \\
\hline PC3 & $\mathrm{MAPbI}_{3}$ & $\mathrm{M}$ & 20.8 & 20.3 spiro & 1.11 & 23.5 & 80.0 & -5.16 & 2.09 & $8.1 \times 10^{-4}$ & $\begin{array}{l}100 \%, 1000 \mathrm{~h} \\
\text { (NE, light, rt) }\end{array}$ & [159] \\
\hline PDTPC-1 & CsFAMA & $\mathrm{P}$ & 16.96 & - & 1.08 & 21.94 & 71.58 & -5.11 & 1.60 & $3.98 \times 10^{-3}$ & & [160] \\
\hline PDTPC-2 & CsFAMA & $\mathrm{P}$ & 12.45 & - & 0.97 & 20.15 & 63.70 & -4.97 & 1.57 & $2.94 \times 10^{-3}$ & & {$[160]$} \\
\hline
\end{tabular}

a M: mesoporous, P: planar. ${ }^{b}$ ref. std. spiro-OMeTAD; ${ }^{c}$ ref. std. PTAA. PCEs for doped standards are reported in bold. 

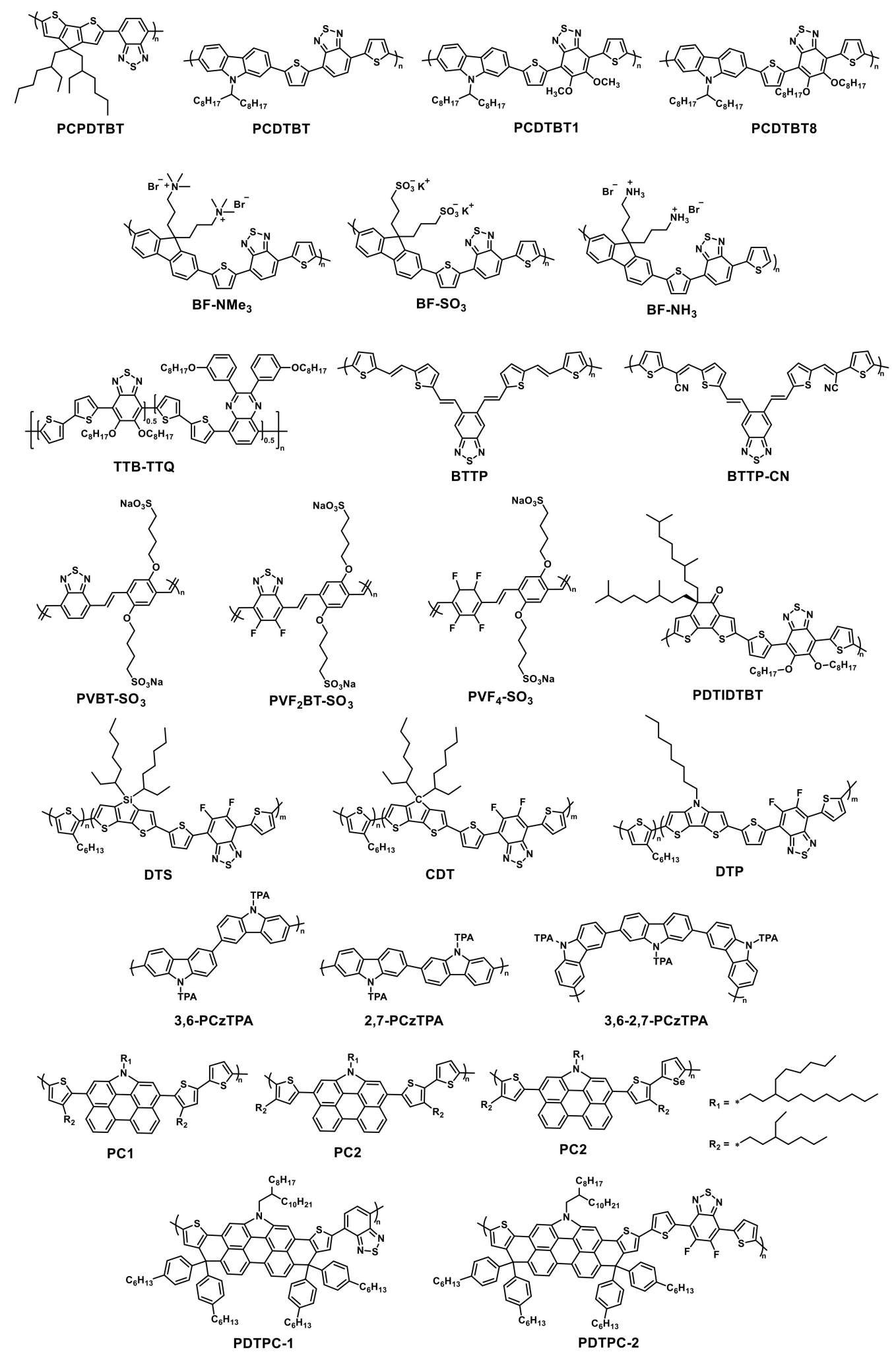

Scheme 6. HTMs containing the benzothiadiazole (BTZ) and or the Carbazole (Cbz) group. 


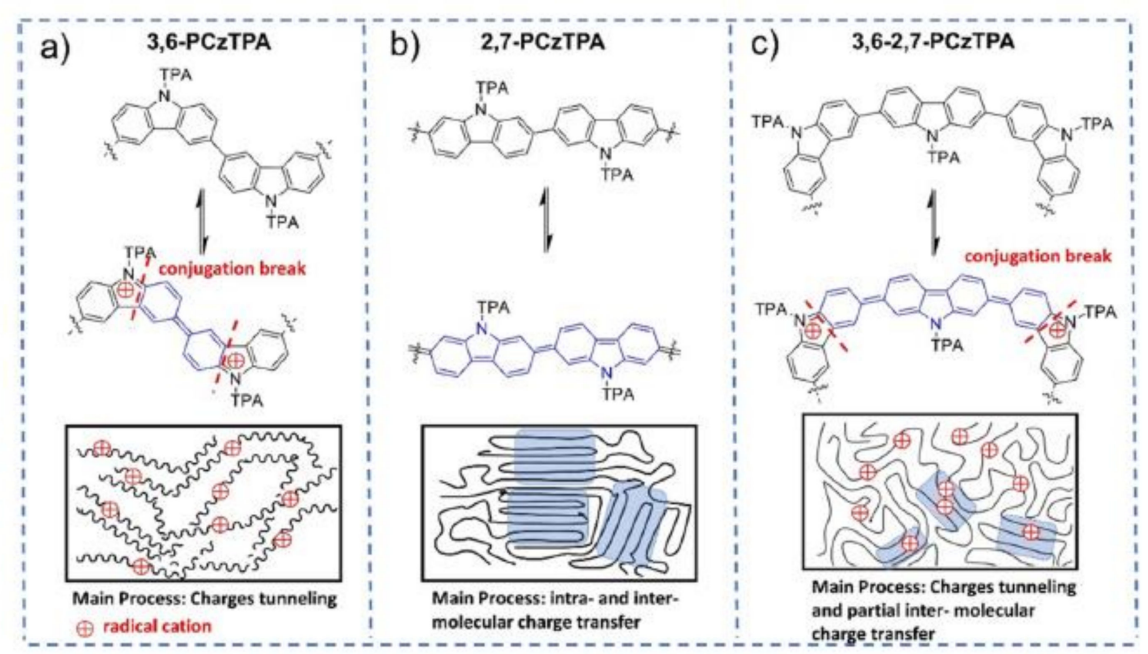

Figure 4. Possibilities of Quinoid States for Three Polycarbazoles and Their Main Charge Transport Processes. Reprinted with permission from (Xie, Y.et al. Macromolecules 2019, 52 (12), 4757-4764) [158]. Copyright (2019) American Chemical Society.

As a further example of BTZ based polymers, the BTTP and BTTP-CN polymers were prepared by Wittig reaction of a benzothiadiazole diphosphonate monomer and a dialdehyde (1,2-bis(2-formylthienyl)ethylene) monomer [154]. BTTP-CN contained a cyano group. The HOMO energy levels were -5.40 and $-5.25 \mathrm{eV}$ respectively, while the LUMO levels were $-3.65 \mathrm{eV}$ and $-3.5 \mathrm{eV}$. Since the $\mathrm{MAPbI}_{3}$ perovskite's conduction band is lying at $-3.9 \mathrm{eV}$, those LUMO levels do not block efficiently the back electron transfer and this should negatively impact the efficiency. Indeed, the PCE were $3.80 \%$ for BTTP and $3.48 \%$ for BTTP-C, while the spiro-OMeTAD gave $7.55 \%$ and $12.53 \%$ in its undoped and doped state, respectively.

Three conjugated polyelectrolytes were prepared on a skeleton made by BTZ and a p-dialkoxybenzene, where the alkyl chains contain the salt moieties [155]. The PVBT$\mathrm{SO}_{3}, \mathrm{PVF}_{2} \mathrm{BT}-\mathrm{SO}_{3}$ and $\mathrm{PVF} 4-\mathrm{SO}_{3}$ polymers were used to explore and understand the hole transfer in inverted PSCs. The difference in the aryl vinylene component helped to modulate the HOMO level. In the inverted PSCs based on $\mathrm{MAPbI}_{3}$, the PCE of those HTMs was $17.57 \% 13.16 \%$ and $6.69 \%$ (with champion cells exhibiting values as high as $18.4 \%$, $13.6 \%$ and $7.3 \%$ ), for PVBT-SO 3 , PVF2BT-SO 3 and PVF4-SO $\mathbf{S O}_{3}$, respectively, which was consistent with the HOMO level and the alignment with perovskite valence band.

The PDTIDTBT polymer was described by Tavakoli et al. and used in mesoporous PSCs [156]. The stannyl derivative of dithienylbenzodthiadiazole was coupled with the 2,7-dibromo-(5,5-bis(30,50-dimethyloctyl)-5H-1,8-dithia-as-indacenone) by the Stille protocol. The production of dithiaindacenone derivatives was attractive from the economic point of view and was environmentally attractive, with E factor values of lower than 400 . The PDTIDTBT HOMO was found at $-5.35 \mathrm{eV}$ and showed good hole mobility, higher than spiro-OMeTAD. The thermal stability was very good, up to $324^{\circ} \mathrm{C}$ and the fluorescence measurements on the perovskite/PDTIDTBT film showed a very strong quenching, accounting for an excellent hole transfer and transport. The PCE of PDTIDTBT on a mesoporous cell based on a CsFAMA perovskite was $17.9 \%$. The introduction of a very thin layer of poly(methyl methacrylate), PMMA, which is an insulating material helped to reduce the interfacial recombination of electrons from the perovskite with the hole in the HOMO of the HTM. This results in an increase in PCE, up to $19.89 \%$. Excellent stability was found since more than $93 \%$ of the pristine PCE was maintained for 42 days at $42 \%$ of relative humidity and room temperature.

Three complex polymers were prepared by Ma et al. by starting from a P3HT skeleton which was further polymerized to include a BTZ monomer and either 4,4bis(2-ethylhexyl)-4H-silolo[3,2-b:4,5-b']dithiophene (obtaining DTS), 4,4-bis(2-ethylhexyl)- 
4H-cyclopenta[2,1-b:3,4-b']dithiophene (obtaining CDT), or 4-n-octyldithieno[3,2-b:2' ,3'd]pyrrole (obtaining DTP)[157]. The P3HT was preliminary prepared as a reasonably high regioregular polymer by the KCTP/GRIM method which maintained a $\mathrm{Br}$ atom at one end [24]. The synthesis of the final polymer was performed by the Stille reaction involving the 5,6-difluoro-4,7-bis(5-(trimethylstannyl)thiophen-2-yl)benzo[c][1,2,5]thiadiazole the brominated P3HT and either the brominated silolodithiophene, cyclopentadithiophene and dithienopyrrole derivatives. The thermal stability was at least $200{ }^{\circ} \mathrm{C}$ showing that the polymers should survive to the conditions used for PSC preparation. The HOMO energy levels were modulated following the order DTP $>$ CDT $>$ DTS. The PCE for dopant-free DTS, CDT and DTP in inverted PSC with $\mathrm{MAPbI}_{3}(\mathrm{Cl})$ perovskite were $17.27 \%, 17.02 \%$ and $14.87 \%$, following the hole mobility order. When the zwitterionic polymer poly(sulfobetaine methacrylate) (PSBMA) was used to better match the wettability of the HTM with the perovskite, the interface was substantially better and free from pinholes. After the deposition of the perovskite, the devices showed a very good performance, overcoming $20 \%: 20.16 \%$, $20.05 \%$ and $17.60 \%$ for DTS, CDT and DTP, respectively.

In this review, carbazole HTM polymers were mainly reported as side-chain vinyl polymers, namely PVCz-OMeDAD [90], P1-PVCz-OMeTAD [92], P2-PVCz-OMeTAD [92], with PCEs over 16\% and P2-PVCz-OMeTAD reaching 18.4\%. This series showed that the approach to the polymeric HTMs can be simplified by producing small molecule monomers, whose polymerization can give optimized polymers. Moreover, the vinyl polymerization processes are well known and can be finely tuned to obtain the material with the desired performance. This is an excellent starting point, towards the industrial production of HTMs (and devices).

Polycarbazoles were studied to use as HTMs in PSCs by Xie and co-workers [158]. They synthetized three polycarbazoles based on the N-TPA-carbazole which was polymerized with the Stille protocol obtaining various polymers by connecting the units at different linking positions, 3,6-PCz-TPA, 2,7-PCz-TPA and 3,6-2,7-PCz-TPA. The latter behaves like a copolymer with perfect alternation of carbazoles which are linked at 2,7- and 3,6- positions. The HOMO energy for 3,6-PCz-TPA, 2,7-PCz-TPA and 3,6-2,7-PCz-TPA were $-5.18 \mathrm{eV},-5.23 \mathrm{eV},-5.22 \mathrm{eV}$ in solution while they were $-5.22 \mathrm{eV},-5.37 \mathrm{eV}$ and $5.34 \mathrm{eV}$ in solid films. This demonstrated the urge for measuring the energy levels both in solution and in solid-state, to better comprehend the behavior of HTMs in PSCs. Normally, the charge transport in conjugated polymers is mainly determined by (i) intramolecular conducting along the polymer main chain, which can be found for 2,7-PCzTPA, (ii) intermolecular charge hopping across chains owing to $\pi-\pi$ stacking, and (iii) charge tunneling between conducting units separated by less conducting segments, usually observed in doped polymers, to which one can ascribe the conductivity of 3,6-PCz-TPA $[158,161]$ (See Figure 4). The electric impedance study and also the following PSC characterization demonstrated that the two processes (i) and (iii) are the most probable to be involved in the case of 3,6-2,7-PCs-TPA. In fact, in 2,7-PCzTPA, the charge probably migrates effectively through the polymer backbone, while the conjugation breaking appearing when the 3,6-link is present can help the charge to be transferred by the tunneling process. Cyclic voltammetry (CV) measurements showed the 3,6-PCzTPA and 3,6-2,7-PCs-TPA to give reversible oxidation waves, which accounts for the formation of radical cations. While the better delocalization of the quinonoid structure of 2,7-PCs-TPA can help the charge transfer, probably it confines the charge into the polymer backbone and the conjugation breaking give chances for the tunneling process to operate, thus improving the hole mobility in the solid. Very interestingly, these polymers were fully transparent, and this makes them ideal for inverted PSCs (where the HTM should not show parasitic light absorption), leading to efficiencies as high as $16.4 \%, 17.1 \%$ and $18.4 \%$ for 3,6-PCz-TPA, 2,7-PCz-TPA and 3,6-2,7-PCz-TPA, respectively. While these results are a bit lower than the actual record of $20-21 \%$ for inverted PSCs, it is noteworthy that these HTMs can be produced by acting on only one monomer, which makes them more affordable than most copolymers. 
More complex scaffolds containing the carbazole were introduced in HTMs. Here we will only report on the last introduced scaffold: phenanthrocarbazole (PC) and dithienopicenocarbazole (DTPC). Three polymers were derived from a more complex scaffold based on carbazole. The polymers, PC1, PC2 and PC3 were built onto the N-(2-hexyldecyl)phenanthrocarbazole scaffold, bearing different substituents [159]. PC1 contains at each side two 4-(2-ethylhexyl)-2,2'-bithiophene moieties, PC2 a 3-(2-ethylhexyl)2,2'-bithiophene and PC3 a 3-(2-ethylhexyl)-2-(selenophen-2-yl)thiophene. The difference between PC1 and PC2 is related to the position of the 2-ethylhexyl chain on the thiophene directly linked to the phenanthrocarbazole. In PC1 the chain points toward the scaffold system and in PC2 it points away from it. PC3 is an evolution of PC2 in which the terminal thiophene is substituted by selenophene. The positional change of the chain modifies the steric requirements giving the PC2 HTMs more chances to achieve planarity than in PC1, which facilitates the $\mathrm{p}-\mathrm{p}$ stacking. This aspect was also confirmed by theoretical calculations and by a redshift into the absorption spectra of PC2 and PC3 with respect to PC1. The substitution of sulfur with selenium in the external heteroaromatic ring, improves the interaction with perovskite surface $\mathrm{Pb}$, and due to its larger polarizability, it should improve the hole mobility. The synthetic path involved several steps, mainly based on Suzuki and Stille coupling. PC1 showed edge-on arrangement onto the perovskite, higher molecular distance in the solid-state film and lower hole mobility, while PC2 and PC3 arranged face-on onto the perovskite and were packed more densely in the solid-state, achieving also higher hole mobility. The HOMOs energy levels were well aligned with perovskite ones and the thermal stability was excellent. All the previously discussed details were confirmed by the PCE obtained in mesoporous $\mathrm{SnO}_{2}$ cells, where PC1 showed a PCE of 8.8\%, PC2 18.3\% and PC3 20.8\%. The stability for the PC3 cells tested in ambient air and under illumination at RT showed complete retention of PCE.

The dithienopicenocarbazole is a further highly planar and complex scaffold containing carbazole. Two polymers, PDTPC-1 and PDTPC-2, were obtained by coupling them with the benzothiadiazole and the dithienylbenzothiadiazole [160]. Those HTMs showed high thermal stability (over $380^{\circ} \mathrm{C}$ ) and lower-lying HOMO for PDTPC-1, which accounted for higher photovoltaic efficiency since it matched better the perovskite valence band. This HTM also showed higher hole mobility. As a final result, PDTPC-1 showed a higher hole extraction ability which enhanced both the $\mathrm{V}_{\mathrm{oc}}$ and the fill factor, giving a PCE of $16.96 \%$, while PDTPC-2 only achieved $12.45 \%$.

\subsubsection{Other Polymers}

In the literature, one can find some other HTM polymers that cannot completely be considered as belonging to the previously reported chapters (for all not specifically classified polymer please see Table 5 and Scheme 7). Some of them pertain mainly to the class of polytriaylamines, some others to benzothiadiazole and some can be considered as simplification of already shown more complex polymers. In some cases, the photovoltaic efficiencies were low but sometimes they got results of absolute relevance. This means that, far to be concluded, the research on the HTMs is still highly promising of relevant results and improvements. Here we will give some description of these HTM, trying to avoid it being a mere list of results.

Some polytriarylamine polymers were synthezsized based on anilines connected by fluorene, diphenylfluorene or indacenodithiophene/indacenodithieno[3,2-b]thiophene spacers, with some excellent remarkable results.

Polytriarylamine polymers based on the 2,4-dimethylanilino moiety were used in conjunction with both $\mathrm{MAPbI}_{3}$ and $\mathrm{MAPbBr}_{3}$. The three PTAApolymers contained different linkers: a biphenyl (PTAA), a diphenylfluorene (PF8-TAA) and a diphenyl fluorenefluorene PIF8-TAA [162]. The hole mobilities for PIF8-TAA $\left(0.04 \mathrm{~cm}^{2} \mathrm{~V}^{-1} \mathrm{~s}^{-1}\right)$ are higher than PF8-TAA $\left(0.02 \mathrm{~cm}^{2} \mathrm{~V}^{-1} \mathrm{~s}^{-1}\right)$ and PTAA $\left(4 \times 10^{-3} \mathrm{~cm}^{2} \mathrm{~V}^{-1} \mathrm{~s}^{-1}\right)$. The PIF8-TAA gave the highest $\mathrm{PCE}$ ever obtained with the $\mathrm{MAPbBr}_{3}$ perovskite $(6.7 \%)$, due to its betteraligned HOMO, which effectively matches with the perovskite valence band, giving also a 
higher $\mathrm{V}_{\mathrm{oc}}$. Moreover, the PIF8-TAA also shows a PCE of $9.1 \%$ with the $\mathrm{MAPbI}_{3}$ perovskite. It is worth noting that the HOMO of PIF8-TAA is lower than $\mathrm{MAPbI}_{3}$ perovskite valence band and so it should constitute a barrier towards the hole injection. The J-V plot shows a "roll-over" effect which could not be fully explained yet by the authors.

A series of three polymers was prepared by Xiao et al., based on an Indacenodithiophene (IDT) and an asymmetric squaraine (DPASQ) or the N,N-diphenyl-3,5-dimethoxyaniline, obtaining PSQ1, PSQ2 and P3-3,5-diOMe [163]. The IDT co-monomer was chosen since it can give high intermolecular interactions as occurring in Organic Solar Cells. The copolymerization with the DPASQ moiety, occurring closer (PSQ1) or farther (PSQ2) from the cyclobutenedione ring, gave the title compounds. The HOMO energy levels were in the range $-5.2 /-5.3 \mathrm{eV}$, while the hole mobility was good for PSQ1, very good for PSQ2 and well lower for P3-3,5-diOMe. The interaction of the ketone of the cyclobutenedione with $\mathrm{Pb}^{2+}$ ion was studied and it was assessed that all the three polymers can interact with the PSK and thus passivate the $\mathrm{Pb}^{2+}$ exposed sites, giving smooth and homogeneous films. In planar PSCs based on a-CsPbI 2 Br perovskite, these polymers showed efficiencies as high as 13.6\% for PSQ1, 15.5\% for PSQ2 and 11.6\% for P3-3,5-diOMe, when spiro-OMeTAD powered a PCE of $14.4 \%$. The results were specifically interesting because, at the time of the paper (i.e., 2019), they approached the record PCE for similar fully inorganic perovskite $(\alpha-$ $\mathrm{CsPbI}_{2} \mathrm{Br}$ ) that was $17.1 \%$ [164]. The stability under continuous illumination was monitored only for PSQ2, maintaining $83 \%$ of the PCE after $300 \mathrm{~h}$.

The same scaffold, Indacenodithiophene (IDT) and its analog, indacenodithieno[3,2b]thiophene (IDTT) were used by You et al. to synthesize novel polymers, PBDTT and PBTTT, in which they were coupled to bis(2-ethylhexyl)benzo[1,2-c:4,5-c' $]$ dithiophene4,8-dione (BDD), using a thienothiophene as a spacer [165]. The IDT or IDTT are playing the donor role while BDD is the acceptor. The two polymers showed similar $\mathrm{M}_{\mathrm{n}}(13$ and $14 \mathrm{kDa}$ ) and quite large PDI, (2.30-4.36) for PBDTT and PBTTT, respectively, and were thermally stable over $400{ }^{\circ} \mathrm{C}$. The HOMO energy levels matched quite well the perovskite valence band. By DFT calculation, the structures of the dimers appeared almost planar, demonstrating a high ability to promote stacking. The hole mobility of those polymers was well higher than that of P3HT, probably due to the higher conjugation caused by fused rings and the quinoid structure. Contact angle measurements showed that they were more hydrophobic than spiro-OMeTAD and thus they were acting to better protect the perovskite layer. In the planar PSC devices, those HTMs were implemented as thinner layers (50-55 nm) than spiro-OMeTAD (around $200 \mathrm{~nm}$ ), giving also excellent PCE: 20.28\% for PBDTT and 19.48\% for PBTTT, while the spiro-OMeTAD achieved a lower value (18.32\%). The devices built with PBDTT and PBTTT were also reasonably stable, by maintaining $80 \%$ for their pristine PCE after $720 \mathrm{~h}$ of storage at $30 \%$ relative humidity at room temperature.

Additionally, the IDTB polymer was built on the indaceno[1,2-b:5,6-b']dithiophene scaffold, but coupled with the bis(alkoxybenzene) co-monomers [166]. The polymer had a HOMO energy level at $-5.20 \mathrm{eV}$ and hole mobility slightly lower than spiro-OMeTAD. The proneness to $\mathrm{p}-\mathrm{p}$ stacking was demonstrated by the UV spectra in the solid-state, while the XPS showed that S-O interaction between the sulphur of the indacenothiophene and the oxygen of the alkoxy groups improved the planarity of the polymeric skeleton. The IDTB HTM was used in PSCs (FTO/c-TiO $\left./ \mathrm{SnO}_{2} / \mathrm{Cs}_{0.05} \mathrm{FA}_{0.8} \mathrm{MA}_{0.15} \mathrm{PbI}_{2.55} \mathrm{Br}_{0.45} / \mathrm{HTM} / \mathrm{Au}\right)$ showed a PCE of $19.38 \%$, overcoming the spiro-OMeTAD (18.22\%). Hysteresis was shown by spiro-OMeTAD, but not by IDTB. The stability was assessed over 60 days at $30{ }^{\circ} \mathrm{C}$ and $30-40 \%$ of relative humidity.

The fluorene core, with pendant chains, terminated by carboxylic groups was used as a spacer in novel polymers, which was coupled with a bithiophene and a fluorinated bithiophene. The two polymers PFDT-COOH and PFDT-2F-COOH were prepared easily, showed that their HOMO energy levels were lowered by the fluorination and attained excellent efficiencies in inverted $\mathrm{FA}_{1-\mathrm{x}} \mathrm{MA}_{\mathrm{x}} \mathrm{PbI}_{3}$ PSCs, reaching $20.64 \%$ and $21.68 \%$ for PFDT-COOH and PFDT-2F-COOH, respectively [167]. These impressive results can be 
the results of well-ordered and pinhole-free perovskite films grown on those HTM layers. The stability at $80^{\circ} \mathrm{C}$, under dark in $\mathrm{N}_{2}$, was measured at $720 \mathrm{~h}$, revealing that those HTMs retained $80 \%$ of their PCE. Once more, this showed that more should be known about HTMs and that the D-p-A, the 2D-star shaped, the triphenylamine paradigms are only a few of the possible conditions that promote an efficient hole transport. A bright future for this research field still has to come and the unexplored space is in front of us. The MEH-PPV polymer was employed in the preparation of PSC showing an effect of the solvent used for the polymer deposition on the PCE. The use of chlorobenzene, dichlorobenzene and toluene slightly improved the PCE in the same order: $7.21 \%, 8.06 \%$ and $8.87 \%$, while P3HT showed a PCE of $6.74 \%$. By improving the PSC preparation procedure $\left(\mathrm{TiO}_{2}\right.$ treatment with $\mathrm{TiCl}_{4}$, one-step preparation of perovskite) the PCE of MEH-PPV approached 10\% [168].

The polymer DTB was prepared by polymerization of the monomeric 1,4-dibromo2,5-bis((2-ethylhexyl)oxy)benzene with the 5,5'-bis(trimethylstannyl)-2,2'-bithiophene, in a Stille coupling reaction.

This polymeric skeleton can be considered as a great simplification of the polymeric skeleton seen above (Section 3.3.2.2) for RCP [126], asy-PBTBDT [128] and PTEG [115]. This "simplified" polymer maintained substantially the excellent results of its parent polymers but with a sensibly lower synthetic effort: indeed, only two steps were needed to accomplish the final synthesis of DTB. This polymer showed lower hole mobility than spiro-OMeTAD, a HOMO energy level lying at $-4.96 \mathrm{eV}$ and an edge-on orientation of its film on PSK, as demonstrated GIWAXS experiments. Albeit this last feature does not help to increase the hole mobility in the vertical direction, the PCE in FAMA perovskite cells was excellent, $19.19 \%$ (best value $19.68 \%$ ), with a certified value of $19.5 \%$, showing again that dopant-free polymers have enormous potential. [169] During stability tests performed at room temperature and 20\% relative humidity, DTB retained $86 \%$ PCE over 30 days. The easy synthesis, high efficiency and good stability promote this kind of structure for further studies and large-scale application.

DTB was also used with the inorganic CUSCN HTM, attaining 22.0\% of PCE [170]. The stability at room temperature was checked at $60 \%$ of relative humidity for non-encapsulated cells, which survived for $1000 \mathrm{~h}$ maintaining more than $90 \%$ of the pristine PCE.

As further improvements starting from the DTB, the DTB(xDEG) polymers were prepared by copolymerizing a small fraction of the PhDEG monomer [171]. This is an easy approach to passivate the uncoordinated $\mathrm{Pb}^{2+}$ surface traps, due to the presence of the diethylene glycol chain whereas the HOMO level was just slightly upshifted. The GIWAXS measurements showed that the introduction of $3 \%$ of PhDEG did not modify the molecular packing but increased the crystallinity considerably, in both edge-on and face-on orientations (Figure 5). When the content of PhDEG was brought to $10 \%$ the crystallinity was decreased in both orientations, loosening lamellar and $\mathrm{p}-\mathrm{p}$ stacking. As a result, both the hole mobility and the PCE followed the crystallinity degree. In mesoporous PSCs, with $\mathrm{Cs}_{0.05} \mathrm{FA}_{0.81} \mathrm{MA}_{0.14} \mathrm{PbI}_{2.55} \mathrm{Br}_{0.45}$, the remarkable efficiencies of $19.65 \%$ for the $\mathbf{D T B}(\mathbf{0} \% \mathrm{DEG})$ polymer and $20.19 \%$ for the DTB(3\%DEG) were obtained.

Four polymers, namely PTA-P1, PTA-P2, PTA-P3 and PTA-P4, derived from an oxygen bridged triphenylamine were prepared and tested in mesoporous PSCs based on perovskite [172]. These materials showed high thermal stability (over $400{ }^{\circ} \mathrm{C}$ ) but only PTA-P1 and PTA-P4 showed reasonably high hole mobility and this was also reflected onto the final photovoltaic behavior. When doped, their PCE was in the range 4.9-7.6\% with PTAA at $17.6 \%$, but when in the undoped state the PCE was $12.1 \%, 1.3 \%, 9.1 \%$ and $11.1 \%$ respectively, with PTAA attaining only $4.8 \%$. 
Table 5. Dopant-free polymeric HTMs of various structures and their performances. (see legend for details).

\begin{tabular}{|c|c|c|c|c|c|c|c|c|c|c|c|c|}
\hline HTM & PSK & Cell $^{\mathrm{a}}$ & $\begin{array}{l}\text { PCE } \\
(\%)\end{array}$ & $\begin{array}{l}\text { Std } \\
\text { PCE } \\
(\%)^{b}\end{array}$ & $\begin{array}{l}\mathrm{V}_{\mathrm{oc}} \\
(\mathrm{mV})\end{array}$ & $\begin{array}{c}J_{s c} \\
\left(\mathrm{~mA} \mathrm{~cm}^{-2}\right)\end{array}$ & $\begin{array}{l}\mathrm{FF} \\
(\%)\end{array}$ & HOMO (eV) & $B_{g}(e V)$ & $\begin{array}{c}\mathrm{HM} \\
\left(\mathrm{cm}^{2} \mathrm{~V}^{-1}\right. \\
\left.\mathrm{S}^{-1}\right)\end{array}$ & Stab. (h) & Ref. \\
\hline PF8-TAA & $\mathrm{MAPbBr}_{3}$ & M & 6.0 & $5.9^{\mathrm{d}}$ & 1.36 & 6.3 & 70.0 & -5.44 & & 0.02 & - & [162] \\
\hline PIF8-TAA & $\mathrm{MAPbBr}_{3}$ & M & 6.7 & $5.9^{\mathrm{d}}$ & 1.40 & 6.1 & 79.0 & -5.51 & & 0.04 & - & [162] \\
\hline PIF8-TAA & $\mathrm{MAPbI}_{3}$ & M & 9.1 & $16.2^{d}$ & 1.04 & 19.0 & 46.0 & -5.51 & & 0.04 & - & [162] \\
\hline PSQ1 & $\begin{array}{c}\alpha- \\
\mathrm{CsPbI}_{2} \mathrm{Br}\end{array}$ & $\mathrm{P}$ & 13.6 & $14.4^{\mathrm{c}}$ & 1.24 & 14.4 & 76.1 & -5.21 & 1.79 & $1.09 \times 10^{-3}$ & - & [163] \\
\hline PSQ2 & $\begin{array}{c}\alpha- \\
\mathrm{CsPbI}_{2} \mathrm{Br}\end{array}$ & $\mathrm{P}$ & 15.5 & $14.4^{\mathrm{c}}$ & 1.27 & 15.4 & 79.0 & -5.31 & 1.86 & $9.87 \times 10^{-3}$ & $\begin{array}{l}83 \%, 300 \text { h, (light } \\
\text { rt) }\end{array}$ & [163] \\
\hline $\begin{array}{l}\text { P3-3,5- } \\
\text { diOMe }\end{array}$ & $\begin{array}{c}\alpha- \\
\mathrm{CsPbI}_{2} \mathrm{Br}\end{array}$ & $\mathrm{P}$ & 11.6 & $14.4^{\mathrm{c}}$ & 1.30 & 12.9 & 69.4 & -5.27 & 2.47 & $1.45 \times 10^{-5}$ & - & [163] \\
\hline PBDTT & $\begin{array}{c}\mathrm{Cs}_{0.05} \mathrm{FA}_{0.81} \mathrm{MA}_{0.14} \\
\mathrm{PbI}_{2.55} \mathrm{Br}_{0.45}\end{array}$ & $\mathrm{P}$ & 20.28 & $13.88^{b}{ }_{c}^{b} 18.32$ & 1.12 & 23.64 & 76.67 & -5.31 & 1.87 & $7.10 \times 10^{-4}$ & $\begin{array}{c}80 \%, 720 \mathrm{~h}, \\
\mathrm{NE}(30 \% \\
\mathrm{RH}, \mathrm{rt})\end{array}$ & [165] \\
\hline РBTTT & $\begin{array}{c}\mathrm{Cs}_{0.05} \mathrm{FA}_{0.81} \mathrm{MA}_{0.14} \\
\mathrm{PbI}_{2.55} \mathrm{Br}_{0.45}\end{array}$ & $\mathrm{P}$ & 19.48 & $13.88_{c}^{b} \mathbf{1 8 . 3 2}$ & 1.10 & 22.30 & 79.57 & -5.24 & 1.89 & $6.99 \times 10^{-4}$ & $\begin{array}{l}80 \%, 720 \mathrm{~h}, \\
\mathrm{NE}(30 \% \\
\mathrm{RH}, \mathrm{rt})\end{array}$ & [165] \\
\hline IDTB & $\begin{array}{c}\mathrm{Cs}_{0.05} \mathrm{FA}_{0.81} \mathrm{MA}_{0.14} \\
\mathrm{PbI}_{2.55} \mathrm{Br}_{0.4}\end{array}$ & $\mathrm{P}$ & $\begin{array}{l}19.38 \text { (best) } \\
16.39 \text { (avg) }\end{array}$ & $18.22^{b}$ & 1.107 & 23.06 & 75.9 & -5.20 & 2.19 & $2.9 \times 10^{-5}$ & $\begin{array}{c}70 \%, 60 \mathrm{~d} \\
(\mathrm{NE}, 30-40 \% \\
\left.\mathrm{RH}, 30^{\circ} \mathrm{C}\right)\end{array}$ & [166] \\
\hline $\begin{array}{l}\text { PFDT- } \\
\text { COOH }\end{array}$ & $\mathrm{FA}_{1-\mathrm{x}} \mathrm{MA}_{x} \mathrm{PbI}_{3}$ & I & $\begin{array}{l}20.64 \text { (best) } \\
19.65 \text { (avg) }\end{array}$ & - & 1.079 & 24.78 & 77.2 & -5.22 & 2.18 & - & $\begin{array}{c}80 \%, 720 \mathrm{~h}, \\
\mathrm{NE}\left(\mathrm{N}_{2}, 85^{\circ} \mathrm{C}\right)\end{array}$ & [167] \\
\hline $\begin{array}{l}\text { PFDT-2F- } \\
\text { COOH }\end{array}$ & $\mathrm{FA}_{1-\mathrm{x}} \mathrm{MA}_{\mathrm{x}} \mathrm{PbI}_{3}$ & I & $\begin{array}{l}21.68 \text { (best) } \\
20.51 \text { (avg) }\end{array}$ & - & 1.111 & 24.86 & 78.5 & -5.32 & 2.3 & - & $\begin{array}{c}80 \%, 720 \mathrm{~h}, \\
\mathrm{NE}\left(\mathrm{N}_{2}, 85^{\circ} \mathrm{C}\right)\end{array}$ & [167] \\
\hline MEH-PPV & $\mathrm{MAPbI}_{3}$ & $\mathrm{M}$ & 9.65 & $6.74^{b} / 13.38^{c}$ & 0.88 & 17.36 & 63.0 & -5.40 & 2.1 & & & [168] \\
\hline DTB & $\begin{array}{l}\mathrm{FA}_{0.85} \mathrm{MA}_{0.15} \\
\mathrm{PbI}_{2.55} \mathrm{Br}_{0.45}\end{array}$ & M & $\begin{array}{l}19.68 \text { (best) } \\
19.19 \text { (avg) } \\
19.5 \text { (cert) }\end{array}$ & $\begin{array}{c}19.81^{\mathrm{c}} \text { (best) } \\
19.38 \text { (avg) }\end{array}$ & 1.10 & 25.50 & 69.85 & -4.96 & 2.14 & $1.0 \times 10^{-4}$ & - & [169] \\
\hline DTB/CuSCN & $\begin{array}{c}\left.\mathrm{FAPbI}_{3}\right)_{0.92} \\
\left(\mathrm{MAPbBr}_{3}\right)_{0.08}\end{array}$ & $\mathrm{P}$ & 22.0 & - & 1.15 & 24.31 & 78.6 & - & - & 0.014 & $\begin{array}{l}90 \%, 1000 \mathrm{~h}, \\
(\mathrm{NE}, 60 \% \\
\mathrm{RH}, \mathrm{rt})\end{array}$ & [170] \\
\hline
\end{tabular}


Table 5. Cont.

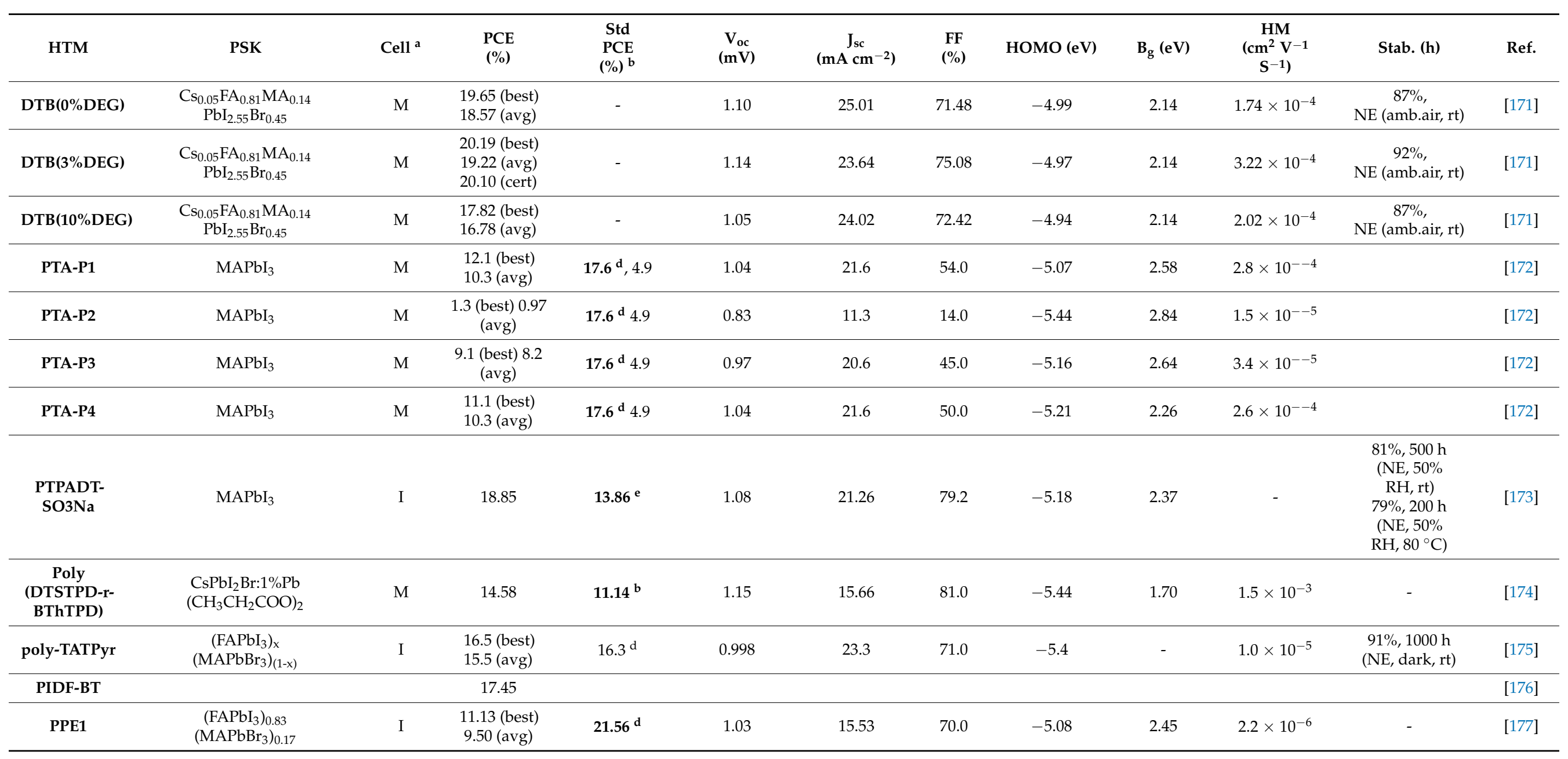


Table 5. Cont.

\begin{tabular}{|c|c|c|c|c|c|c|c|c|c|c|c|c|}
\hline HTM & PSK & Cell ${ }^{a}$ & $\begin{array}{l}\text { PCE } \\
(\%)\end{array}$ & $\begin{array}{l}\text { Std } \\
\text { PCE } \\
(\%)^{b}\end{array}$ & $\begin{array}{c}\mathrm{V}_{\mathrm{oc}} \\
(\mathrm{mV})\end{array}$ & $\begin{array}{c}\mathrm{J}_{\mathrm{sc}} \\
\left(\mathrm{mA} \mathrm{cm} \mathrm{cm}^{-2}\right)\end{array}$ & $\begin{array}{c}\text { FF } \\
(\%)\end{array}$ & HOMO (eV) & $B_{g}(e V)$ & $\begin{array}{c}\text { HM } \\
\left(\mathrm{cm}^{2} \mathrm{~V}^{-1}\right. \\
\left.\mathrm{S}^{-1}\right)\end{array}$ & Stab. (h) & Ref. \\
\hline PPE2 & $\begin{array}{c}\left(\mathrm{FAPbI}_{3}\right)_{0.83} \\
\left(\mathrm{MAPbBr}_{3}\right)_{0.17}\end{array}$ & I & $\begin{array}{l}19.33 \text { (best) } \\
18.10 \text { (avg) }\end{array}$ & $21.56^{d}$ & 1.07 & 22.84 & 79 & -5.06 & 2.70 & $1.9 \times 10^{-6}$ & - & [177] \\
\hline $\begin{array}{c}\text { PPE2 } \\
\text { (PSK } \\
\text { passivation } \\
\text { with PEAI) }\end{array}$ & $\left(\mathrm{FAPbI}_{3}\right)_{0.83}\left(\mathrm{MAPbBr}_{3}\right)_{0.17}$ & I & $\begin{array}{l}21.31 \text { best } \\
19.77 \text { (avg) }\end{array}$ & $21.56^{d}$ & 1.18 & 22.30 & 81 & -5.06 & 2.70 & $1.9 \times 10^{-6}$ & - & [177] \\
\hline PPY1 & $\left(\mathrm{FA}_{0.92} \mathrm{MA}_{0.08}\right)_{0.9} \mathrm{Cs}_{0.1} \mathrm{~Pb}\left(\mathrm{I}_{0.92} \mathrm{Br}_{0.08}\right)$ & )$_{3} \mathrm{I}$ & 15.08 & $20.98^{d}$ & 0.92 & 22.15 & 74.0 & -4.96 & 2.67 & $1.30 \times 10^{-3}$ & - & [178] \\
\hline PPY2 & $\left(\mathrm{FA}_{0.92} \mathrm{MA}_{0.08}\right)_{0.9} \mathrm{Cs}_{0.1} \mathrm{~Pb}\left(\mathrm{I}_{0.92} \mathrm{Br}_{0.08}\right)$ & & 22.41 & $20.98^{d}$ & 1.16 & 23.56 & 82.0 & -5.17 & 2.48 & $1.90 \times 10^{-3}$ & $\begin{array}{l}>97 \%, 500 \mathrm{~h}(\mathrm{NE}, \\
\text { light, rt9 }\end{array}$ & [178] \\
\hline PDT-T & & $\mathrm{P}$ & 18.69 & $13.69^{b}$ & 1.13 & 21.36 & 77.63 & -5.45 & 1.88 & $6.29 \times 10^{-4}$ & $\begin{array}{c}>90 \%, 100 \mathrm{~d},(\mathrm{E} \\
30 \% \mathrm{RH}, \mathrm{rt})\end{array}$ & [179] \\
\hline PDTT-T & & $\mathrm{P}$ & 19.02 & $13.69^{b}$ & 1.14 & 21.68 & 76.79 & -5.44 & 1.89 & $7.41 \times 10^{-4}$ & $\begin{array}{c}>90 \%, 100 \mathrm{~d},(\mathrm{E}, \\
30 \% \mathrm{RH}, \mathrm{rt})\end{array}$ & [179] \\
\hline TZ-P1 & $\mathrm{FA}_{0.81} \mathrm{MA}_{0.15} \mathrm{PbI}_{2.5} \mathrm{Br}_{0.45}$ & $\mathrm{M}$ & 10.26 & $13.02^{c}$ & 0.94 & 17.62 & 62.0 & -5.21 & 1.88 & - & - & [180] \\
\hline TZ-P2 & $\mathrm{FA}_{0.81} \mathrm{MA}_{0.15} \mathrm{PbI}_{2.5} \mathrm{Br}_{0.45}$ & $\mathrm{M}$ & 13.21 & $13.02^{c}$ & 1.02 & 19.87 & 65.0 & -5.19 & 1.83 & - & $\begin{array}{c}80 \%, 113 \mathrm{~d}, \mathrm{NE} \\
\quad\left(\mathrm{N}_{2}, \mathrm{rt}\right)\end{array}$ & [180] \\
\hline TZ-P3 & $\mathrm{FA}_{0.81} \mathrm{MA}_{0.15} \mathrm{PbI}_{2.5} \mathrm{Br}_{0.45}$ & $\mathrm{M}$ & 8.47 & $13.02^{\mathrm{c}}$ & 0.90 & 16.47 & 57.0 & -5.20 & 1.84 & - & - & [180] \\
\hline $\begin{array}{l}\text { PEDOT- } \\
\text { TMbCD-P1 }\end{array}$ & $\mathrm{MAPbI}_{3}$ & M & $\begin{array}{l}5.54 \text { (best) } \\
3.64 \text { (avg) }\end{array}$ & $6.27^{c} / 14.41^{c}$ & 0.74 & 19.51 & 38.0 & -4.20 & 2.60 & - & - & [181] \\
\hline $\begin{array}{l}\text { PEDOT- } \\
\text { TMbCD-P2 }\end{array}$ & $\mathrm{MAPbI}_{3}$ & $\mathrm{M}$ & $\begin{array}{l}3.80 \text { (best) } \\
2.02 \text { (avg) }\end{array}$ & $6.27^{c} / 14.41^{c}$ & 0.60 & 13.55 & 47.0 & -4.32 & 2.20 & - & - & [181] \\
\hline TQ1 & $\mathrm{CsBi}_{3} \mathrm{I}_{10}$ & $\mathrm{M}$ & 0.51 & $0.36^{b} / 0.003^{c}$ & 0.48 & 2.9 & 37.0 & -5.70 & 1.78 & $1.6 \times 10^{-3}$ & & [182] \\
\hline P3TI & $\mathrm{CsBi}_{3} \mathrm{I}_{10}$ & $\mathrm{M}$ & 0.47 & $0.36^{b} / 0.003^{c}$ & 0.47 & 2.6 & 38.0 & -5.69 & 1.72 & $1.8 \times 10^{-3}$ & & [182] \\
\hline
\end{tabular}

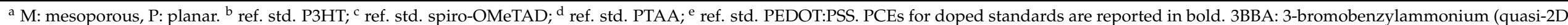
perovskite). PEAI: Phenylethylammonium iodide. PSBMA: poly(sulfobetaine methacrylate). PMMA: poly(methyl metacrylate). 

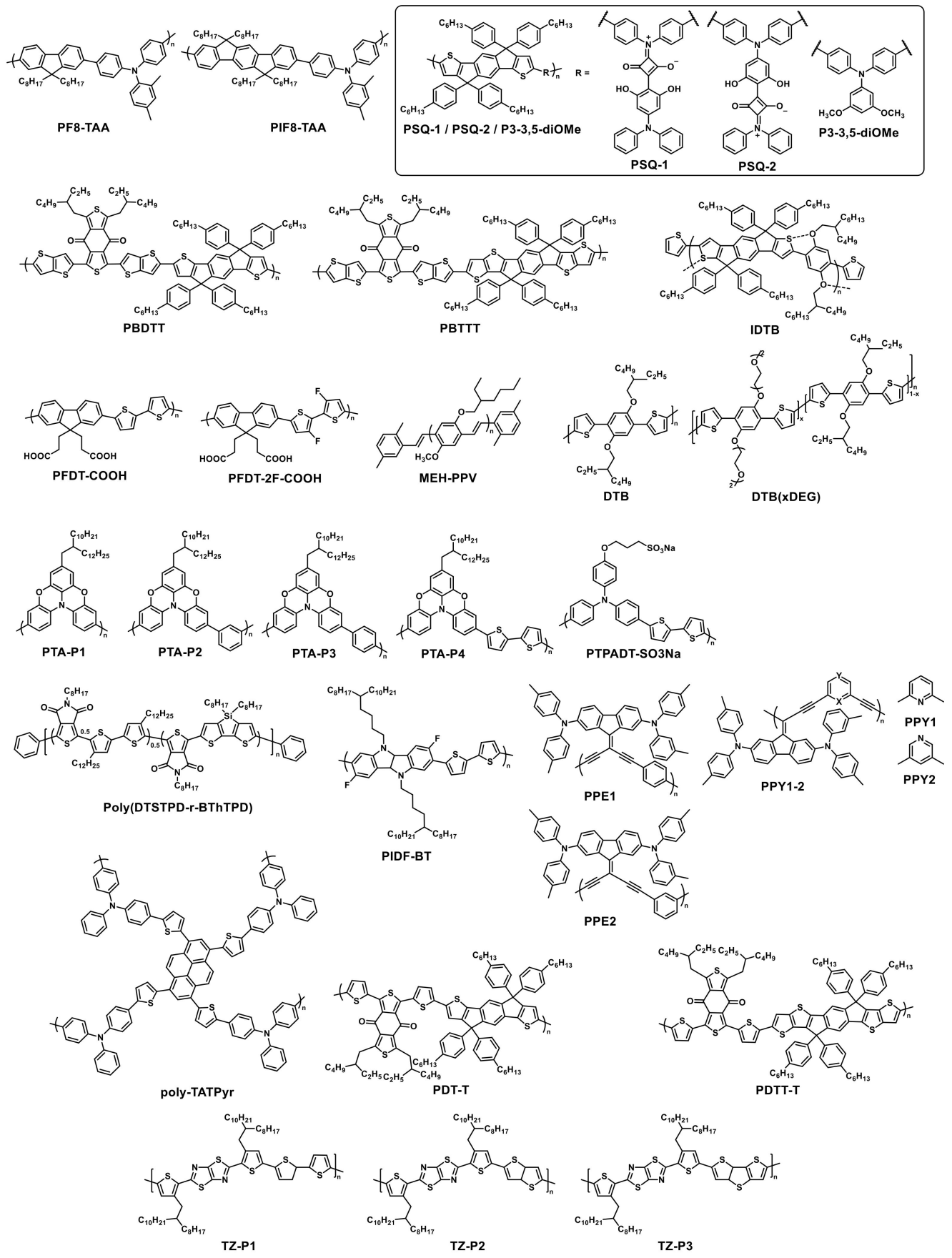

Scheme 7. Cont. 


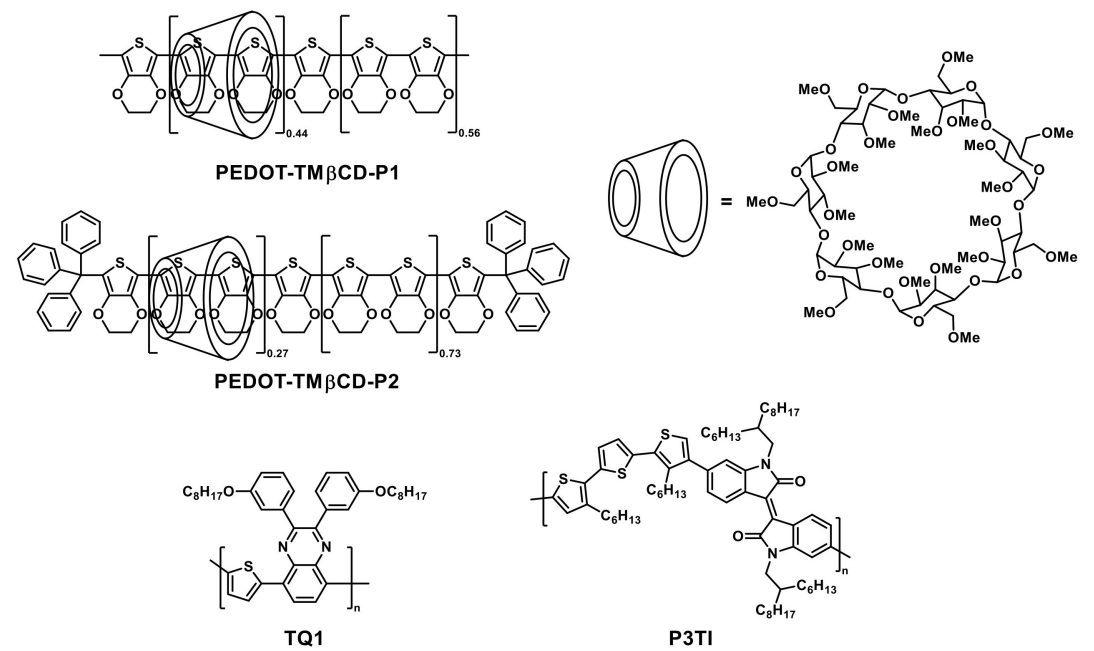

Scheme 7. Miscellaneous of dopant-free HTM polymers.
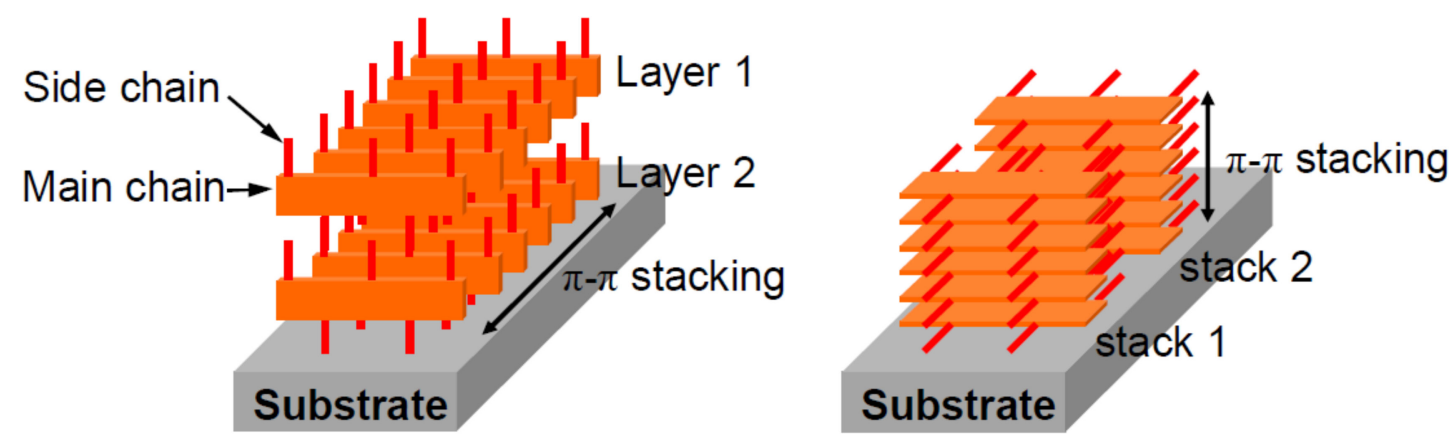

Figure 5. Different packing of polymers: edge-on (left); face-on (right). Reprinted with permission from ref. [171] Copyright 2015 John Wiley and Sons.

The conjugated polyelectrolyte PTPADT-SO3Na was prepared by assembling a bisthiophene with a triphenylamine moiety, to which a sulphonic residue was tethered [173]. This material showed a conductivity of $2.68 \times 10^{-1} \mathrm{~S} \mathrm{~cm}^{-1}$ conductivity and it gave smooth and homogenous film when deposited onto ITO, which was essential for potential use in inverted PSC. The photovoltaic behavior was excellent, giving a PCE of $18.15 \%$, about $30 \%$ higher than the PEDOT:PSS (13.86\%). Stability tests showed that PTPADT-SO3Na maintained $81 \%$ of the initial PCE for not-encapsulated cells at $50 \%$ of relative humidity and rt, while in the same conditions they saved $79 \%$ of the pristine PCE after heating at $85 \%$ for $200 \mathrm{~h}$.

The Poly(DTSTPD-r-BThTPD) polymer was obtained as a complex copolymer, prepared by reacting the 1,3-dibromo-5-octyl-4H-thieno[3,4-c]pyrrole-4,6(5H)-dione (TPD) with an equimolar mixture of the (4,4'-didodecyl-[2,2'-bithiophene]-5, $5^{\prime}$-diyl)bis (trimethylstannane) (bithiophene, BTh) and 4,4-dioctyl-2,6-bis(trimethylstannyl)-4H-silolo dithiophene (Dithienosilole, DTS) [174]. The $\mathrm{CsPbI}_{2} \mathrm{Br}$ perovskite was treated with $1 \%$ of lead propionate to passivate the lead surface traps. This kind of perovskite was used to build mesoporous devices in which the Poly(DTSTPD-r-BThTPD) gave a PCE of $14.58 \%$.

Starting from the concept of the OMe-TATPyr 2D star-shaped small molecule, which obtained a PCE of $20.6 \%$ a polymer was derived, coded poly-TATPyr [175]. It was conceived as pyrene as a scaffold bearing four triphenylamines, through thiophene as a spacer. The final coupling to obtain the monomer was performed through a Suzuki reaction of the 1,3,6,8-tetra(5-bromothiophen-2-yl)pyrene with the 4-(diphenylamino)phenylboronic 
acid. The polymer poly-TATPyr was prepared from the monomer by electropolymerization, giving a $\mathrm{n}$ amorphous polymer. This kind of polymer showed low solubility, and this suggested using it for inverted architectures. Its low wettability towards the DMF was thought to suppress the heterogeneous nucleation and in turn, promoted the production of very large perovskite grains. The HOMO energy level was lying at $-5.4 \mathrm{eV}$, very close to the perovskite valence band, $-5.5 \mathrm{eV}$. Into a PSC with the $\mathrm{ITO} / \mathrm{HTM} /\left(\mathrm{FAPbI}_{3}\right)_{x}\left(\mathrm{MAPbBr}_{3}\right)_{(1-\mathrm{x})} / \mathrm{PC}_{61} \mathrm{BM} / \mathrm{BCP} / \mathrm{Ag}$, the $\mathrm{PCE}$ of poly-TATPyr attained $16.5 \%$, similar to PTAA (16.38\%).

A polymer prepared by the Stille reaction on the basis of the isoindoloindole (IDID), PIDF-BT, to which bithiophene, was linked, attained interesting results. All these polymers were studied mainly to check the charge transfer with the dopant F4-TCNQ [176]. The dopant-free PIDF-BT obtained some good results about PCE, which was around $17.45 \%$ for PIDF-BT and was increased to $20.21 \%$ by F4-TCNQ doping. Unfortunately, no other data were shown on the dopant-free performances of the other polymeric materials.

Two polymers belonging to the poly(phenylene enylene) class were prepared, with pendant groups constitute by fluorene moieties decorated with two bis(4-methylphenyl)amines [177]. The synthetic path followed the transformation of the 2,7-bis(di-4-methylphenylamino)9H-fluoren-9-one into the 9-(dibromomethylene)- $N^{2}, N^{2}, N^{7}, N^{7}$-tetra-p-tolyl-9H-fluorene2,7-diamine. This intermediate was reacted with both 1,4-diethynylbenzene and 1,3diethynylbenzene by the Sonogashira protocol to give the PPE1 and PPE2. Those HTMs were used in inverted perovskites, where the PPE2 film helped to grow larger and betteraligned perovskite crystals than PPE1. This gave an account for a better and outstanding PCE, 21.31\% for PPE2 (doped PTAA 21.56\%) while PPE1 performance was lower, $11.13 \%$.

As evolution in the class of poly(phenylene enylene), the PPY1 and PPY2 polymers were prepared, embedding in the polymer skeleton a pyridine moiety to help to passivate the perovskite $\mathrm{Pb}$ surface traps [178]. The synthesis was accomplished by the Sonogashira method. The difference between the two polymers is related to the two pyridines involved in the reaction, the 2,6-diethynylpiridine (PPY1) and the 3,5-diethynylpiridine (PPY2). The PPY1 HTM was shown to be an oligomer $(2.2 \mathrm{kDa})$ and this can in part explain its lower photovoltaic results with respect to PPY2. The reason is probably due to the electron-withdrawing effect of the pyridine nitrogen which reduces the electron density to the ethynyl groups, also reducing their reactivity. On the contrary, PPY2 was a polymer $(7.6 \mathrm{kDa})$. In the $\left(\mathrm{FA}_{0.92} \mathrm{MA}_{0.08}\right)_{0.9} \mathrm{Cs}_{0.1} \mathrm{~Pb}\left(\mathrm{I}_{0.92} \mathrm{Br}_{0.08}\right)_{3}$ perovskite based PSCs, the two HTMs obtained a PCE of $15.08 \%$ and $22.41 \%$ for PPY1 and PPY2 respectively, with PPY2 overcoming the PTAA by $1.4 \%$.

Two polymers, PDT-T and PDTT-T were prepared by the Stille coupling of a benzo[1,2c:4,5-c']dithiophene-4, 8-dione (BDD) monomer and 4,9-dihydro-s-indaceno[1,2-b:5,6$\mathrm{b}^{\prime}$ ]dithiophene (IDT) monomer for PDT-T, and 6,12-dihydro-dithieno[2,3-d:2',3'-d']-sindaceno[1,2- b:5,6-b']dithiophene monomer for PDTT-T [179]. The polymers were slightly soluble in THF and this fact demonstrated a proneness to $\pi-\pi$ stacking. The HOMO energy levels of the two HTMs were at -5.45 and $5.44 \mathrm{eV}$ for PDT-T and PDTT-T, respectively and the hole mobility was quite good and comparable between the two polymers. The thermal stability of these polymers was very good, over $400^{\circ} \mathrm{C}$. The polymers gave very good and smooth films that were used to build planar PSCs. The PCE was $18.63 \%$ for PDT-T and $19.02 \%$ for PDTT-T, also thanks to a fill factor approaching $80 \%$ for both polymers.

Thiazolothiazole-based HTMs, P1, P2 and P3 were prepared by Li and coworkers, who showed that the introduction of the thiazolothiazole moiety gave important results, showing excellent hole mobilities [180]. In order to avoid misunderstanding due to eponymous polymers already cited, here we will name these polymers as TZ-P1, TZ-P2 and TZ-P3. The main building block was assembled with bithiophene (TZ-P1), thieno[3,2b]thiophene (TZ-P2), and dithieno[3,2-b:2', $3^{\prime}$-d] thiophene (TZ-P3). The HOMO energy level for TZ-P1, TZ-P2 and TZ-P3 were very similar $(-5.21 \mathrm{eV},-5.19 \mathrm{eV}$ and $-5.20 \mathrm{eV}$, respectively) with LUMO being $-3.33,-3.36$ and $-3.36 \mathrm{eV}$. Thus, the difference of PCE among the three polymers (see below) could not be ascribed to a different level alignment. 
The XRD measurements showed that TZ-P2 was more crystalline and this helped a better hole extraction from the perovskite, also confirmed by Time-Resolved Fluorescence measurements. On a mesoporous PSC containing a $\mathrm{FA}_{0.81} \mathrm{MA}_{0.15} \mathrm{PbI}_{2.55} \mathrm{Br}_{0.45}$ perovskite, TZ-P1, TZ-P2 and TZ-P3 gave 10.26\%, 13.21\% and 8.47\% PCE respectively, with the best cell, showing $14.02 \%$ for TZ-P2. In the same conditions, spiro-OMeTAD gave a $13.02 \%$ PCE. Under $\mathrm{N}_{2}$, in a glovebox, the TZ-P2 retained $80 \%$ of the initial PCE over 113 days, while for spiro-OMeTAD only 40\% PCE was maintained over 97 days. Notably, TZ-P2 maintained $97 \%$ of the pristine Fill Factor over 113 days, which demonstrated that the charge extraction ability was preserved.

PEDOT-TM $\beta C D$ polymers were prepared and tested in perovskite solar cells [181]. They were prepared by polymerization of EDOT in the presence of 2,3,6-tri-O-methyl $\beta$-cyclodextrin (TM $\beta C D$ ) as a complexing agent. The TM $\beta C D$ and EDOT were complexed and after they were polymerized by an oxidation reaction with $\mathrm{FeCl}_{3}$. The addition of a minimal quantity of the triphenylmethane-EDOT stopper was needed to obtain PEDOT-TM $\beta$ CD-P2. These polymers were applied in $\mathrm{MAPbI}_{3}$ perovskite-based PSCs with a structure like glass $/ \mathrm{FTO} / \mathrm{c}-\mathrm{TiO}_{2} / \mathrm{m}-\mathrm{TiO}_{2} /$ perovskite/HTM/Au). The HOMO of PEDOT-TM $\beta$ CD-P1 and PEDOT-TM $\beta$ CD-P2 were -4.32 and $-4.20 \mathrm{eV}$, respectively. The polymers showed high melting point and crystallinity and powered a PCE as high as 5.54\% for PEDOT-TM $\beta$ CD-P1, 3.80\% for PEDOT-TM $\beta$ CD-P2 and 6.27\% for spiro-OMeTAD, without dopants. The reasons for the relatively low performance of PCE should be further studied, but as first evidence, the presence of a stopper in these "rotaxane" polymers. probably stabilizes the polymer inducing a better photovoltaic behaviour, with a $65 \%$ PCE increase for PEDOT-TM $\beta$ CD-P2 over PEDOT-TM $\beta$ CD-P1, which was not capped with the stopper.

The development of PSC is also involving the use of fully inorganic perovskites to overcome the inherent instability of organo-inorganic perovskites [183]. In this respect, while already reaching remarkable efficiencies, the dopant-free HTMs used with fully inorganic perovskite are just a few.

PSC cells using a new lead-free (i.e., $\mathrm{CsBi}_{3} \mathrm{I}_{10}$ ) perovskite were built with three HTMs, TQ1, P3HT and P3TI[182]. The HOMO was $-5.10 \mathrm{eV}$ for P3HT, $-5.69 \mathrm{eV}$ for P3TI and $-5.70 \mathrm{eV}$ for TQ1 and LUMO stands at $-3.21 \mathrm{eV},-3.97 \mathrm{eV}$ and $-3.92 \mathrm{eV}$ respectively. Albeit the PCE obtained in this case is relatively low, $0.36 \%$ for P3HT, $0.47 \%$ for P3TI and $0.51 \%$ for TQ1, this approach is really meaningful evidencing the issues toward a lead-free PSC technology. The recrystallization of the perovskite with tBP showed an increase in the perovskite crystals size which, however, did not fully cover the $\mathrm{TiO}_{2}$. On recrystallized perovskite, the TQ1 was the only one HTM showing an increase of the PCE to $0.55 \%$ with the best cell reaching $0.77 \%[182]$. These are the first results ever obtained on this new perovskite, which does not contain lead and should be less toxic and harmful.

\section{Conclusions}

The dopant-free polymers are relatively novel Hole Transporting Materials that appeared for the first time in 2013, showing high hole mobility without the use of any dopant that is partially responsible for the low stability of this technology. In this review, we collected all the dopant-free polymers reported in the literature implemented as HTMs in Perovskite Solar Cells. HTMs were considered not only from the photovoltaic efficiency point of view but we looked also at the structural features of the polymers. They were classified as homopolymers and donor-acceptor copolymers. Most of the highly efficient dopant-free polymers belong to the latter category. As a matter of fact, the continuous alternation of donor and acceptor moieties is one of the most important characteristics to achieve high performances along with a fully conjugated skeleton, in which the hole transfer is promoted. However, some well-performing polymers were not fully conjugated and sometimes they were homopolymers, e.g., polytriarylamines, or polyvinyl structures embodying pendants small molecule HTMs. Another critical point to obtain very efficient devices is the close contact among polymeric chains, which can help the hole transfer by 
hopping mechanism. It was clearly shown that polymers that can arrange face-on on the perovskite surface can show very high hole mobility in the vertical direction, improving the PSC efficiency, while often those that show an edge-on packing show lower performances. The polymers were studied from their structural point of view, classifying them based on the few largely occurring different donors or acceptor groups, such as diketopyrrolopyrrole (DPP), benzodithiophene (BDT), Benzothiadiazole (BTZ), Carbazole (Cbz). It was shown that minimal structural differences can cause a reasonably large increase of the photovoltaic efficiency in PSC. In the case of DPP core, for example, the simple insertion of a thienothiophene moiety increased the PCE from $7.1 \%$ of DPP-P1 to $17.8 \%$ of PDPPT-TT, also named DPP-DTT). Moreover, DPP-P4 (PCE 9.3\%) that differs from PDPPT-TT only for the lateral chain length evidenced that the main conjugated chain analogy is not enough to obtain the same efficiency but that the lateral chains have great importance too. The same concept applies in the case of the BDT donor core in which very simple thiophene was used as a spacer among BDT groups, showing that it was sufficient to increase the planarity of the polymer and to improve packing and close contact, to achieve outstanding performances (19.6\% for P2-T and 20.3\% for P3-T-F). Very remarkably, most of the complex acceptor groups coupled with BDT did not achieve the results obtained by using a simple thiophene spacer. A further interesting aspect was that some HTMs which did not give high performances with a specific perovskite (DPP-P4), e.g., the classical $\mathrm{MAPbI}_{3}$, can greatly improve their performance in presence of other perovskites with which they are showing a better energy level alignment. These point toward the need for thoughtful design of HTMs to be employed with specific PSKs. Last but not least, the insertion of structural elements that can improve the contact between the perovskite and the HTM was found to be essential in improving the device's efficiency. As an example, a few polymers were functionalized with methoxytriethylenoxy chains, which were found to interact with the lead cations exposed at the perovskite surface, strongly reducing the trap surface states and giving a better wetting and adhesion of the polymer onto the perovskite surface. This improved the contact and the hole transfer, giving outstanding efficiencies (19.8\% for PTEG, $21.2 \%$ for Alkoxy-PTEG and $20.19 \%$ for DTB(3\%DEG)). Finally, it was shown that all the different PSC structures reached efficiencies even higher than 20\%. The mesoporous PSCs reached $20.3 \%$ with P3-T-F (and a certified PCE of $20.10 \%$ with DTB(3\%DEG)), the planar PSCs $21.2 \%$ with Alkoxy-PTEG and the inverted PSCs $21.68 \%$ with PFDT-2F-COOH. Additionally, other groups were shown to act as passivating groups/agents for the perovskite $\mathrm{Pb}$ surface traps, such as (but not exclusively!) the trialylamino pendant groups, as for PBDT-N0, PBDT-N5 and PBDT-N20. In the absence of the passivating group, PBDT-N0 showed a decent $\mathrm{PCE}$ of $12.4 \%$, but when the passivating groups were introduced in the polymer, up to $20 \%$ for PBDT-N20, the PCE grew to $18.9 \%$ showing that almost every HTM structure should be engineered for trap passivation. Alternative approaches are now followed, such as the use of polyectrolytes or passivating polymers directly during the perovskite preparation process, to improve the charge mobility throughout the perovskite material, which seems to be an element that limits the performance. This is also witnessed by several cases in which the surface traps passivation is performed by using very thin interlayers of passivant polyelectrolytesor conductive polymers, on which the HTM is finally deposited, improving its performance, e.g., the common P3HT, which increased its PCE from about $13 \%$ up to $19 \%$ by depositing first an interlayer of P3CT-BN. The same polymer attained a record PCE of $23 \%$ when deposited onto a classical perovskite capped with a thin layer of a 2D perovskite, which was passivating surface traps. In the last year, several polymers overcame the PCE barrier of 21\% (21.31\% for PPE2, 21.2\% for Alkoxy-PTEG, $21.53 \%$ for 2DP-TPB, $21.68 \%$ for PFDT-2F-COOH) and some of them achieved PCE of $22 \%$ and more (22.0\% for a DTB composite with CuSCN, and $22.41 \%$ for PPY2). The last case of PPY2 showed that a phenylene-vinylene polymer with a simple HTM as a pendant group can achieve outstanding results. All these cases show that there is plenty of space for playing with organic chemistry to build more performant molecules. As an example, the 2D star-shaped concept, well applied with success in the small molecules HTM field 
was applied to the synthesis of a branched polymer, 2DP-TPB, which attained an excellent PCE $(21.53 \%)$ which rose up to $22.17 \%$ with an optimized perovskite. These impressive results were obtained in just a few years and the urge for efficient and stable photovoltaic systems will push the research to obtain better efficiencies. As a final remark, we hope that this journey onto the dopant-free HTM structures can be more than just a collection of interesting data but can give some insights towards a fruitful innovation in HTM design.

Funding: This work was supported by the Italian Ministry of Economic Development in the framework of the Operating Agreement with ENEA for Research on the Electric System.

Conflicts of Interest: The authors declare no conflict of interest.

\section{Abbreviations}

\begin{tabular}{|c|c|}
\hline AgTFSI & Silver bis(TriFluoromethane-Sulfonyl)Imide \\
\hline $\mathrm{ALD}^{-\mathrm{TiO}_{2}}$ & Atomic Layer Deposited Titanium dioxide thin film \\
\hline $\mathrm{BCF}$ & Tris(pentaflurophenyl)borane \\
\hline BDT & Benzodithiophene \\
\hline $\mathrm{BG}$ or $\mathrm{B}_{\mathrm{g}}$ & Band-Gap \\
\hline BIPV & Building-integrated photovoltaics \\
\hline BTZ & Benzothiadiazole \\
\hline CB & Conduction Band \\
\hline $\mathrm{CBz}$ & Carbazole \\
\hline $\mathrm{CsPbI}_{3}$ & Cesium Lead Iodide Perovskite \\
\hline CsFAMA & Cesium FormAmidinium/MethylAmmonium Perovskite \\
\hline $\mathrm{c}-\mathrm{TiO}_{2}$ & Compact Titanium Dioxide \\
\hline $\mathrm{CV}$ & Cyclic Voltammetry \\
\hline D-A & Donor-Acceptor \\
\hline$D-\pi-A$ & Donor- $\pi$-conjugated bridge-Acceptor \\
\hline DFT & Density Functional Theory \\
\hline DSC or DSSCs & Dye-Sensitized Solar Cells \\
\hline ETL & Electron Transporting Layer \\
\hline ETM & Electron Transporting Material \\
\hline FA & Formamidinium \\
\hline FAMA & Formamidinium methylammonium \\
\hline $\mathrm{FAPbI}_{3}$ & FormAmidinium Lead triiodide Perovskite \\
\hline $\mathrm{FF}$ & Fill Factor \\
\hline FTO & Fluorine doped Tin Oxide \\
\hline GIWAXS & Grazing Incidence Wide Angle X-Ray Scattering \\
\hline $\mathrm{HM}$ & Hole Mobility \\
\hline $\mathrm{HOMO}$ & Highest Occupied Molecular Orbital \\
\hline HTL & Hole Transporting Layer \\
\hline HTM & Hole Transporting Material \\
\hline IDT & Indacenothiophene \\
\hline IDTT & Indacenodithieno[3,2-b]thiophene $\mathrm{T}$ \\
\hline $\mathrm{J}_{\mathrm{SC}}$ & Short Circuit Current Density \\
\hline LiTFSI & Lithium bis(TriFluoromethylSulfonyl)Imide \\
\hline LUMO & Lowest Unoccupied Molecular Orbital \\
\hline $\mathrm{M}_{\mathrm{n}}$ & Number Average Molecular Weight \\
\hline $\mathrm{M}_{\mathrm{W}}$ & Weight Average Molecular Weight \\
\hline MA & Methylammonium \\
\hline $\mathrm{MAPbBr}_{3}$ & MethylAmmonium Lead Bromide Perovskite \\
\hline $\mathrm{MAPbI}_{3}$ & MethylAmmonium Lead Iodide Perovskite \\
\hline $\mathrm{MAPbI}_{3-\mathrm{x}} \mathrm{Cl}_{\mathrm{x}}$ & MethylAmmonium Lead Iodide/Chloride \\
\hline $\mathrm{m}-\mathrm{TiO}_{2}$ & Mesoporous titanium dioxide \\
\hline
\end{tabular}




$\begin{array}{ll}\text { NE } & \text { Non-Encapsulated devices } \\ \text { NMR } & \text { Nuclear Magnetic Resonance } \\ \text { OFET } & \text { Organic thin-film transistor } \\ \text { OLED } & \text { Organic Light Emitting Diode } \\ \text { OPV } & \text { Organic PhotoVoltaics } \\ \text { P } & \text { Maximum Power } \\ \text { P }_{\text {in }} & \text { Incident Power at Constant Flux of Photons } \\ \text { P3HT } & \text { Poly(3-hexyl)thiophene } \\ \text { PANI } & \text { Polyaniline } \\ \text { PCE } & \text { Power Conversion Efficiency } \\ \text { PDI } & \text { Polydispersity index } \\ \text { PEDOT:PSS } & \text { Poly(3,4-ethylenedioxythiophene) polystyrene sulfonate } \\ \text { PFN } & \text { Poly[(9,9-bis(3'-(N,N-dimethylamino)propyl)-2,7-fluorene)-alt-2,7-(9,9-dioctylfluorene)] } \\ \text { PPN } & \text { Poly(4,4'-bis(N-carbazolyl)-1,10-biphenyl) } \\ \text { PPP } & \text { Polyphenylene } \\ \text { PSC } & \text { Perovskite Solar Cell } \\ \text { PT } & \text { Polythiophene } \\ \text { PTAA } & \text { Poly TriArylAmine } \\ \text { QD } & \text { Quantum Dot } \\ \text { RH } & \text { Relative Humidity } \\ \text { Spiro-OMeTAD } & \text { 2,2',7,7'-Tetrakis[N,N-di(4-methoxyphenyl)amino]-9,9'-spirobifluorene } \\ \text { tBP } & \text { 4-Tert-ButylPyridine } \\ \text { Voc } & \text { Open Circuit Voltage } \\ \text { VB } & \text { Valence Band }\end{array}$

\section{References}

1. Lu, L.; Zheng, T.; Wu, Q.; Schneider, A.M.; Zhao, D.; Yu, L. Recent Advances in Bulk Heterojunction Polymer Solar Cells. Chem. Rev. 2015, 115, 12666-12731. [CrossRef] [PubMed]

2. Carella, A.; Borbone, F.; Centore, R. Research Progress on Photosensitizers for DSSC. Front. Chem. 2018, 6, 481. [CrossRef] [PubMed]

3. Nazeeruddin, M.K.; Snaith, H. Methylammonium lead triiodide perovskite solar cells: A new paradigm in photovoltaics. MRS Bull. 2015, 40, 641-645. [CrossRef]

4. $\quad$ Kim, H.S.; Lee, C.R.; Im, J.H.; Lee, K.B.; Moehl, T.; Marchioro, A.; Moon, S.J.; Humphry-Baker, R.; Yum, J.H.; Moser, J.E.; et al. Lead iodide perovskite sensitized all-solid-state submicron thin film mesoscopic solar cell with efficiency exceeding $9 \%$. Sci. Rep. 2012, 2, 591. [CrossRef] [PubMed]

5. Yang, W.S.; Park, B.-W.; Jung, E.H.; Jeon, N.J.; Kim, Y.C.; Lee, D.U.; Shin, S.S.; Seo, J.; Kim, E.K.; Noh, J.H.; et al. Iodide management in formamidinium-lead-halide-based perovskite layers for efficient solar cells. Science 2017, 356, 1376. [CrossRef]

6. NREL. Available online: https:/ / www.nrel.gov / pv/cell-efficiency.html (accessed on 6 May 2021).

7. Calio, L.; Kazim, S.; Gratzel, M.; Ahmad, S. Hole-Transport Materials for Perovskite Solar Cells. Angew. Chem. Int. Ed. Engl. 2016, 55, 14522-14545. [CrossRef]

8. Motta, C.; El-Mellouhi, F.; Sanvito, S. Charge carrier mobility in hybrid halide perovskites. Sci. Rep. 2015, 5, 12746. [CrossRef]

9. Chandrasekhar, P. Conducting Polymers, Fundamentals and Applications, 2nd ed.; Springer: Berlin/Heidelberg, Germany, 2018 ; p. 850.

10. Chen, J.; Park, N.-G. Causes and Solutions of Recombination in Perovskite Solar Cells. Adv. Mater. 2018, 31, 1803019. [CrossRef]

11. Rakstys, K.; Igci, C.; Nazeeruddin, M.K. Efficiency vs. stability: Dopant-free hole transporting materials towards stabilized perovskite solar cells. Chem. Sci. 2019, 10, 6748-6769. [CrossRef]

12. Zhou, W.; Wen, Z.; Gao, P. Less is More: Dopant-Free Hole Transporting Materials for High-Efficiency Perovskite Solar Cells. Adv. Energy Mater. 2018, 8, 1702512. [CrossRef]

13. Urieta-Mora, J.; Garcia-Benito, I.; Molina-Ontoria, A.; Martin, N. Hole transporting materials for perovskite solar cells: A chemical approach. Chem. Soc. Rev. 2018, 47, 8541-8571. [CrossRef] [PubMed]

14. Ummadisingu, A.; Seo, J.Y.; Stojanovic, M.; Zakeeruddin, S.M.; Gratzel, M.; Hagfeldt, A.; Vlachopoulos, N.; Saliba, M. Additives, Hole Transporting Materials and Spectroscopic Methods to Characterize the Properties of Perovskite Films. Chimia 2017, 71, 754-761. [CrossRef] [PubMed]

15. Chiang, C.K.; Fincher, C.R.; Park, Y.W.; Heeger, A.J.; Shirakawa, H.; Louis, E.J.; Gau, S.C.; MacDiarmid, A.G. Electrical Conductivity in Doped Polyacetylene. Phys. Rev. Lett. 1977, 39, 1098-1101. [CrossRef]

16. Shahnawaz Sudheendran Swayamprabha, S.; Nagar, M.R.; Yadav, R.A.K.; Gull, S.; Dubey, D.K.; Jou, J.-H. Hole-transporting materials for organic light-emitting diodes: An overview. J. Mater. Chem. C 2019, 7, 7144-7158. [CrossRef]

17. Quinn, J.T.E.; Zhu, J.; Li, X.; Wang, J.; Li, Y. Recent progress in the development of n-type organic semiconductors for organic field effect transistors. J. Mater. Chem. C 2017, 5, 8654-8681. [CrossRef]

18. Garnier, F. Functionalized conducting polymers-Towards intelligent materials. Angew. Chem. 1989, 101, 529-533. [CrossRef] 
19. Foot, P.J.S.; Kaiser, A.B. Conducting Polymers; John Wiley \& Sons, Inc.: Hoboken, NJ, USA, 2004; pp. 513-550.

20. Wessling, B. Conductive Polymers as Organic Nanometals; CRC Press LLC: Boca Raton, FL, USA, 2007; pp. 1/3-1/75.

21. Magomedov, A.; Kasparavičius, E.; Rakstys, K.; Paek, S.; Gasilova, N.; Genevičius, K.; Juška, G.; Malinauskas, T.; Nazeeruddin, M.K.; Getautis, V. Pyridination of hole transporting material in perovskite solar cells questions the long-term stability. J. Mater. Chem. C 2018, 6, 8874-8878. [CrossRef]

22. Boyd, C.C.; Cheacharoen, R.; Leijtens, T.; McGehee, M.D. Understanding Degradation Mechanisms and Improving Stability of Perovskite Photovoltaics. Chem Rev. 2019, 119, 3418-3451. [CrossRef]

23. Desoky, M.M.H.; Bonomo, M.; Buscaino, R.; Fin, A.; Viscardi, G.; Barolo, C.; Quagliotto, P. Dopant-free All-Organic Small Molecule HTMs for Perovskite Solar Cells: Concepts and Structure-Property Relationships. Energies 2021, 14, 2279. [CrossRef]

24. Quagliotto, P.; Fin, A. Advances in Synthetic Methods for the Preparation of Poly(3-hexylthiophene) (P3HT). Lett. Org. Chem. 2018, 15, 991-1006. [CrossRef]

25. Tremel, K.; Ludwigs, S. Morphology of P3HT in Thin Films in Relation to Optical and Electrical Properties. In P3HT RevisitedFrom Molecular Scale to Solar Cell Devices; Ludwig, S., Ed.; Springr: Heidelberg, Germany, 2014; Volume 265, pp. 39-82.

26. Maruo, H.; Sasaki, Y.; Harada, K.; Suwa, K.; Oyaizu, K.; Segawa, H.; Carter, K.; Nishide, H. Hole-transporting diketopyrrolopyrrolethiophene polymers and their additive-free application for a perovskite-type solar cell with an efficiency of 16.3\%. Polym. J. 2019, 51, 91-96. [CrossRef]

27. Schopf, G.; Kossmehl, G. Polythiophenes-Electrically Conductive Polymers; Springer: Berlin/Heidelberg, Germany, $1997 ;$ Volume 129.

28. Yaghoobi Nia, N.; Bonomo, M.; Zendehdel, M.; Lamanna, E.; Desoky, M.M.H.; Paci, B.; Zurlo, F.; Generosi, A.; Barolo, C.; Viscardi, G.; et al. Impact of P3HT Regioregularity and Molecular Weight on the Efficiency and Stability of Perovskite Solar Cells. ACS Sustain. Chem. Eng. 2021, 9, 5061-5073. [CrossRef]

29. De Rossi, F.; Renno, G.; Taheri, B.; Yaghoobi Nia, N.; Ilieva, V.; Fin, A.; Di Carlo, A.; Bonomo, M.; Barolo, C.; Brunetti, F. Modified P3HT materials as hole transport layers for flexible perovskite solar cells. J. Power Sources 2021, 494, 229735. [CrossRef]

30. Sun, X.; Zhao, D.; Li, Z.A. Recent advances in the design of dopant-free hole transporting materials for highly efficient perovskite solar cells. Chin. Chem. Lett. 2018, 29, 219-231. [CrossRef]

31. Liu, D.; Yongsheng, L. Recent progress of dopant-free organic hole-transporting materials in perovskite solar cells. J. Semicond. 2017, 38, 011005.

32. Kojima, A.; Teshima, K.; Shirai, Y.; Miyasaka, T. Organometal halide perovskites as visible-light sensitizers for photovoltaic cells. J. Am. Chem. Soc. 2009, 131, 6050-6051. [CrossRef]

33. Fan, Q.; Biesold-McGee, G.V.; Ma, J.; Xu, Q.; Pan, S.; Peng, J.; Lin, Z. Lead-Free Halide Perovskite Nanocrystals: Crystal Structures, Synthesis, Stabilities, and Optical Properties. Angew. Chem. Int. Ed. 2020, 59, 1030-1046. [CrossRef]

34. Umari, P.; Mosconi, E.; De Angelis, F. Relativistic GW calculations on $\mathrm{CH}_{3} \mathrm{NH}_{3} \mathrm{PbI}_{3}$ and $\mathrm{CH}_{3} \mathrm{NH}_{3} \mathrm{SnI}_{3}$ perovskites for solar cell applications. Sci. Rep. 2014, 4, 4467. [CrossRef]

35. Yusoff, A.R.B.M.; Nazeeruddin, M.K. Organohalide Lead Perovskites for Photovoltaic Applications. J. Phys. Chem. Lett. 2016, 7, 851-866. [CrossRef]

36. Zhu, H.; Zhang, F.; Liu, X.; Sun, M.; Han, J.; You, J.; Wang, S.; Xiao, Y.; Li, X. Dopant-Free Hole-Transport Material with a Tetraphenylethene Core for Efficient Perovskite Solar Cells. Energy Technol. 2017, 5, 1257-1264. [CrossRef]

37. Roy, A.; Ghosh, A.; Bhandari, S.; Sundaram, S.; Mallick, T.K. Perovskite Solar Cells for BIPV Application: A Review. Buildings 2020, 10, 129. [CrossRef]

38. Knutson, J.L.; Martin, J.D.; Mitzi, D.B. Tuning the band gap in hybrid tin iodide perovskite semiconductors using structural templating. Inorg. Chem. 2005, 44, 4699-4705. [CrossRef] [PubMed]

39. Dong, Q.; Fang, Y.; Shao, Y.; Mulligan, P.; Qiu, J.; Cao, L.; Huang, J. Solar cells. Electron-hole diffusion lengths $>175$ mum in solution-grown $\mathrm{CH}_{3} \mathrm{NH}_{3} \mathrm{PbI}_{3}$ single crystals. Science 2015, 347, 967-970. [CrossRef] [PubMed]

40. Stranks, S.D.; Eperon, G.E.; Grancini, G.; Menelaou, C.; Alcocer, M.J.; Leijtens, T.; Herz, L.M.; Petrozza, A.; Snaith, H.J. Electronhole diffusion lengths exceeding 1 micrometer in an organometal trihalide perovskite absorber. Science 2013, 342, 341-344. [CrossRef]

41. Eperon, G.E.; Stranks, S.D.; Menelaou, C.; Johnston, M.B.; Herz, L.M.; Snaith, H.J. Formamidinium lead trihalide: A broadly tunable perovskite for efficient planar heterojunction solar cells. Energy Environ. Sci. 2014, 7, 982. [CrossRef]

42. Xing, G.; Mathews, N.; Sun, S.; Lim, S.S.; Lam, Y.M.; Gratzel, M.; Mhaisalkar, S.; Sum, T.C. Long-range balanced electron- and hole-transport lengths in organic-inorganic $\mathrm{CH}_{3} \mathrm{NH}_{3} \mathrm{PbI}_{3}$. Science 2013, 342, 344-347. [CrossRef]

43. Xue, Y.; Wu, Y.; Li, Y. Readily synthesized dopant-free hole transport materials with phenol core for stabilized mixed perovskite solar cells. J. Power Sources 2017, 344, 160-169. [CrossRef]

44. Saliba, M.; Matsui, T.; Seo, J.Y.; Domanski, K.; Correa-Baena, J.P.; Nazeeruddin, M.K.; Zakeeruddin, S.M.; Tress, W.; Abate, A.; Hagfeldt, A.; et al. Cesium-containing triple cation perovskite solar cells: Improved stability, reproducibility and high efficiency. Energy Environ. Sci. 2016, 9, 1989-1997. [CrossRef]

45. Dong, C.; Wang, Z.-K.; Liao, L.-S. Progress of Triple Cation Organometal Halide Perovskite Solar Cells. Energy Technol. 2020, 8, 1900804. [CrossRef]

46. Djurišić, A.B.; Liu, F.Z.; Tam, H.W.; Wong, M.K.; Ng, A.; Surya, C.; Chen, W.; He, Z.B. Perovskite solar cells-An overview of critical issues. Prog. Quantum Electron. 2017, 53, 1-37. [CrossRef] 
47. Li, G.; Zhang, T.; Zhao, Y. Hydrochloric acid accelerated formation of planar $\mathrm{CH}_{3} \mathrm{NH}_{3} \mathrm{PbI}_{3}$ perovskite with high humidity tolerance. J. Mater. Chem. A 2015, 3, 19674-19678. [CrossRef]

48. Jeon, N.J.; Noh, J.H.; Kim, Y.C.; Yang, W.S.; Ryu, S.; Seok, S.I. Solvent engineering for high-performance inorganic-organic hybrid perovskite solar cells. Nat. Mater. 2014, 13, 897-903. [CrossRef]

49. Ahn, N.; Son, D.Y.; Jang, I.H.; Kang, S.M.; Choi, M.; Park, N.G. Highly Reproducible Perovskite Solar Cells with Average Efficiency of $18.3 \%$ and Best Efficiency of 19.7\% Fabricated via Lewis Base Adduct of Lead(II) Iodide. J. Am. Chem. Soc. 2015, 137, 8696-8699. [CrossRef] [PubMed]

50. Li, T.; Pan, Y.; Wang, Z.; Xia, Y.; Chen, Y.; Huang, W. Additive engineering for highly efficient organic-inorganic halide perovskite solar cells: Recent advances and perspectives. J. Mater. Chem. A 2017, 5, 12602-12652. [CrossRef]

51. Yin, J.; Qu, H.; Cao, J.; Tai, H.; Li, J.; Zheng, N. Vapor-assisted crystallization control toward high performance perovskite photovoltaics with over 18\% efficiency in the ambient atmosphere. J. Mater. Chem. A 2016, 4, 13203-13210. [CrossRef]

52. Leyden, M.R.; Ono, L.K.; Raga, S.R.; Kato, Y.; Wang, S.; Qi, Y. High performance perovskite solar cells by hybrid chemical vapor deposition. J. Mater. Chem. A 2014, 2, 18742-18745. [CrossRef]

53. Schloemer, T.H.; Christians, J.A.; Luther, J.M.; Sellinger, A. Doping strategies for small molecule organic hole-transport materials: Impacts on perovskite solar cell performance and stability. Chem. Sci. 2019, 10, 1904-1935. [CrossRef]

54. Tress, W.; Marinova, N.; Inganas, M.; Nazeeruddin, M.K.; Zakeeruddin, S.M.; Michael, G. The Role of the Hole-Transport Layer in Perovskite Solar Cells-Reducing Recombination and Increasing Absorption. In Proceedings of the 2014 IEEE 40th Photovoltaic Specialist Conference (PVSC), Denver, CO, USA, 8-13 June 2014; pp. 1563-1566.

55. Berry, J.; Buonassisi, T.; Egger, D.A.; Hodes, G.; Kronik, L.; Loo, Y.L.; Lubomirsky, I.; Marder, S.R.; Mastai, Y.; Miller, J.S.; et al. Hybrid Organic-Inorganic Perovskites (HOIPs): Opportunities and Challenges. Adv. Mater. 2015, 27, 5102-5112. [CrossRef]

56. Jung, H.S.; Han, G.S.; Park, N.-G.; Ko, M.J. Flexible Perovskite Solar Cells. Joule 2019, 3, 1850-1880. [CrossRef]

57. Liu, Z.; Zhu, A.; Cai, F.; Tao, L.; Zhou, Y.; Zhao, Z.; Chen, Q.; Cheng, Y.-B.; Zhou, H. Nickel oxide nanoparticles for efficient hole transport in p-i-n and n-i-p perovskite solar cells. J. Mater. Chem. A 2017, 5, 6597-6605. [CrossRef]

58. Momblona, C.; Gil-Escrig, L.; Bandiello, E.; Hutter, E.M.; Sessolo, M.; Lederer, K.; Blochwitz-Nimoth, J.; Bolink, H.J. Efficient vacuum deposited $\mathrm{p}-\mathrm{i}-\mathrm{n}$ and $\mathrm{n}-\mathrm{i}-\mathrm{p}$ perovskite solar cells employing doped charge transport layers. Energy Environ. Sci. 2016, 9, 3456-3463. [CrossRef]

59. Li, M.-H.; Shen, P.-S.; Wang, K.-C.; Guo, T.-F.; Chen, P. Inorganic p-type contact materials for perovskite-based solar cells. J. Mater. Chem. A 2015, 3, 9011-9019. [CrossRef]

60. Cetin, C.; Chen, P.; Hao, M.; He, D.; Bai, Y.; Lyu, M.; Yun, J.-H.; Wang, L. Inorganic p-Type Semiconductors as Hole Conductor Building Blocks for Robust Perovskite Solar Cells. Adv. Sustain. Syst. 2018, 2, 1800032. [CrossRef]

61. MacDiarmid, A.G. "Synthetic metals": A novel role for organic polymers (Nobel Lecture). Angew. Chem. Int. Ed. 2001, 40, 2581-2590. [CrossRef]

62. Heeger, A.J. Semiconducting and metallic polymers: The fourth generation of polymeric materials. Synth. Met. 2001, 125, 23-42. [CrossRef]

63. Fu, K.; Wing Yi Ho-Baillie, A.; Kumar Mulmudi, H.; Trang, P.T.T. Perovskite Solar Cells: Technology and Practices; Apple Academic Press: Boca Raton, FL, USA, 2019; p. 332.

64. Schloemer, T.H.; Gehan, T.S.; Christians, J.A.; Mitchell, D.G.; Dixon, A.; Li, Z.; Zhu, K.; Berry, J.J.; Luther, J.M.; Sellinger, A. Thermally Stable Perovskite Solar Cells by Systematic Molecular Design of the Hole-Transport Layer. ACS Energy Lett. 2019, 4, 473-482. [CrossRef]

65. Tsai, C.-E.; Liao, M.-H.; Chen, Y.-L.; Cheng, S.-W.; Lai, Y.-Y.; Cheng, Y.-J.; Hsu, C.-S. Triarylamine-based crosslinked holetransporting material with an ionic dopant for high-performance PEDOT:PSS-free polymer solar cells. J. Mater. Chem. C 2015, 3, 6158-6165. [CrossRef]

66. Habisreutinger, S.N.; Noel, N.K.; Snaith, H.J.; Nicholas, R.J. Investigating the Role of 4-TertButylpyridine in Perovskite Solar Cells. Adv. Energy Mater. 2017, 7, 1601079. [CrossRef]

67. Yang, J.; Siempelkamp, B.D.; Liu, D.; Kelly, T.L. Investigation of $\mathrm{CH}_{3} \mathrm{NH}_{3} \mathrm{PbI}_{3}$ degradation rates and mechanisms in controlled humidity environments using in situ techniques. ACS Nano 2015, 9, 1955-1963. [CrossRef]

68. Li, Z.; Xiao, C.; Yang, Y.; Harvey, S.P.; Kim, D.H.; Christians, J.A.; Yang, M.; Schulz, P.; Nanayakkara, S.U.; Jiang, C.-S.; et al. Extrinsic ion migration in perovskite solar cells. Energy Environ. Sci. 2017, 10, 1234-1242. [CrossRef]

69. Yue, Y.; Salim, N.; Wu, Y.; Yang, X.; Islam, A.; Chen, W.; Liu, J.; Bi, E.; Xie, F.; Cai, M.; et al. Enhanced Stability of Perovskite Solar Cells through Corrosion-Free Pyridine Derivatives in Hole-Transporting Materials. Adv. Mater. 2016, 28, 10738-10743. [CrossRef] [PubMed]

70. Snaith, H.J.; Grätzel, M. Electron and Hole Transport through Mesoporous $\mathrm{TiO}_{2}$ Infiltrated with Spiro-MeOTAD. Adv. Mater. 2007, 19, 3643-3647. [CrossRef]

71. Liu, J.; Wu, Y.; Qin, C.; Yang, X.; Yasuda, T.; Islam, A.; Zhang, K.; Peng, W.; Chen, W.; Han, L. A dopant-free hole-transporting material for efficient and stable perovskite solar cells. Energy Environ. Sci. 2014, 7, 2963-2967. [CrossRef]

72. Liu, Y.; Chen, Q.; Duan, H.-S.; Zhou, H.; Yang, Y.; Chen, H.; Luo, S.; Song, T.-B.; Dou, L.; Hong, Z.; et al. A dopant-free organic hole transport material for efficient planar heterojunction perovskite solar cells. J. Mater. Chem. A 2015, 3, 11940-11947. [CrossRef] 
73. Wang, Y.; Chen, W.; Wang, L.; Tu, B.; Chen, T.; Liu, B.; Yang, K.; Koh, C.W.; Zhang, X.; Sun, H.; et al. Dopant-Free Small-Molecule Hole-Transporting Material for Inverted Perovskite Solar Cells with Efficiency Exceeding 21. Adv. Mater. 2019, 31 , e1902781. [CrossRef]

74. Hou, W.; Xiao, Y.; Han, G.; Lin, J.Y. The Applications of Polymers in Solar Cells: A Review. Polymers 2019, 11, 143. [CrossRef]

75. Kimpel, J.; Michinobu, T. Conjugated polymers for functional applications: Lifetime and performance of polymeric organic semiconductors in organic field-effect transistors. Polym. Int. 2020, 70, 367-373. [CrossRef]

76. Alsalhi, M.S.; Alam, J.; Dass, L.A.; Raja, M. Recent advances in conjugated polymers for light emitting devices. Int. J. Mol. Sci 2011, 12, 2036-2054. [CrossRef]

77. Cai, B.; Xing, Y.; Yang, Z.; Zhang, W.-H.; Qiu, J. High performance hybrid solar cells sensitized by organolead halide perovskites. Energy Environ. Sci. 2013, 6, 1480-1485. [CrossRef]

78. Heo, J.H.; Han, H.J.; Kim, D.; Ahn, T.K.; Im, S.H. Hysteresis-less inverted $\mathrm{CH}_{3} \mathrm{NH}_{3} \mathrm{PbI}_{3}$ planar perovskite hybrid solar cells with 18.1\% power conversion efficiency. Energy Environ. Sci. 2015, 8, 1602-1608. [CrossRef]

79. Jung, E.H.; Jeon, N.J.; Park, E.Y.; Moon, C.S.; Shin, T.J.; Yang, T.Y.; Noh, J.H.; Seo, J. Efficient, stable and scalable perovskite solar cells using poly(3-hexylthiophene). Nature 2019, 567, 511-515. [CrossRef]

80. Tepliakova, M.M.; Akkuratov, A.V.; Tsarev, S.A.; Troshin, P.A. Suzuki polycondensation for the synthesis of polytriarylamines: A method to improve hole-transport material performance in perovskite solar cells. Tetrahedron Lett. 2020, 61, 152317. [CrossRef]

81. Kim, Y.; Kim, G.; Jeon, N.J.; Lim, C.; Seo, J.; Kim, B.J. Methoxy-Functionalized Triarylamine-Based Hole-Transporting Polymers for Highly Efficient and Stable Perovskite Solar Cells. ACS Energy Lett. 2020, 5, 3304-3313. [CrossRef]

82. Lu, H.; Ma, Y.; Gu, B.; Tian, W.; Li, L. Identifying the optimum thickness of electron transport layers for highly efficient perovskite planar solar cells. J. Mater. Chem. A 2015, 3, 16445-16452. [CrossRef]

83. Li, M.-H.; Liu, S.-C.; Qiu, F.-Z.; Zhang, Z.-Y.; Xue, D.-J.; Hu, J.-S. High-Efficiency CsPbI ${ }_{2}$ Br Perovskite Solar Cells with Dopant-Free Poly(3-hexylthiophene) Hole Transporting Layers. Adv. Energy Mater. 2020, 10, 2000501. [CrossRef]

84. Zhang, W.; Wan, L.; Li, X.; Wu, Y.; Fu, S.; Fang, J. A dopant-free polyelectrolyte hole-transport layer for high efficiency and stable planar perovskite solar cells. J. Mater. Chem. A 2019, 7, 18898-18905. [CrossRef]

85. Zhang, W.; Wan, L.; Fu, S.; Li, X.; Fang, J. Reducing energy loss and stabilizing the perovskite/poly(3-hexylthiophene) interface through a polyelectrolyte interlayer. J. Mater. Chem. A 2020, 8, 6546-6554. [CrossRef]

86. Huan, Y.; Tan, C.; Wu, B.; Feng, X.; Xu, W.; Gao, D. A Dopant-Free Zwitterionic Conjugated Polyelectrolyte as a Hole-Transporting and Interfacial Material for Perovskite Solar Cells. Sol. RRL 2020, 4, 2000206. [CrossRef]

87. Han, S.; Jiang, X.; Yu, Z.; Wan, X.; Zang, J.; Zhang, C.; Rui, H.; Yang, X.; Hagfeldt, A.; Sun, L. Side-chain engineering of PEDOT derivatives as dopant-free hole-transporting materials for efficient and stable n-i-p structured perovskite solar cells. J. Mater. Chem. C 2020, 8, 9236-9242. [CrossRef]

88. Xiao, Y.; Han, G.; Chang, Y.; Zhou, H.; Li, M.; Li, Y. An all-solid-state perovskite-sensitized solar cell based on the dual function polyaniline as the sensitizer and p-type hole-transporting material. J. Power Sources 2014, 267, 1-8. [CrossRef]

89. Yan, W.; Li, Y.; Li, Y.; Ye, S.; Liu, Z.; Wang, S.; Bian, Z.; Huang, C. High-performance hybrid perovskite solar cells with open circuit voltage dependence on hole-transporting materials. Nano Energy 2015, 16, 428-437. [CrossRef]

90. Xu, Y.; Bu, T.; Li, M.; Qin, T.; Yin, C.; Wang, N.; Li, R.; Zhong, J.; Li, H.; Peng, Y.; et al. Non-Conjugated Polymer as an Efficient Dopant-Free Hole-Transporting Material for Perovskite Solar Cells. ChemSusChem 2017, 10, 2578-2584. [CrossRef] [PubMed]

91. Gu, J.; Ji, R.; Xu, W.; Yin, C.; Wen, K.; Gao, H.; Yang, R.; Pan, Z.; Wang, K.; Zhang, C.; et al. Non-Conjugated Polymer Based on Polyethylene Backbone as Dopant-Free Hole-Transporting Material for Efficient and Stable Inverted Quasi-2D Perovskite Solar Cells. Sol. RRL 2020, 4, 2000184. [CrossRef]

92. Wu, J.; Liu, C.; Li, B.; Gu, F.; Zhang, L.; Hu, M.; Deng, X.; Qiao, Y.; Mao, Y.; Tan, W.; et al. Side-Chain Polymers as Dopant-Free Hole-Transporting Materials for Perovskite Solar Cells-The Impact of Substituents' Positions in Carbazole on Device Performance. ACS Appl. Mater. Interfaces 2019, 11, 26928-26937. [CrossRef]

93. Lan, L.; Deng, X.; Zhang, J.; Luo, J.; Jen, A.K.Y. Synthesis of a side-chain hole transporting polymer through Mitsunobu post-functionalization for efficient inverted perovskite solar cells. Polym. Chem. 2020, 11, 2883-2888. [CrossRef]

94. Tremblay, M.-H.; Schutt, K.; Zhang, Y.; Lim, J.; Lin, Y.-H.; Warby, J.H.; Barlow, S.; Snaith, H.J.; Marder, S.R. A photo-crosslinkable bis-triarylamine side-chain polymer as a hole-transport material for stable perovskite solar cells. Sustain. Energy Fuels 2020, 4, 190-198. [CrossRef]

95. Zhang, Y.; Kou, C.; Zhang, J.; Liu, Y.; Li, W.; Bo, Z.; Shao, M. Crosslinked- and dopant-free hole transport materials for efficient and stable planar perovskite solar cells. J. Mater. Chem. A 2019, 7, 5522-5529. [CrossRef]

96. Vaitukaityte, D.; Al-Ashouri, A.; Daskeviciene, M.; Kamarauskas, E.; Nekrasovas, J.; Jankauskas, V.; Magomedov, A.; Albrecht, S.; Getautis, V. Enamine-Based CrossLinkable Hole-Transporting Materials for Perovskite Solar Cells. Sol. RRL 2021, 5, 2000597. [CrossRef]

97. Wu, J.; Liu, C.; Hu, M.; Deng, X.; Tan, W.; Tian, Y.; Xu, B. Polystyrene with a methoxytriphenylamine-conjugated-thiophene moiety side-chain as a dopant-free hole-transporting material for perovskite solar cells. J. Mater. Chem. A 2018, 6, 13123-13132. [CrossRef]

98. Ruankham, P.; Sagawa, T. Dopant-free $\pi$-conjugated polymers as hole-transporting materials for stable perovskite solar cells. J. Mater. Sci.: Mater. Electron. 2018, 29, 9058-9066. [CrossRef] 
99. Lin, Q.; Armin, A.; Nagiri, R.C.R.; Burn, P.L.; Meredith, P. Electro-optics of perovskite solar cells. Nat. Photonics 2014, 9, 106. [CrossRef]

100. Guo, X.; Zhang, B.; Lin, Z.; Su, J.; Yang, Z.; Zhang, C.; Chang, J.; Liu, S.; Hao, Y. Highly efficient perovskite solar cells based on a dopant-free conjugated DPP polymer hole transport layer: Influence of solvent vapor annealing. Sustain. Energy Fuels 2018, 2, 2154-2159. [CrossRef]

101. Dubey, A.; Adhikari, N.; Venkatesan, S.; Gu, S.; Khatiwada, D.; Wang, Q.; Mohammad, L.; Kumar, M.; Qiao, Q. Solution processed pristine PDPP3T polymer as hole transport layer for efficient perovskite solar cells with slower degradation. Sol. Energy Mater. Sol. Cells 2016, 145, 193-199. [CrossRef]

102. Kwon, Y.S.; Lim, J.; Yun, H.-J.; Kim, Y.-H.; Park, T. A diketopyrrolopyrrole-containing hole transporting conjugated polymer for use in efficient stable organic-inorganic hybrid solar cells based on a perovskite. Energy Environ. Sci. 2014, 7, 1454-1460. [CrossRef]

103. Kang, I.; An, T.K.; Hong, J.-A.; Yun, H.-J.; Kim, R.; Chung, D.S.; Park, C.E.; Kim, Y.-H.; Kwon, S.-K. Effect of Selenophene in a DPP Copolymer Incorporating a Vinyl Group for High-Performance Organic Field-Effect Transistors. Adv. Mater. 2013, 25, 524-528. [CrossRef]

104. Liu, J.; Ge, Q.Q.; Zhang, W.F.; Ma, J.Y.; Ding, J.; Yu, G.; Hu, J.S. Highly pi-extended copolymer as additive-free hole-transport material for perovskite solar cells. Nano Res. 2018, 11, 185-194. [CrossRef]

105. Kulshreshtha, C.; Clement, A.; Pascher, T.; Sundstroem, V.; Matyba, P. Investigating ultrafast carrier dynamics in perovskite solar cells with an extended $\pi$-conjugated polymeric diketopyrrolopyrrole layer for hole transportation. RSC Adv. 2020, 10, 6618-6624. [CrossRef]

106. Liu, W.; Ma, Y.; Wang, Z.; Zhu, M.; Wang, J.; Khalil, M.; Wang, H.; Gao, W.; Fan, W.J.; Li, W.-S.; et al. Improving the Fill Factor of Perovskite Solar Cells by Employing an Amine-tethered Diketopyrrolopyrrole-Based Polymer as the Dopant-free Hole Transport Layer. ACS Appl. Energy Mater. 2020, 3, 9600-9609. [CrossRef]

107. Liu, W.; Ma, Y.; Wang, Z.; Mu, Z.; Gao, W.; Fan, W.; Li, W.-S.; Zhang, Q. Improving the hole transport performance of perovskite solar cells through adjusting the mobility of the as-synthesized conjugated polymer. J. Mater. Chem. C 2021, 9, 3421-3428. [CrossRef]

108. Fu, Q.; Xu, Z.; Tang, X.; Liu, T.; Dong, X.; Zhang, X.; Zheng, N.; Xie, Z.; Liu, Y. Multifunctional Two-Dimensional Conjugated Materials for Dopant-Free Perovskite Solar Cells with Efficiency Exceeding 22\%. ACS Energy Lett. 2021, 6, 1521-1532. [CrossRef]

109. Beimling, P.; Kobmehl, G. Synthesis of benzo[1,2-b:4,5-b']dithiophene and its 4,8-dimethoxy and 4,8-dimethyl derivatives. Chem. Ber. 1986, 119, 3198-3203. [CrossRef]

110. Pan, H.; Li, Y.; Wu, Y.; Liu, P.; Ong, B.S.; Zhu, S.; Xu, G. Low-temperature, solution-processed, high-mobility polymer semiconductors for thin-film transistors. J. Am. Chem. Soc. 2007, 129, 4112-4113. [CrossRef] [PubMed]

111. Zhang, Y.; Hau, S.K.; Yip, H.-L.; Sun, Y.; Acton, O.; Jen, A.K.Y. Efficient Polymer Solar Cells Based on the Copolymers of Benzodithiophene and Thienopyrroledione. Chem. Mater. 2010, 22, 2696-2698. [CrossRef]

112. Chen, L.; Shen, X.; Chen, Y. A Novel Thiophene Derivative-based Conjugated Polymer for Polymer Solar Cells with High Open-circuit Voltage. Chin. J. Chem. 2012, 30, 2219-2224. [CrossRef]

113. Busireddy, M.R.; Mantena, V.N.R.; Chereddy, N.R.; Shanigaram, B.; Kotamarthi, B.; Biswas, S.; Sharma, G.D.; Vaidya, J.R. Dithienopyrrole-benzodithiophene based donor materials for small molecular BHJSCs: Impact of side chain and annealing treatment on their photovoltaic properties. Org. Electron. 2016, 37, 312-325. [CrossRef]

114. Zhou, J.; Zuo, Y.; Wan, X.; Long, G.; Zhang, Q.; Ni, W.; Liu, Y.; Li, Z.; He, G.; Li, C.; et al. Solution-processed and high-performance organic solar cells using small molecules with a benzodithiophene unit. J. Am. Chem. Soc. 2013, 135, 8484-8487. [CrossRef]

115. Kim, G.W.; Lee, J.; Kang, G.; Kim, T.; Park, T. Donor-Acceptor Type Dopant-Free, Polymeric Hole Transport Material for Planar Perovskite Solar Cells (19.8\%). Adv. Energy Mater. 2018, 8, 1701935. [CrossRef]

116. Lee, J.; Kim, G.-W.; Kim, M.; Park, S.A.; Park, T. Nonaromatic Green-Solvent-Processable, Dopant-Free, and Lead-Capturable Hole Transport Polymers in Perovskite Solar Cells with High Efficiency. Adv. Energy Mater. 2020, 10, 1902662. [CrossRef]

117. Marin-Beloqui, J.M.; Hernández, J.P.; Palomares, E. Photo-induced charge recombination kinetics in $\mathrm{MAPbI}_{3-\mathrm{x}} \mathrm{Cl}_{\mathrm{x}}$ perovskite-like solar cells using low band-gap polymers as hole conductors. Chem. Commun. 2014, 50, 14566-14569. [CrossRef]

118. Kim, J.; Kim, G.; Kim, T.K.; Kwon, S.; Back, H.; Lee, J.; Lee, S.H.; Kang, H.; Lee, K. Efficient planar-heterojunction perovskite solar cells achieved via interfacial modification of a sol-gel ZnO electron collection layer. J. Mater. Chem. A 2014, 2, 17291-17296. [CrossRef]

119. Jiang, X.; Liu, X.; Zhang, J.; Ahmad, S.; Tu, D.; Qin, W.; Jiu, T.; Pang, S.; Guo, X.; Li, C. Simultaneous hole transport and defect passivation enabled by a dopant-free single polymer for efficient and stable perovskite solar cells. J. Mater. Chem. A 2020, 8, 21036-21043. [CrossRef]

120. Liu, X.; Fu, P.; Tu, D.; Yang, Q.; Yu, S.; Guo, X.; Li, C. Bifunctional donor polymers bearing amino pendant groups for efficient cathode interlayer-free polymer solar cells. J. Mater. Chem. A 2018, 6, 19828-19833. [CrossRef]

121. Murugesan, V.S.; Michael, R.R.; Jena, A.K.; Kang, J.-W.; Kim, N.H.; Segawa, H.; Miyasaka, T.; Lee, J.H. Benzodithiophenethienopyrroledione-thienothiophene-based random copolymeric hole transporting material for perovskite solar cell. Chem. Eng. J. 2020, 382, 122830. [CrossRef]

122. Yuan, J.; Ling, X.; Yang, D.; Li, F.; Zhou, S.; Shi, J.; Qian, Y.; Hu, J.; Sun, Y.; Yang, Y.; et al. Band-Aligned Polymeric Hole Transport Materials for Extremely Low Energy Loss $\alpha-\mathrm{CsPbI}_{3}$ Perovskite Nanocrystal Solar Cells. Joule 2018, 2, 2450-2463. [CrossRef] 
123. Lee, J.-W.; Park, S.; Ko, M.J.; Son, H.J.; Park, N.-G. Enhancement of the Photovoltaic Performance of $\mathrm{CH}_{3} \mathrm{NH}_{3} \mathrm{PbI}_{3} \mathrm{Perovskite} \mathrm{Solar}$ Cells through a Dichlorobenzene-Functionalized Hole-Transporting Material. ChemPhysChem 2014, 15, 2595-2603. [CrossRef]

124. Chen, W.; Bao, X.; Zhu, Q.; Zhu, D.; Qiu, M.; Sun, M.; Yang, R. Simple planar perovskite solar cells with a dopant-free benzodithiophene conjugated polymer as hole transporting material. J. Mater. Chem. C 2015, 3, 10070-10073. [CrossRef]

125. Nagarjuna, P.; Narayanaswamy, K.; Swetha, T.; Rao, G.H.; Singh, S.P.; Sharma, G.D. $\mathrm{CH}_{3} \mathrm{NH}_{3} \mathrm{PbI}_{3}$ Perovskite Sensitized Solar Cells Using a D-A Copolymer as Hole Transport Material. Electrochim. Acta 2015, 151, 21-26. [CrossRef]

126. Kim, G.-W.; Kang, G.; Kim, J.; Lee, G.-Y.; Kim, H.I.; Pyeon, L.; Lee, J.; Park, T. Dopant-free polymeric hole transport materials for highly efficient and stable perovskite solar cells. Energy Environ. Sci. 2016, 9, 2326-2333. [CrossRef]

127. Kranthiraja, K.; Gunasekar, K.; Kim, H.; Cho, A.-N.; Park, N.-G.; Kim, S.; Kim, B.J.; Nishikubo, R.; Saeki, A.; Song, M.; et al. High-Performance Long-Term-Stable Dopant-Free Perovskite Solar Cells and Additive-Free Organic Solar Cells by Employing Newly Designed Multirole $\pi$-Conjugated Polymers. Adv. Mater. 2017, 29, 1700183. [CrossRef]

128. Lee, J.; Malekshahi Byranvand, M.; Kang, G.; Son, S.Y.; Song, S.; Kim, G.-W.; Park, T. Green-Solvent-Processable, Dopant-Free Hole-Transporting Materials for Robust and Efficient Perovskite Solar Cells. J. Am. Chem. Soc. 2017, 139, 12175-12181. [CrossRef]

129. Liao, H.-C.; Tam, T.L.D.; Guo, P.; Wu, Y.; Manley, E.F.; Huang, W.; Zhou, N.; Soe, C.M.M.; Wang, B.; Wasielewski, M.R.; et al. Dopant-Free Hole Transporting Polymers for High Efficiency, Environmentally Stable Perovskite Solar Cells. Adv. Energy Mater. 2016, 6, 1600502. [CrossRef]

130. Kranthiraja, K.; Park, S.H.; Kim, H.; Gunasekar, K.; Han, G.; Kim, B.J.; Kim, C.S.; Kim, S.; Lee, H.; Nishikubo, R.; et al. Accomplishment of Multifunctional $\pi$-Conjugated Polymers by Regulating the Degree of Side-Chain Fluorination for Efficient Dopant-Free Ambient-Stable Perovskite Solar Cells and Organic Solar Cells. ACS Appl. Mater. Interfaces 2017, 9, 36053-36060. [CrossRef]

131. Kranthiraja, K.; Arivunithi, V.M.; Aryal, U.K.; Park, H.-Y.; Cho, W.; Kim, J.; Reddy, S.S.; Kim, H.-K.; Kang, I.-N.; Song, M.; et al. Efficient and hysteresis-less perovskite and organic solar cells by employing donor-acceptor type $\pi$-conjugated polymer. Org. Electron. 2019, 72, 18-24. [CrossRef]

132. Kyeong, M.; Lee, J.; Lee, K.; Hong, S. BODIPY-based conjugated polymers for use as dopant-free hole transporting materials for durable perovskite solar cells: Selective tuning of HOMO/LUMO levels. ACS Appl. Mater. Interfaces 2018, 10, $23254-23262$. [CrossRef]

133. Rana, P.J.S.; Gunasekaran, R.K.; Park, S.H.; Tamilavan, V.; Karuppanan, S.; Kim, H.-J.; Prabakar, K. Open Atmosphere-Processed Stable Perovskite Solar Cells Using Molecular Engineered, Dopant-Free, Highly Hydrophobic Polymeric Hole-Transporting Materials: Influence of Thiophene and Alkyl Chain on Power Conversion Efficiency. J. Phys. Chem. C 2019, 123, 8560-8568. [CrossRef]

134. Qi, F.; Deng, X.; Wu, X.; Huo, L.; Xiao, Y.; Lu, X.; Zhu, Z.; Jen, A.K.Y. A Dopant-Free Polymeric Hole-Transporting Material Enabled High Fill Factor Over 81\% for Highly Efficient Perovskite Solar Cells. Adv. Energy Mater. 2019, 9, 1902600. [CrossRef]

135. Wang, P.; Wang, H.; Jeong, M.; Lee, S.M.; Du, B.; Mao, Y.; Ye, F.; Zhang, H.; Li, D.; Liu, D.; et al. Dopant-free polymeric hole transport materials for efficient $\mathrm{CsPbI}_{2} \mathrm{Br}$ perovskite cells with a fill factor exceeding 84\%. J. Mater. Chem. C 2020, 8, $8507-8514$. [CrossRef]

136. Zhang, F.; Yao, Z.; Guo, Y.; Li, Y.; Bergstrand, J.; Brett, C.J.; Cai, B.; Hajian, A.; Guo, Y.; Yang, X.; et al. Polymeric, Cost-Effective, Dopant-Free Hole Transport Materials for Efficient and Stable Perovskite Solar Cells. J. Am. Chem. Soc. 2019, 141, 19700-19707. [CrossRef] [PubMed]

137. Zhang, L.; Wu, J.; Li, D.; Li, W.; Meng, Q.; Bo, Z. Ladder-like conjugated polymers used as hole-transporting materials for high-efficiency perovskite solar cells. J. Mater. Chem. A 2019, 7, 14473-14477. [CrossRef]

138. Kong, X.; Jiang, Y.; Wu, X.; Chen, C.; Guo, J.; Liu, S.; Gao, X.; Zhou, G.; Liu, J.-M.; Kempa, K.; et al. Dopant-free F-substituted benzodithiophene copolymer hole-transporting materials for efficient and stable perovskite solar cells. J. Mater. Chem. A 2020, 8, 1858-1864. [CrossRef]

139. Firdaus, Y.; Maffei, L.P.; Cruciani, F.; Müller, M.A.; Liu, S.; Lopatin, S.; Wehbe, N.; Ndjawa, G.O.N.; Amassian, A.; Laquai, F.; et al. Polymer Main-Chain Substitution Effects on the Efficiency of Nonfullerene BHJ Solar Cells. Adv. Energy Mater. 2017, 7, 1700834. [CrossRef]

140. Kappe, C.O.; Pieber, B.; Dallinger, D. Microwave effects in organic synthesis: Myth or reality? Angew. Chem. Int. Ed. Engl. 2013, 52, 1088-1094. [CrossRef] [PubMed]

141. Nagahata, R.; Takeuchi, K. Encouragements for the Use of Microwaves in Industrial Chemistry. Chem. Rec. 2018, 19, 51-64. [CrossRef] [PubMed]

142. Kim, G.W.; Choi, H.; Kim, M.; Lee, J.; Son, S.Y.; Park, T. Hole Transport Materials in Conventional Structural (n-i-p) Perovskite Solar Cells: From Past to the Future. Adv. Energy Mater. 2020, 10, 1903403. [CrossRef]

143. Liu, Y.; Hong, Z.; Chen, Q.; Chen, H.; Chang, W.-H.; Yang, Y.; Song, T.-B.; Yang, Y. Perovskite Solar Cells Employing Dopant-Free Organic Hole Transport Materials with Tunable Energy Levels. Adv. Mater. 2016, 28, 440-446. [CrossRef]

144. Zhao, D.; Zhu, Z.; Kuo, M.Y.; Chueh, C.C.; Jen, A.K. Hexaazatrinaphthylene Derivatives: Efficient Electron-Transporting Materials with Tunable Energy Levels for Inverted Perovskite Solar Cells. Angew. Chem. Int. Ed. Engl. 2016, 55, 8999-9003. [CrossRef]

145. Song, Y.; Lv, S.; Liu, X.; Li, X.; Wang, S.; Wei, H.; Li, D.; Xiao, Y.; Meng, Q. Energy level tuning of TPB-based hole-transporting materials for highly efficient perovskite solar cells. Chem. Commun. 2014, 50, 15239-15242. [CrossRef] 
146. Li, M.; Wang, Z.; Liang, M.; Liu, L.; Wang, X.; Sun, Z.; Xue, S. Low-Cost Carbazole-Based Hole-Transporting Materials for Perovskite Solar Cells: Influence of S,N-Heterocycle. J. Phys. Chem. C 2018, 122, 24014-24024. [CrossRef]

147. Gao, L.; Schloemer, T.H.; Zhang, F.; Chen, X.; Xiao, C.; Zhu, K.; Sellinger, A. Carbazole-Based Hole-Transport Materials for High-Efficiency and Stable Perovskite Solar Cells. ACS Appl. Energy Mater. 2020, 3, 4492-4498. [CrossRef]

148. Wu, F.; Ji, Y.; Wang, R.; Shan, Y.; Zhu, L. Molecular engineering to enhance perovskite solar cell performance: Incorporation of benzothiadiazole as core unit for low cost hole transport materials. Dyes Pigm. 2017, 143, 356-360. [CrossRef]

149. Rodriguez-Seco, C.; Mendez, M.; Roldan-Carmona, C.; Cabau, L.; Asiri, A.M.; Nazeeruddin, M.K.; Palomares, E. Benzothiadiazole Aryl-amine Based Materials as Efficient Hole Carriers in Perovskite Solar Cells. ACS Appl. Mater. Interfaces 2020, 12, 32712-32718. [CrossRef]

150. Cai, F.; Cai, J.; Yang, L.; Li, W.; Gurney, R.S.; Yi, H.; Iraqi, A.; Liu, D.; Wang, T. Molecular engineering of conjugated polymers for efficient hole transport and defect passivation in perovskite solar cells. Nano Energy 2018, 45, 28-36. [CrossRef]

151. Wong-Stringer, M.; Bishop, J.E.; Smith, J.A.; Mohamad, D.K.; Parnell, A.J.; Kumar, V.; Rodenburg, C.; Lidzey, D.G. Efficient perovskite photovoltaic devices using chemically doped PCDTBT as a hole-transport material. J. Mater. Chem. A 2017, 5, 15714-15723. [CrossRef]

152. Liu, P.-H.; Chuang, C.-H.; Zhou, Y.-L.; Wang, S.-H.; Jeng, R.-J.; Rwei, S.-P.; Liau, W.-B.; Wang, L. Conjugated polyelectrolytes as promising hole transport materials for inverted perovskite solar cells: Effect of ionic groups. J. Mater. Chem. A 2020, 8, 25173-25177. [CrossRef]

153. Kim, G.-W.; Kim, J.; Lee, G.-Y.; Kang, G.; Lee, J.; Park, T. A Strategy to Design a Donor- $\pi$-Acceptor Polymeric Hole Conductor for an Efficient Perovskite Solar Cell. Adv. Energy Mater. 2015, 5, 1500471. [CrossRef]

154. Mahesh, K.; Karpagam, S.; Putnin, T.; Le, H.; Bui, T.-T.; Ounnunkad, K.; Goubard, F. Role of cyano substituents on thiophene vinylene benzothiadiazole conjugated polymers and application as hole transporting materials in perovskite solar cells. J. Photochem. Photobiol. A 2019, 371, 238-247. [CrossRef]

155. Zhang, Z.; Sheri, M.; Page, Z.A.; Emrick, T.; Saeki, A.; Liu, Y.; Russell, T.P. Understanding Hole Extraction of Inverted Perovskite Solar Cells. ACS Appl. Mater. Interfaces 2020, 12, 56068-56075. [CrossRef]

156. Tavakoli, M.M.; Po, R.; Bianchi, G.; Carbonera, C.; Kong, J. Efficient and Stable Mesoscopic Perovskite Solar Cells Using a Dopant-Free D-A Copolymer Hole-Transporting Layer. Sol. RRL 2021, 5, 2000801. [CrossRef]

157. Ma, H.; Yuan, L.; Chen, Q.; Fu, J.; Zhang, J.; Jiang, Z.; Dong, B.; Zhou, Y.; Yin, S.; Song, B. Conjugated copolymers as dopingand annealing-free hole transport materials for highly stable and efficient p-i-n perovskite solar cells. J. Mater. Chem. A 2021, 9, 2269-2275. [CrossRef]

158. Xie, Y.; Wang, X.; Chen, Q.; Liu, S.; Yun, Y.; Liu, Y.; Chen, C.; Wang, J.; Cao, Y.; Wang, F.; et al. Dopant-Free Hole-Transporting Polycarbazoles with Tailored Backbones for Efficient Inverted Perovskite Solar Cells. Macromolecules 2019, 52, $4757-4764$. [CrossRef]

159. Yao, Z.; Zhang, F.; Guo, Y.; Wu, H.; He, L.; Liu, Z.; Cai, B.; Guo, Y.; Brett, C.J.; Li, Y.; et al. Conformational and compositional tuning of phenanthrocarbazole-based dopant-free hole-transport polymers boosting performance of perovskite solar cells. J. Am. Chem. Soc. 2020, 142, 17681-17692. [CrossRef] [PubMed]

160. Zhang, Z.; Liang, L.; Deng, L.; Ren, L.; Zhao, N.; Huang, J.; Yu, Y.; Gao, P. Fused Dithienopicenocarbazole Enabling High Mobility Dopant-Free Hole-Transporting Polymers for Efficient and Stable Perovskite Solar Cells. ACS Appl. Mater. Interfaces 2021, 13, 6688-6698. [CrossRef] [PubMed]

161. Tiwari, S.; Greenham, N.C. Charge mobility measurement techniques in organic semiconductors. Opt. Quantum Electron. 2009, 41, 69-89. [CrossRef]

162. Ryu, S.; Noh, J.H.; Jeon, N.J.; Chan Kim, Y.; Yang, W.S.; Seo, J.; Seok, S.I. Voltage output of efficient perovskite solar cells with high open-circuit voltage and fill factor. Energy Environ. Sci. 2014, 7, 2614-2618. [CrossRef]

163. Xiao, Q.; Tian, J.; Xue, Q.; Wang, J.; Xiong, B.; Han, M.; Li, Z.; Zhu, Z.; Yip, H.-L.; Li, Z.A. Dopant-Free Squaraine-Based Polymeric Hole-Transporting Materials with Comprehensive Passivation Effects for Efficient All-Inorganic Perovskite Solar Cells. Angew. Chem. Int. Ed. 2019, 58, 17724-17730. [CrossRef]

164. Wang, Y.; Zhang, T.; Kan, M.; Zhao, Y. Bifunctional Stabilization of All-Inorganic $\alpha-\mathrm{CsPbI}_{3}$ Perovskite for $17 \%$ Efficiency Photovoltaics. J. Am. Chem. Soc. 2018, 140, 12345-12348. [CrossRef]

165. You, G.; Zhuang, Q.; Wang, L.; Lin, X.; Zou, D.; Lin, Z.; Zhen, H.; Zhuang, W.; Ling, Q. Dopant-Free, Donor-Acceptor-Type Polymeric Hole-Transporting Materials for the Perovskite Solar Cells with Power Conversion Efficiencies over 20\%. Adv. Energy Mater. 2020, 10, 1903146. [CrossRef]

166. Chawanpunyawat, T.; Funchien, P.; Wongkaew, P.; Henjongchom, N.; Ariyarit, A.; Ittisanronnachai, S.; Namuangruk, S.; Cheacharoen, R.; Sudyoadsuk, T.; Goubard, F.; et al. A Ladder-like Dopant-free Hole-Transporting Polymer for Hysteresis-less High-Efficiency Perovskite Solar Cells with High Ambient Stability. ChemSusChem 2020, 13, 5058-5066. [CrossRef]

167. Wan, L.; Zhang, W.; Fu, S.; Chen, L.; Wang, Y.; Xue, Z.; Tao, Y.; Zhang, W.; Song, W.; Fang, J. Achieving over 21\% efficiency in inverted perovskite solar cells by fluorinating a dopant-free hole transporting material. J. Mater. Chem. A 2020, 8, 6517-6523. [CrossRef]

168. Chen, H.-W.; Huang, T.-Y.; Chang, T.-H.; Sanehira, Y.; Kung, C.-W.; Chu, C.-W.; Ikegami, M.; Miyasaka, T.; Ho, K.-C. Efficiency Enhancement of Hybrid Perovskite Solar Cells with MEH-PPV Hole-Transporting Layers. Sci. Rep. 2016, 6, 34319. [CrossRef] 
169. Zhang, L.; Liu, C.; Zhang, J.; Li, X.; Cheng, C.; Tian, Y.; Xu, B.; Liu, C.; Jen, A.K.Y.; Jen, A.K.Y. Intensive Exposure of Functional Rings of a Polymeric Hole-Transporting Material Enables Efficient Perovskite Solar Cells. Adv. Mater. 2018, 30, e1804028. [CrossRef] [PubMed]

170. Liu, C.; Zhang, L.; Li, Y.; Zhou, X.; She, S.; Wang, X.; Tian, Y.; Jen, A.K.Y.; Xu, B. Highly Stable and Efficient Perovskite Solar Cells with 22.0\% Efficiency Based on Inorganic-Organic Dopant-Free Double Hole Transporting Layers. Adv. Funct. Mater. 2020, 30, 1908462. [CrossRef]

171. Zhang, L.; Liu, C.; Wang, X.; Tian, Y.; Jen, A.K.Y.; Xu, B. Side-chain engineering on dopant-free hole-transporting polymers toward highly efficient perovskite solar cells (20.19\%). Adv. Funct. Mater. 2019, 29, 1904856. [CrossRef]

172. Hashimoto, R.; Truong, M.A.; Gopal, A.; Rafieh, A.I.; Nakamura, T.; Murdey, R.; Wakamiya, A. Hole-transporting polymers containing partially oxygen-bridged triphenylamine units and their application for perovskite solar cells. J. Photopolym. Sci. Technol. 2020, 33, 505-516. [CrossRef]

173. Li, S.; Wan, L.; Chen, L.; Deng, C.; Tao, L.; Lu, Z.; Zhang, W.; Fang, J.; Song, W. Self-Doping a Hole-Transporting Layer Based on a Conjugated Polyelectrolyte Enables Efficient and Stable Inverted Perovskite Solar Cells. ACS Appl. Energy Mater. 2020, 3, 11724-11731. [CrossRef]

174. Oz, S.; Jena, A.K.; Kulkarni, A.; Mouri, K.; Yokoyama, T.; Takei, I.; Unlu, F.; Mathur, S.; Miyasaka, T. Lead(II) Propionate Additive

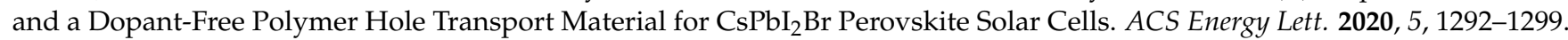
[CrossRef]

175. Shao, J.-Y.; Yu, B.; Wang, Y.-D.; Lan, Z.-R.; Li, D.; Meng, Q.; Zhong, Y.-W. In-Situ Electropolymerized Polyamines as Dopant-Free Hole-Transporting Materials for Efficient and Stable Inverted Perovskite Solar Cells. ACS Appl. Energy Mater. 2020, 3, 5058-5066. [CrossRef]

176. Park, J.; Yoon, S.E.; Lee, J.; Whang, D.R.; Lee, S.Y.; Shin, S.J.; Han, J.M.; Seo, H.; Park, H.J.; Kim, J.H.; et al. Unraveling Doping Capability of Conjugated Polymers for Strategic Manipulation of Electric Dipole Layer toward Efficient Charge Collection in Perovskite Solar Cells. Adv. Funct. Mater. 2020, 30, 2001560. [CrossRef]

177. Sun, X.; Deng, X.; Li, Z.; Xiong, B.; Zhong, C.; Zhu, Z.; Li, Z.A.; Jen, A.K.Y. Dopant-Free Crossconjugated Hole-Transporting Polymers for Highly Efficient Perovskite Solar Cells. Adv. Sci. 2020, 7, 1903331. [CrossRef]

178. Sun, X.; Li, Z.; Yu, X.; Wu, X.; Zhong, C.; Liu, D.; Lei, D.; Jen, A.K.Y.; Li, Z.A.; Zhu, Z. Efficient Inverted Perovskite Solar Cells with Low Voltage Loss Achieved by a Pyridine-Based Dopant-Free Polymer Semiconductor. Angew. Chem. Int. Ed. 2021, 60, 7227-7233. [CrossRef]

179. Wang, L.; Zhuang, Q.; You, G.; Lin, X.; Li, K.; Lin, Z.; Zhen, H.; Ling, Q. Donor-Acceptor Type Polymers Containing Fused-Ring Units as Dopant-Free, Hole-Transporting Materials for High-Performance Perovskite Solar Cells. ACS Appl. Energy Mater. 2020, 3, 12475-12483. [CrossRef]

180. Li, X.; Tang, X.; Yang, Y.; Ye, T.; Wu, D.; Wang, H.; Li, J.; Wang, X. A dopant-free polymer as hole-transporting material for highly efficient and stable perovskite solar cells. Prog. Photovolt. 2018, 26, 994-1002. [CrossRef]

181. Putnin, T.; Le, H.; Bui, T.-T.; Jakmunee, J.; Ounnunkad, K.; Peralta, S.; Aubert, P.-H.; Goubard, F.; Farcas, A. Poly(3,4ethylenedioxythiophene/permethylated $\beta$-cyclodextrin) polypseudorotaxane and polyrotaxane: Synthesis, characterization and application as hole transporting materials in perovskite solar cells. Eur. Polym. J. 2018, 105, 250-256. [CrossRef]

182. Zhu, H.; Johansson, M.B.; Johansson, E.M.J. The Effect of Dopant-Free Hole-Transport Polymers on Charge Generation and Recombination in Cesium-Bismuth-Iodide Solar Cells. ChemSusChem 2018, 11, 1114-1120. [CrossRef]

183. Miyasaka, T.; Kulkarni, A.; Kim, G.M.; Oez, S.; Jena, A.K. Perovskite Solar Cells: Can We Go Organic-Free, Lead-Free, and Dopant-Free? Adv. Energy Mater. 2020, 10, 1902500. [CrossRef] 